HOCHSCHULE

MITTWEIDA

UNIVERSITY OF

APPLIED SCIENCES

\title{
DIPLOMARBEIT
}

Herr Ing.

Harald Roider

\section{Projektmanagement im \\ Bauwesen}

Mittweida, 2012 
Fakultät Wirtschaftswissenschaften

DIPLOMARBEIT

\title{
Projektmanagement im Bauwesen
}

\author{
Autor: \\ Herr Ing. Harald Roider \\ Studiengang: \\ Wirtschaftsingenieurwesen \\ Seminargruppe: \\ KW08w2SA \\ Erstprüfer: \\ Prof. Dr. Ulla Meister \\ Zweitprüfer: \\ Prof. Dr. Holger Meister \\ Einreichung: \\ Mittweida, 31.05.2012 \\ Verteidigung/Bewertung: \\ Mittweida, 2012
}




\section{Bibliografische Beschreibung:}

Roider, Harald:

Projektmanagement im Bauwesen. -2012. - V, 86, V, S.

Mittweida, Hochschule Mittweida, Fakultät Wirtschaftswissenschaften, Diplomarbeit, 2012

\section{Referat:}

Die vorliegende Arbeit befasst sich mit dem Thema „Projektmanagement im Bauwesen“. Häufig wird Projektmanagement im Bauwesen ausgeführt, ohne die entsprechende theoretische Fachkenntnis zu besitzen. Das Ziel dieser Arbeit ist, die Abläufe des Projektmanagement zuerst vom theoretischen Standpunkt aus zu betrachten, um die Abläufe verstehen zu können. Im zweiten Teil der Arbeit werden die einzelnen Schritte anhand eines Bauablaufes, von der Projektentwicklung über die Projektplanung bis zur Projektausführung, dargestellt. 


\section{Inhaltsverzeichnis}

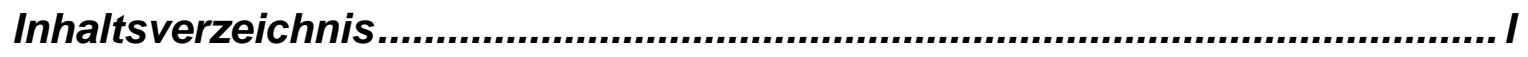

Abbildungsverzeichnis...........................................................................

Abkürzungsverzeichnis................................................................................

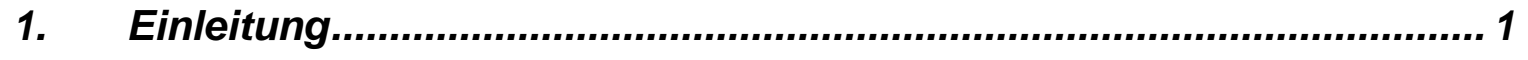

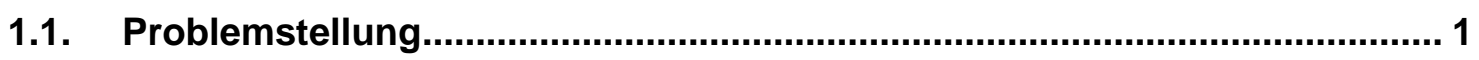

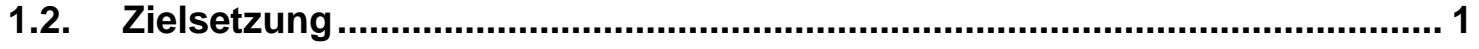

1.3. Methodisches Vorgehen ...................................................................... 2

2. Allgemeines Projektmanagement................................................... 4

2.1. Grundlagen des Projektmanagements ....................................................... 4

2.1.1. Definition des Projektmanagements........................................................... 4

2.1.2. Strukturen des Projektmanagements ...........................................................

2.1.2.1 Projektauftraggeber/Bauherr ........................................................................

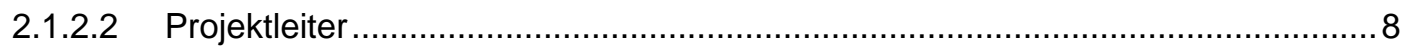

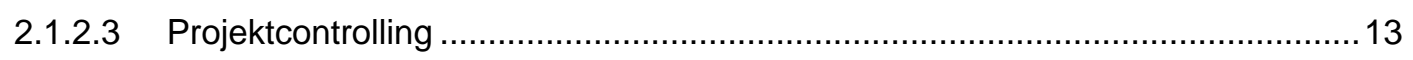

2.1.2.4 Projektsteuerung........................................................................................ 14

2.1.3. Projektorganisation des Projektmanagements ..................................................16

2.1.3.1. Aufbauorganisation.................................................................................

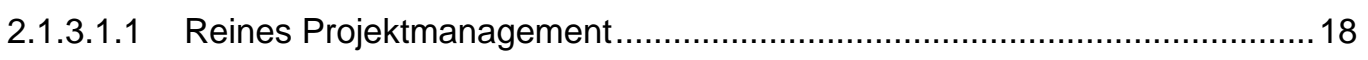

2.1.3.1.2 Matrixprojektmanagement............................................................... 20

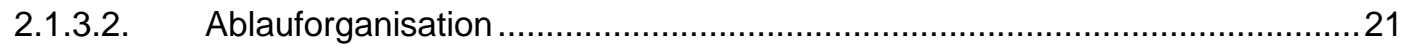

2.2. Projektmanagement eines Bauprojektes ……........................................ 26

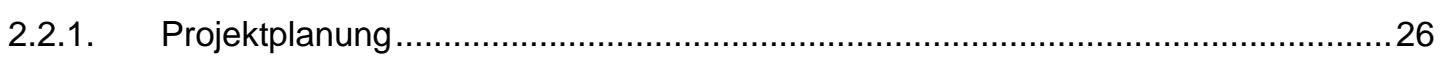

2.2.1.1 Strukturierung der Projektaufgaben / des Projektablaufs .................................2

2.2.1.2 Terminplanung ................................................................................. 28

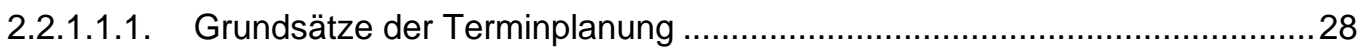

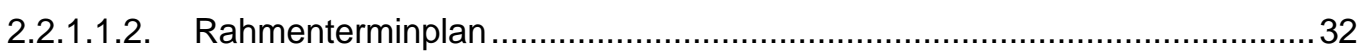

2.2.1.1.3. Generalablaufplan (Generalablaufterminplan) …….................................33

2.2.1.1.4. Steuerungsterminplan ..............................................................................

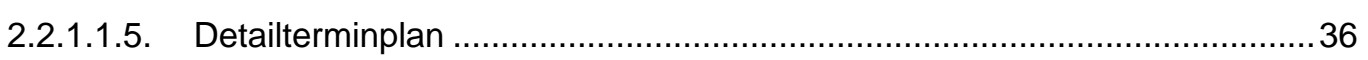

2.2.1.1.6. Feinterminplan..................................................................................

2.2.1.1.7. Terminverfolgung/Terminkontrolle im Projektablauf ...................................37

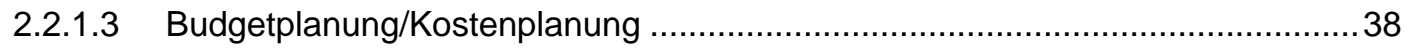

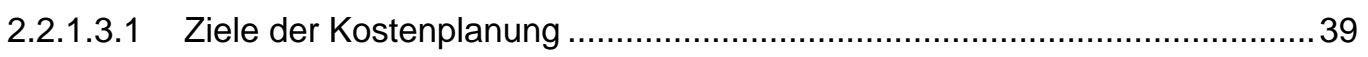

2.2.1.3.2 Phasen der Kostenplanung .................................................................. 40 


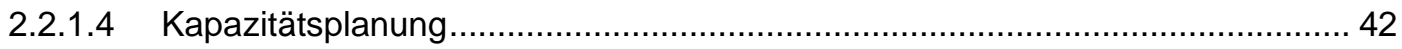

2.2.1.4.1 Grundsätze der Kapazitätsplanung ............................................. 42

2.2.1.4.2 Schritte der Kapazitätsplanung ................................................. 44

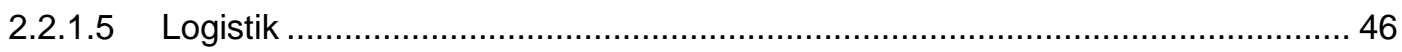

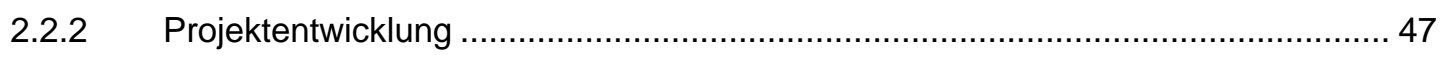

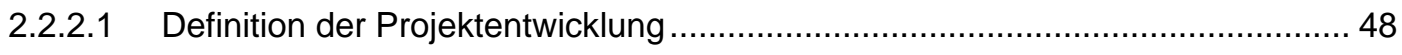

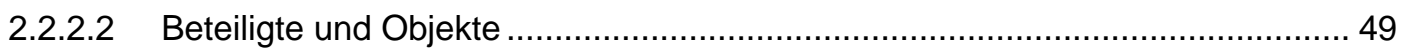

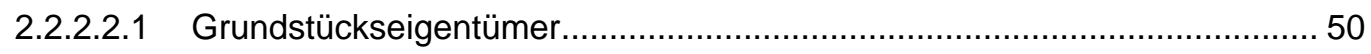

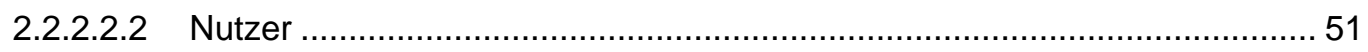

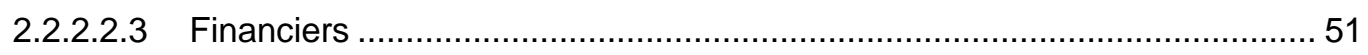

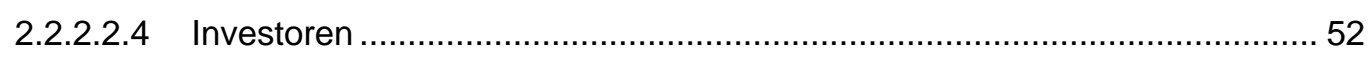

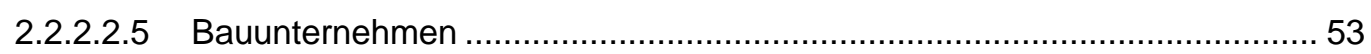

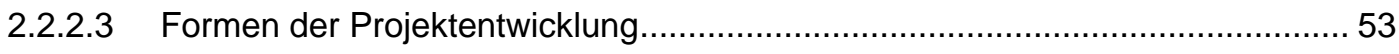

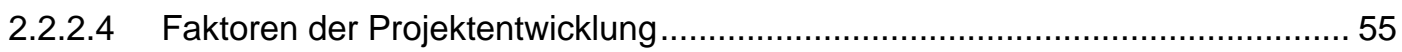

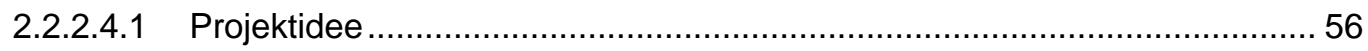

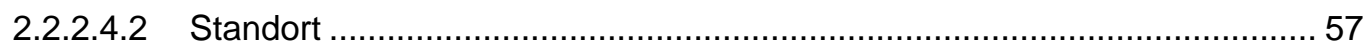

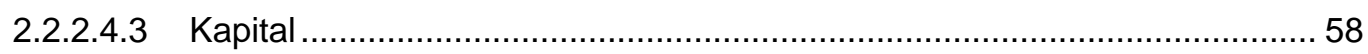

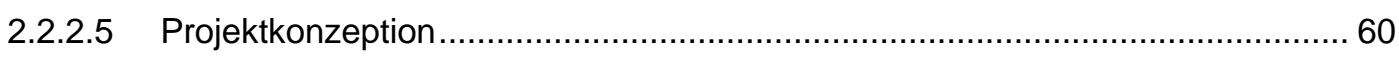

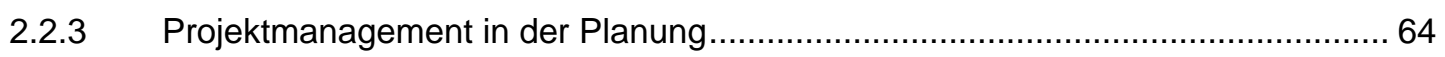

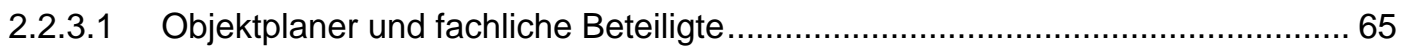

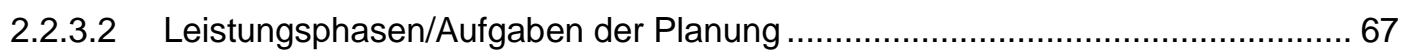

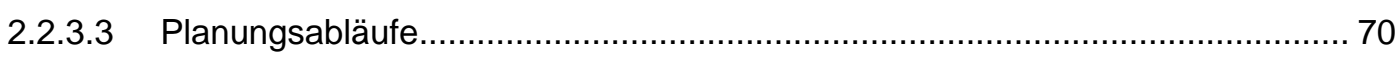

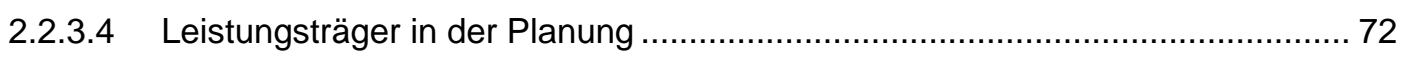

2.2.4 Projektmanagement in der Ausführungsphase ............................................. 74

2.2.4.1 Leistungsphasen/Aufgaben des Planungsteams in der Ausführung ............... 74

2.2.4.2 Leistungsphasen/Aufgaben der örtlichen Bauaufsicht in der Ausführung ......... 77

2.2.4.3 Vorraussetzungen in der Ausführung ................................................ 82

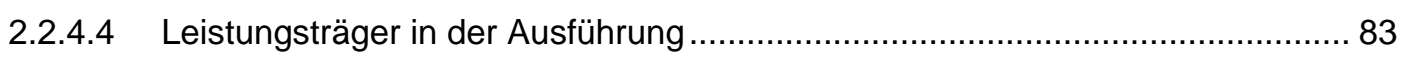

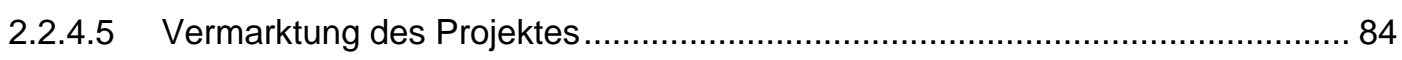

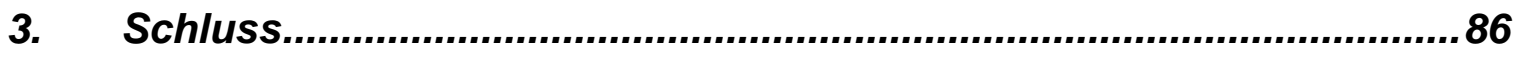

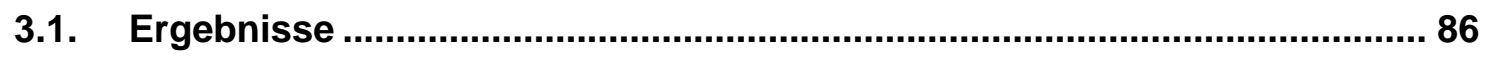

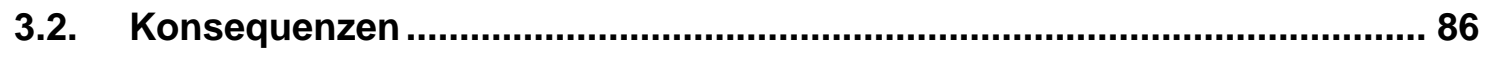

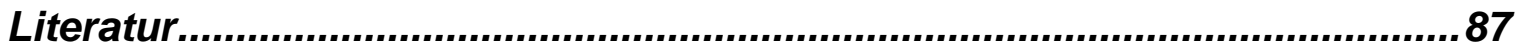

Selbstständigkeitserklärung .................................................................. 91 


\section{Abbildungsverzeichnis}

Abbildung 1: Position des Projektleiters in der Projektorganisation ................................. 9

Abbildung 2: Wichtige Eigenschaften eines Projektmanagers ................................. 11

Abbildung 3: Position der Projektsteuerung in der Projektorganisation ........................ 14

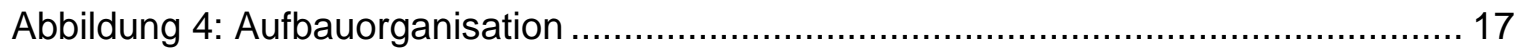

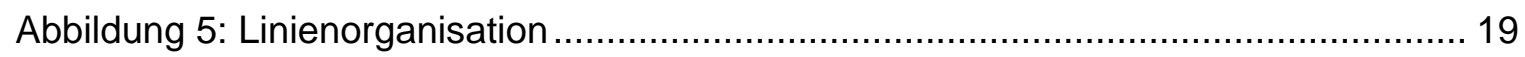

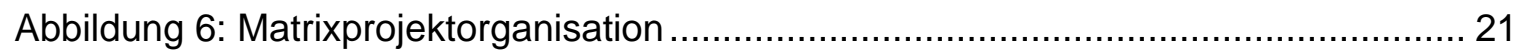

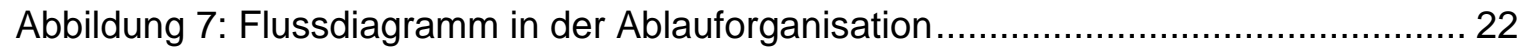

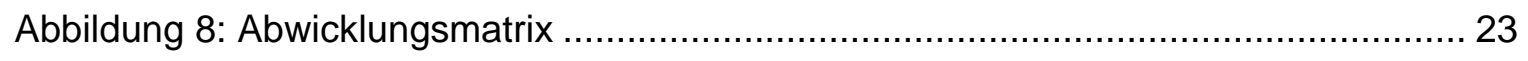

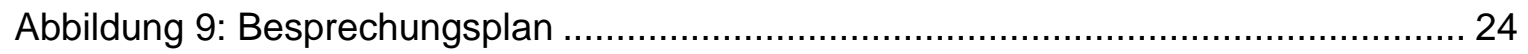

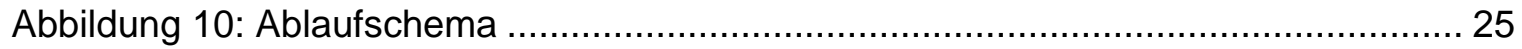

Abbildung 11: Beziehung des Bauherren zu den Vertragspartnern ............................. 26

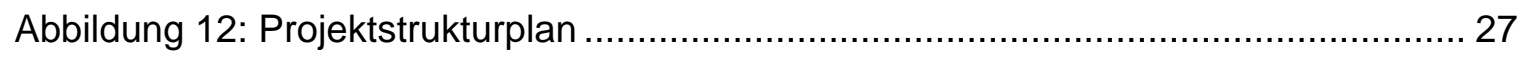

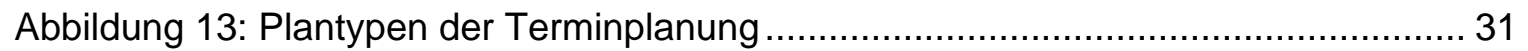

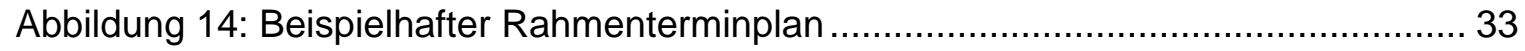

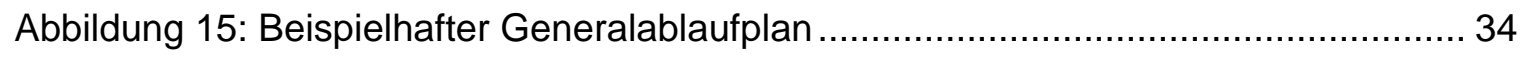

Abbildung 16: Steuerungsterminplan mit den Elementen der Vorentwurfsplanung........ 36

Abbildung 17: Kostenplanung laut ÖNORM B1801-1:2009 ..................................... 40

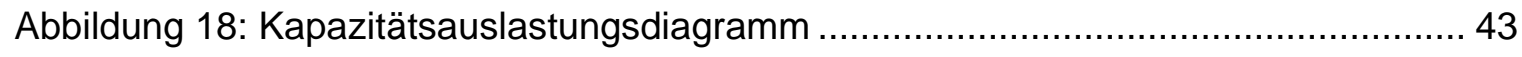

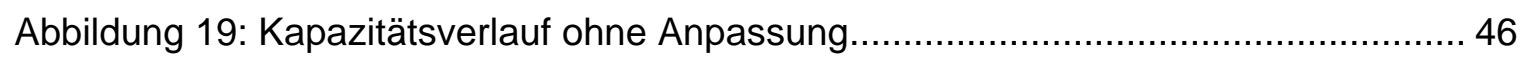

Abbildung 20: Kapazitätsverlauf unter Ausnützung der Pufferzeiten ............................ 46 
Abbildung 22: Abgrenzung der Projektentwicklung 55

Abbildung 23: Kostenbeeinflussbarkeit in der Projektphase 60

Abbildung 24: Risiken der Projektentwicklung ..... 63

Abbildung 25: Übersicht der Planungsleistungen 64

Abbildung 26: Grundsätzliche Planungsabläufe 71

Abbildung 27: Teilleistungen der ÖBA in Abhängigkeit der Bauphasen 78 


\section{Abkürzungsverzeichnis}

bzw. beziehungsweise

ca. cirka

d.h. das heißt

EU Europäische Union

etc. et cetera

f. folgende

ff. fort folgende

ggf. gegebenenfalls

Mrd. Milliarden

neg. negativ

ÖBA örtliche Bauaufsicht

Pkt. Punkt

pos. positive

u.a. unter anderem

u.ä. und ähnliche

udgl. und der gleichen

usw. und so weiter

Vgl. Vergleiche

z.B. zum Beispiel 


\section{Einleitung}

\subsection{Problemstellung}

Projektmanagement ist ein sehr umfangreiches und komplexes Thema. Per Definition ist Projektmanagement unter anderem die ständige Beobachtung und Steuerung von komplexen Abläufen mit einem definierten Ziel. Die Anforderungen an Projektmanager sind daher sehr vielfältig. Die Zeitvorgaben für die Realisierung von Bauvorhaben sind meist sehr kurz. Und dennoch gilt der Leitsatz für den Projektmanager, dass man nur an den Ergebnissen gemessen wird.

Projekte werden laufend durch die ständige Voranschreitung der Technik und den zusätzlichen Anforderungen, die an Gebäude gestellt werden, immer komplexer. Da die Finanzierung von Ressourcen immer teuerer wird, nimmt auch der Fortschritt der Technik zu. Um diese vielen Aufgaben und die Erreichung des Projektzieles sicherzustellen ist ein Projektmanagement unbedingt notwendig. Ein wirkungsvolles Controlling als Teil des Projektmanagement ist ein wesentlicher Faktor, um ein Projekt zum Projekterfolg zu führen und die vorhandenen Risiken aufzuzeigen, zu erkennen, und möglichst rasch gegenzusteuern.

\subsection{Zielsetzung}

Bei fast allen Entscheidungen des täglichen Lebens entscheidet ein gewisser Zufall über den positiven oder den weniger positiven Ausgang. Jedoch kann durch ein geschicktes Management bzw. durch frühzeitige und richtige Planung der positive Ausgang eines Vorhabens gesteuert, bzw. beeinflusst werden.

Ein Sprichwort besagt:

Planung ist das Ersetzen des Zufalls durch den Irrtum.

(Samuel Goldwyn, Gründer von MGM, 1882 - 1974)

Und diesem Zufall soll mit einer ordentlichen Projektvorbereitung, einer Projektplanung und einem Projektmanagement vorgebeugt werden. 
Zum Thema Projektmanagement im Bereich des Bauwesens gibt es eine sehr umfangreiche Literatur. In der folgenden Arbeit wird versucht die komplexe Thematik des Projektmanagement in den einzelnen Facetten darzustellen. Viele Entscheidungen im Bauwesen, vor allem bei kleineren Projekten werden, „aus dem Bauch“ heraus gefällt. Da jedoch im Wirtschaftsleben fast jede Alternative eine unterschiedliche finanzielle Auswirkung hat, muss diese Entscheidungsfindung mit entsprechenden Fakten und Berechnungen begründet werden. Diese Grundlagen müssen für viele verschiedene Bereiche erhoben, und zusammengetragen werden, damit der Projektauftraggeber eine Entscheidungsgrundlage hat. Von Projekt zu Projekt muss festlegten werden, welche Leistungen vom Bauherren in Eigenregie durchgeführt und welche vergeben werden. Im privaten Wohnbau (Einfamilienhaus) wird der Aufwand einer Projektentwicklung um vieles geringer sein, als zum Beispiel im Industriebau bei der Errichtung mehrerer tausender Quadratmeter Nutzfläche.

\subsection{Methodisches Vorgehen}

Im Rahmen der vorliegenden Arbeit wird aufgezeigt, welchen Beitrag das Projektmanagement zum Projekterfolg leistet, und wie wichtig ein gut geplanter und organisierter Ablauf für die Projektausführung ist. Im ersten Teil dieser Arbeit werden wichtige Definitionen zum allgemeinen Verständnis und der Strukturen des Projektmanagement mit den dazugehörigen Akteuren dargestellt. In weiterer Folge werden im ersten Teil die Projektorganisationen, Erklärungen und Zusammenhänge des Projektmanagement im Bauwesen beschrieben.

Im zweiten Teil der Arbeit (Projektmanagement eines Bauprojektes) werden die wesentlichen Bestandteile eines Projektablaufs von Anfang bis zum Ende erklärt. Im ersten Unterpunkt werden dabei allgemeine, für den gesamten Projektablauf entscheidende Tätigkeiten, aufgelistet. Im Punkt "Projektentwicklung" werden die ersten Leistungen eines Projektes nämlich die Überlegungen der möglichen Projektentwickler und Projektinitiatoren gezeigt. Die weiteren Abschnitte des Projektablaufes werden im dritten und vierten Teil des Punktes "Projektablauf" erklärt. In diesem werden die nach der Projektentwicklung erforderlichen Planungsaufgaben, sowie die Leistungsträger der Planung dargestellt. Im dritten Teil werden Abläufe und Leistungsträger der Bauausführung erörtert. 
Am Ende der Diplomarbeit werden die Erkenntnisse, Maßnahmen und daraus resultierende Konsequenzen dargestellt. 


\section{Allgemeines Projektmanagement}

Der Abschnitt „Allgemeines Projektmanagement“ gliedert sich in zwei Hauptpunkte. Im ersten Teil werden grundlegende Begriffe des Projektmanagement, Definitionen und Strukturen erklärt.

Im zweiten Teil wird der Begriff Ablauf des Projektmanagement eines Bauprojektes erklärt.

\subsection{Grundlagen des Projektmanagements}

Im ersten Abschnitt wird der Begriff Projektmanagement definiert. Im zweiten Teil werden die Strukturen des Projektmanagement ausgehend vom Bauherren und den unterstützenden Stellen gezeigt. Im dritten Teil werden die Projektorganisationsformen des Projektmanagements dargestellt.

\subsubsection{Definition des Projektmanagements}

Der Begriff „Projektmanagement“ kann auf viele verschiedene Arten definiert werden.

Im Duden wird der Begriff wie folgt definiert: ${ }^{1}$

„Gesamtheit der Planungs-, Leitungs- und Kontrollaktivitäten, die bei [größeren] Projekten anfallen“

Auffallend ist in dieser Definition, dass von einer "Gesamtheit" von verschiedenen Aufgaben sowie von „größeren“ Projekten die Rede ist. Das heißt, dass es eine Vielzahl an unterschiedlichen Aufgaben gibt, die bei (größeren) Projekten von einer (oder mehreren) dafür ausgebildeten Person(en) im Sinne des Projektmanagement abgewickelt werden müssen.

In anderen Definitionen wird der Begriff „Projektmanagement“ zur Erklärung meist unterteilt in die Begriffe „Projekt" und den Begriff „Management“. Sowohl Litke ${ }^{2}$ als

\footnotetext{
${ }^{1}$ Duden (http://www.duden.de/rechtschreibung/Projektmanagement) 17.12.2011

${ }^{2}$ Litke: Projektmanagement München/Wien 2004 S. 18
} 
auch Keßer/Winkelhofer ${ }^{3}$ und auch Schröder ${ }^{4}$ erklären das Wort anhand ihrer Wortstämme.

Der Begriff Projekt wird dabei von Schröder aus der Quelle von R.L. Martino ${ }^{5}$ in folgender Weise definiert: ${ }^{6}$

„Als Projekt kann jede Aufgabe bezeichnet werden, die einen definierbaren Anfang und ein definierbares Ende besitzt, die den Einsatz mehrer Produktionsfaktoren für jeden der einzelnen, miteinander verbundenen und wechselseitigen von einander abhängigen Teilvorgänge erfordert, die ausgeführt werden müssen, um dieser Aufgabe vorgegebenes Ziel zu erreichen."

"Litke ${ }^{7 \text { “ bezieht sich in seiner Definition auf das Verb „managen“, das laut Duden }}{ }^{8}$ mit „abwickeln, bewältigen, durchführen, fertigbekommen, fertigbringen, meistern, organisieren, schaffen, verwirklichen" erklärt werden kann. Unter Berücksichtigung dieser Herleitung wird in weiterer Folge auf die Definition von Fluri ${ }^{9}$ zurückgegriffen:

"Management ist die Leitung soziotechnischer Systeme in personen- und sachbezogener Hinsicht mit Hilfe von professionellen Methoden. In der sachbezogenen Dimension des Managements geht es um die Bewältigung der Aufgaben, die sich aus den obersten Zielen des Systems ableiten, in der personenbezogenen Dimension, um den richtigen Umgang mit allen Menschen, auf deren Kooperation das Management zur Aufgabenerfüllung angewiesen ist"

Es kann daher der Begriff „Projektmanagement“ als eine Steuerung einer Vielzahl von komplexen Abläufen und ein Ineinandergreifen unterschiedlicher Tätigkeiten unter ständiger Koordinierung der einzelnen Abläufe miteinander und unter stän-

\footnotetext{
${ }^{3}$ Kessler, H.: Winkelhofer, G.: Projektmanagement, Leitfaden zur Steuerung und Führung von Projekten Berlin 1997 S. 10

${ }^{4}$ Schröder: Forschung und Entwicklung in der Unternehmung Wiesbaden 1977 S. 17

${ }^{5}$ Martino, R.L.: Projektmanagement und Control, Vol 1 Finding the Critical Path, New York 1964 S.17

${ }^{6}$ Schröder: Forschung und Entwicklung in der Unternehmung Wiesbaden 1977 S. 17

${ }^{7}$ Litke: Projektmanagement München/Wien 2004 S. 18

${ }^{8}$ Duden (http://www.duden.de/rechtschreibung/managen\#block_2) 17.12.2011

${ }^{9}$ Ulrich, P.: Fluri, E.: Management. Eine konzentrierte Einführung, Bern/Stuttgart 1995, S. 36
} 
diger Beobachtung des Zieles betrachtet werden. Die Aufgabe des Projektmanagement umfasst daher die Organisation, die Planung, die Überwachung und die Steuerung komplexer Vorhaben. ${ }^{10}$

In der ÖNORM B1801-3 ${ }^{11}$ (Bauprojekt und Objektmanagement) wird der Begriff "Bauprojektmanagement" als eine Gesamtheit von Führungsaufgaben, -organisation, -techniken und -mitteln für die Abwicklung eines Bauprojektes definiert.

Bei dieser Definition wird, wie schon im Duden, die „Gesamtheit“ der unterschiedlichen Aufgaben hervorgehoben. Zusammenfassend kann daher die Definition des Begriffs Projektmanagement folgendermaßen definiert werden:

Projektmanagement im Bauwesen ist die Steuerung aller Führungsaufgaben vom Beginn bis zum Ende des Projektes, unter Berücksichtigung sämtlicher Abläufe und Erreichung der mit dem Auftraggeber vereinbarten Ziele.

\subsubsection{Strukturen des Projektmanagements}

Eine gute Gliederung und eine transparente Aufgaben- und Kompetenzverteilung ist wichtig um Synergieeffekte ausnutzen zu können und Doppelgleisigkeiten zu vermeiden.

\subsubsection{Projektauftraggeber/Bauherr}

Der Projektauftraggeber/Bauherr ist die rechtlich, finanziell und wirtschaftlich verantwortliche Person. Als Bauherr gilt, wer im eigenen Namen oder für eigene oder fremde Rechnung Bauvorhaben vorbereitet, ausführt oder ausführen lässt. ${ }^{12}$

Ein Bauherr kann eine juristische Einzelperson, eine Gesellschaft (Personenmehrheiten, Ges.m.b.H), eine öffentlich rechtliche Körperschaft oder eine Behörde sein. Dieser ist die oberste Kontroll- und Weisungsperson für das gesamte Projekt. Bei einer größeren Anzahl an Bauherren, z.B. im öffentlich rechtlichen Bereich, werden von den einzelnen Bauherren oft unterschiedliche Ziele verfolgt. Bei-

\footnotetext{
${ }^{10}$ Vgl. Litke: Projektmanagement München/Wien 2004 S. 20

${ }^{11}$ ÖNORM B1801-3 Ausgabe 1999-07-01 Österreichisches Normungsinstitut

${ }^{12}$ Vgl. Kalusche: Projektmanagement für Bauherren und Planer München/Wien 2005 S. 23
} 
spielsweise strebt einer eine möglichst hohe ökologische Bauweise und der andere eine kostengünstige Bauweise an.

Im Ablauf eines Projektes sind viele organisatorische und administrative Aufgaben zu erledigen. Bei kleineren Projekten können diese Aufgaben von einem geschulten Bauherren selbst wahrgenommen werden, bei Projekten mit größerem Ausmaß und bei Mega-Projekten kann ein Teil der Aufgaben an einen oder mehrere Projektleiter/Projektcontroller abgegeben werden.

Der Bauherr hat sowohl delegierbare als auch nicht delegierbare Aufgaben zu erledigen. Nachstehend ein Auszug aus nicht delegierbaren Aufgaben ${ }^{13}$ :

> Festlegen des Projektziels z.B. Qualitätsvorstellungen, Ausführungsstandards udgl.

Aufstellen eines Organisations- und Terminplans

$>$ Abschluss von Verträgen zur Verwirklichung der Projektziele

Beauftragen eines Projektteams und gegebenenfalls eines Projektleiters

$>$ Koordination und Steuerung der Projektbeteiligten mit unterschiedlichen Fachbereichen

$>$ Untersuchung von Zielkonflikten und Entscheidung zur Fortschreibung der Projektziele

$>$ Ergänzung der Kostenermittlungen, soweit die anderen Projektteilnehmer nicht dafür zuständig sind

$>$ Erfüllung der öffentlich rechtlichen Vorschriften, wie z.B. Beantragen einer Bauverhandlung, Erledigung der öffentlichen Anträge udgl.

Weiters muss vom Bauherren der Projektstart sowie das Projektende festgelegt werden.

Der Bauherr hat die Möglichkeit eine Vielzahl an Aufgaben zu delegieren und diese von verschiedenen „externen Personen“ in der Funktion als Projektleiter, Pro-

\footnotetext{
${ }^{13}$ Vgl. Kalusche: Projektmanagement für Bauherren und Planer München/Wien 2005 S. 23
} 
jektcontroller, Generalübernehmer, Generalplaner udgl. (Erklärung dieser Begriffe unter Pkt. 2.1.3.1) ausführen zu lassen. Durch diese Übertragung von verschiedenen Arbeitsleistungen werden Teilkompetenzen und Teilverantwortungen abgegeben. Die Gesamtverantwortung bleibt jedoch beim Bauherren. Projektauftraggeber/Bauherren können demnach nur Personen sein, die die Kompetenz haben, die durch das Projekt verursachten Kosten zu genehmigen und die Ergebnisse und die gesamten Folgen des Projekts zu verantworten. ${ }^{14}$

\subsubsection{Projektleiter}

Der Erfolg oder der Misserfolg eines Projektes ist meist abhängig vom Projektmanagement in Form des Projektleiters, zumindest wird von diesem das Ergebnis entscheidend beeinflusst. Der Projektleiter oder das Projektteam vertritt die Bauherrenaufgaben im Außenverhältnis gegenüber allen Auftragnehmern und Projektbeteiligten während der gesamten Zeit des Projekts und über alle Projektstufen hinweg.

\footnotetext{
${ }^{14}$ Vgl. Kessler, H.: Winkelhofer, G.: Projektmanagement, Leitfaden zur Steuerung und Führung von Projekten Berlin 1997 S. 94
} 


\section{Abbildung 1: Position des Projektleiters in der Projektorganisation}

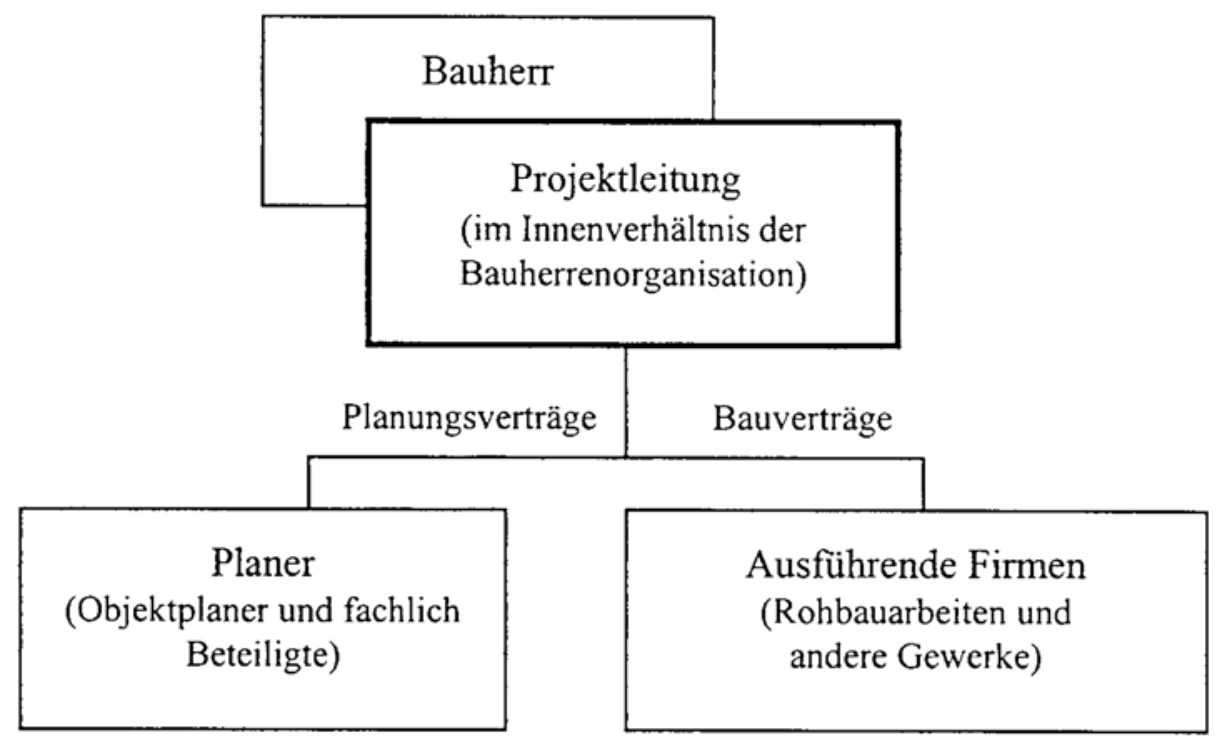

Quelle: Kalusche: Projektmanagement für Bauherren und Planer München/Wien 2005 S. 45

Die Auswahl eines Projektleiters ist daher eine wichtige Entscheidung und maßgebend für ein Projekt. Vom Bauherren muss entschieden werden welche delegierbaren „Bauherrenaufgaben“ auf den Projektleiter übertragen werden. Weiters muss vom Auftraggeber festgelegt werden, welche Aufgaben, Entscheidungen und Vollmachten an den Projektleiter abgegeben werden. Im Laufe eines Projektes müssen vom Projektleiter viele maßgebende Entscheidungen getroffen werden. Diese sind aus Sicht des Projektleiters immer im Sinne des Bauherren oder des Auftraggebers unter Berücksichtigung des Projekterfolges zu treffen. In weiterer Folge muss der Bauherr auch hinter den Entscheidungen seiner Vertrauensperson (Projektleiter) stehen, um die „Macht“Position dieser nicht zu schwächen. ${ }^{15}$

Für diese Entscheidungen muss der Projektleiter vom Auftraggeber mit einer Vielzahl an entsprechenden Kompetenzen ausgestattet werden, um Entscheidungen treffen zu können und um die Führungsposition der Projekt-Organisationsstruktur nicht zu verlieren.

${ }^{15}$ Vgl. Kalusche: Projektmanagement für Bauherren und Planer München/Wien 2005 S. 45 
Von Keßler und Winkelhofer werden die Vollmachten und Weisungsbefugnisse eines Projektleiters folgendermaßen zusammengefasst: ${ }^{16}$

- Vollmachten

- Verfügungsmacht über das Budget

- Kontrahierungsfähigkeit für Arbeitspakete und Leistungsvereinbarungen (Vertragsvollmacht)

- Weisungsbefugnis

- Führungsbefugnis

- Juristische Vertretungsmacht für alle mit dem Projekt zusammenhängenden Vereinbarungen

Die Person des Projektleiters muss viele unterschiedliche Anforderungen und Eigenschaften erfüllen. Im Buch „Ganzheitliches Projektmanagement“ werden von Pfetzing/Rohde die wichtigsten Eigenschaften zusammengestellt:

\footnotetext{
${ }^{16}$ Vgl. Kessler, H.: Winkelhofer, G.: Projektmanagement, Leitfaden zur Steuerung und Führung von Projekten Berlin 1997 S. 99
} 


\section{Abbildung 2: Wichtige Eigenschaften eines Projektmanagers}

\begin{tabular}{|c|c|c|c|}
\hline $\begin{array}{c}\text { Persönliche } \\
\text { Anforderungen }\end{array}$ & $\begin{array}{l}\text { Führungs- } \\
\text { eigenschaften }\end{array}$ & $\begin{array}{l}\text { Methodisches } \\
\text { Wissen }\end{array}$ & $\begin{array}{c}\text { Fachliche } \\
\text { Anforderungen }\end{array}$ \\
\hline $\begin{array}{l}\text { - Fähigkeit zur } \\
\text { Selbstkritik } \\
\text { - Kontaktfreudig- } \\
\text { keit } \\
\text { - Einsatzbereit- } \\
\text { schaft } \\
\text { - Freude an der } \\
\text { Verantwortung } \\
\text { - Belastbarkeit } \\
\text { und Ausdauer } \\
\text { - Lernbereitschaft } \\
\text { und -fähigkeit } \\
\text { - Selbstständig- } \\
\text { keit und Flexibi- } \\
\text { lität } \\
\text { - Zielstrebigkeit } \\
\text { - Selbstdisziplin }\end{array}$ & $\begin{array}{l}\text { - Teamorientie- } \\
\text { rung } \\
\text { - kooperative Mit- } \\
\text { arbeiterführung } \\
\text { - Motivations- } \\
\text { fähigkeit } \\
\text { - Verhandlungs- } \\
\text { geschick und } \\
\text { Oberzeugungs- } \\
\text { kraft } \\
\text { - Durchsetzungs- } \\
\text { vermögen } \\
\text { - Konfliktmana- } \\
\text { gement } \\
\text { Entscheidungs- } \\
\text { freudigkeit } \\
\text { Autorität }\end{array}$ & $\begin{array}{l}\text { - PM-Instrumente } \\
\text { - Kostenbewusst- } \\
\text { sein, Streben } \\
\text { nach Wirtschaft- } \\
\text { lichkeit } \\
\text { - Organisations- } \\
\text { fähigkeit } \\
\text { - Zusammen- } \\
\text { hänge erkennen } \\
\text { - Improvisation } \\
\text { - Changemana- } \\
\text { gement } \\
\text { - Chaosorganisa- } \\
\text { tion } \\
\text { richtige und } \\
\text { rasche Risiko- } \\
\text { beurteilung }\end{array}$ & $\begin{array}{l}\text { - ausreichende } \\
\text { Fachkenntnis } \\
\text { (Berufs- } \\
\text { erfahrung) } \\
\text { - Spezialwissen } \\
\text { (z.B. technisches } \\
\text { Verständnis) } \\
\text { - Branchenwissen } \\
\text { (Betriebs- } \\
\text { kenntnisse) }\end{array}$ \\
\hline
\end{tabular}

Quelle: Pfetzing, Rohde: Ganzheitliches Projektmanagement, Gießen 2009 S. 53

Der Aufgabenbereich eines Projektleiters kann je nach Projekt variieren.

In Anlehnung an das Buch „Projektmanagement“ von Zielasek ${ }^{17}$ werden die Projektleitertätigkeiten aufgelistet und in die Aufgabenbereiche Kontrolltätigkeit, Koordinationstätigkeit aufgeteilt.

Ergänzend zur Auflistung der Projektleitertätigkeiten und der Projektleiterpflichten von Zielasek ${ }^{18}$ müssen die Projektleitertätigkeiten in Organisations-, Kosten-, und Termintätigkeiten unterteilt werden:

Organisation:

1. Zielvorgabe/Entscheidungstätigkeit:

- Definition und Planung des Projektes mit Zeit- und Aufwandsschätzung (Kosten, Ressourcen)

\footnotetext{
${ }^{17}$ Vgl. Zielasek: Projektmanagement: Erfolgreich durch Aktivierung aller Unternehmensebenen, Berlin, Heidelberg 1995, S. 75

${ }^{18}$ Vgl. Zielasek: Projektmanagement: Erfolgreich durch Aktivierung aller Unternehmensebenen, Berlin, Heidelberg 1995, S. 75
} 
- Beeinflussung von anzuwendenden Methoden und Verfahren

- Durchsetzen und Vollzug der erforderlichen Maßnahmen zur Einhaltung der vertraglichen Verpflichtungen (Termine, Qualität)

2. Kontrolltätigkeiten:

- Zielverfolgung

- Überwachung und Steuerung von Projektfortschritt/Leistungsumfang (Quantität und Qualität), Zeit (Termine), Kosten, Kapazität und Änderungen

- Wahrnehmung fachlicher Aufgaben entsprechend vorhandener Kenntnisse und Fähigkeiten

- Dokumentation und Berichtswesen

3. Koordinationstätigkeiten

- Rechtzeitiges Herbeiführen bzw. Treffen von Entscheidungen sowie Koordination des Projektteams, der Fachabteilungen

- Förderung und Unterstützung der Teammitglieder

- Abgrenzung der Teilgebiete des Projektes und Aufgabenverteilung (Arbeitspakete)

- Information und Kommunikation innerhalb des Teams, mit Fachabteilungen und beteiligtem Management

- Kontakthaltung und Zusammenarbeit mit dem Auftraggeber und gegebenenfalls mit externen Partnern

- Leitung der Besprechungen und Projektbesprechungen auf allen Ebenen, und Herbeiführen von erforderlichen Entscheidungen und Freigaben

- Konfliktmanagement in Bezug auf die unterschiedlichen Interessen der Projektmitglieder im Hinblick auf das Projektziel

Der Projektleiter ist für die inm mittels Vollmachten übertragenen Bereiche verantwortlich. Für Bereiche ohne entsprechende Vollmachten ist er nur berichts- und informationspflichtig, jedoch nicht verantwortlich. Das Projektcontrolling wird häufig 
vom Projektleiter durchgeführt. Bei entsprechend großen Projekten wird dieses von einer weiteren Person des Projektteams oder einer dritten externen Person ausgeführt.

\subsubsection{Projektcontrolling}

Der Begriff „Projektcontrolling“ ist in der Praxis und in der Literatur nicht eindeutig definiert. In der Praxis ist es daher erforderlich den Aufgabenbereich, der die Stelle Projektcontrolling ausführt, genau zu definieren und inhaltlich abzugrenzen.

Der Begriff „Controlling“ lässt sich anhand des Wortstammes im Sinne des englischen Begriffs „control“ mit „Beherrschung, Lenkung, Steuerung, und Regelung von Prozessen übersetzen ${ }^{19}$.

In der deutschen DIN $69904^{20}$ wird der Begriff „Controlling“ als „Prozesse und Regeln, die innerhalb des Projektmanagements zur Sicherung und Erreichung der Projektziele beitragen“, definiert.

In der ÖNORM B 1801- $5^{21}$ ist die Definition nahezu ident. Die Prozesse und Regeln im Projekt und zum Projektumfeld, die innerhalb des Projektmanagements zur Sicherung des Erreichens der Projektziele beitragen, sind festzulegen. Die Prozesse umfassen betriebswirtschaftliches Controlling zur Steuerung der Projektplanung und Projektabwicklung, sowie technisches Controlling zur Erreichung der geforderten Gebrauchswerte.

Die Aufgaben des Controllings müssen grundsätzlich mit dem Auftraggeber definiert werden. Üblicherweise werden im Controllingbereich messbare Größen wie zum Beispiel Kosten, Finanzierung sowie Termine und Kapazitäten des Projektes in regelmäßigen Abständen zusammengetragen. Diese Werte werden analysiert und so weit aufbereitet, dass anhand dieser Werte Aussagen über das aktuelle Projekt getroffen werden können. Es werden beispielsweise die Kosten auf die verbaute Fläche umgelegt oder die Ausführungszeit in Relation zu den Errichtungskosten gesetzt, um diese Kennwerte anschließend mit anderen Projekten zu

\footnotetext{
${ }^{19}$ Vgl. http://www.wirtschaftslexikon24.net/d/controlling/controlling.htm 01.02.2012

${ }^{20}$ DIN 69904 Ausgabe 2000-11 Deutsches Institut für Normen

${ }^{21}$ ÖNORM B1801-5 Ausgabe 2001-06-01 Österreichisches Normungsinstitut
} 
vergleichen. Durch diese Analyse können ungewöhnliche Schwankungen, wie im oben genannten Beispiel bei den Kosten oder bei der Ausführungszeit, frühzeitig erkannt werden. Weiters ist ein rascher Soll//st-Vergleich möglich. ${ }^{22}$

\subsubsection{Projektsteuerung}

\section{Abbildung 3: Position der Projektsteuerung in der Projektorganisation}

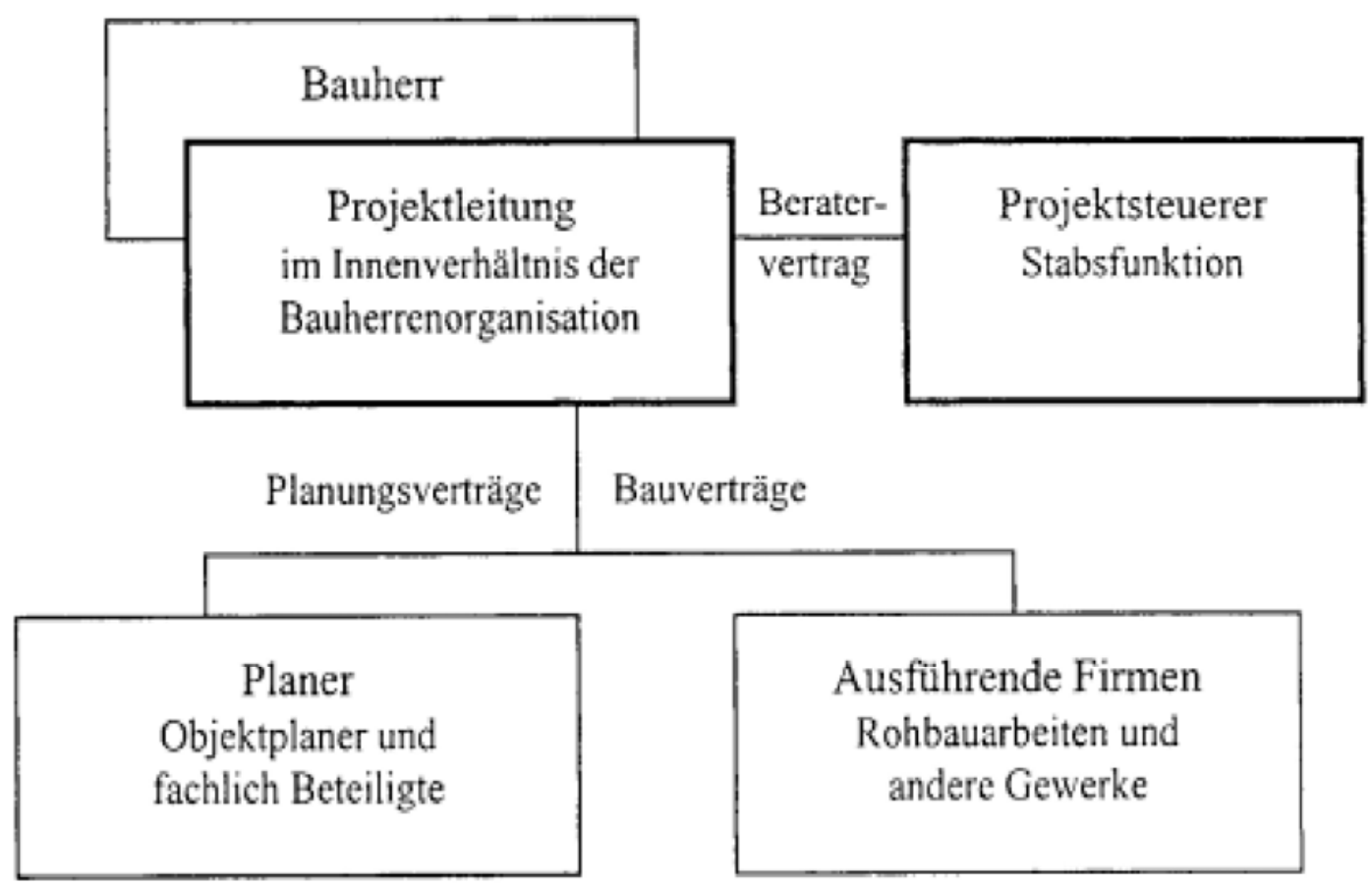

Quelle: Kalusche: Projektmanagement für Bauherren und Planer München/Wien 2005 S. 45

Eine weitere Form einen ausgelasteten Bauherren zu entlasten und ein paar delegierbare Aufgaben an eine externe Person zu übertragen, stellt die Tätigkeit der Projektsteuerung dar. Diese Stelle wird als Stabstelle (=Stabfunktion) geführt. Die Veranschaulichung über die Position dieser Stelle wird in oben stehender Grafik dargestellt. Der Projektsteuerer hat die Aufgabe dem Bauherren in den Themenbereichen Beratung, Koordination, Information, und Kontrolle beratend zur Seite zu stehen. Weitere Aufgaben bzw. in welchem Umfang die genannten vier Aufgaben zu erfüllen sind, wird zwischen dem Projektsteuerer und dem Auftraggeber festgelegt. Unabhängig vom Themenbereich, für den die Projektsteuerung beauftragt wurde, beschränkt sich die Leistung immer auf die Beratung bzw. auf die

\footnotetext{
${ }^{22}$ Vgl. Kalusche: Projektmanagement für Bauherren und Planer München/Wien 2005 S. 60
} 
Aufbereitung der einzelnen Themen zum Treffen von Entscheidungen durch den Bauherren oder der Projektsteuerung. ${ }^{23}$

Weitere Aufgaben bestehen in der objektiven Verfolgung des Projektes aus externer Auftraggebersicht. Durch die Unbefangenheit einer externen kompetenten Stelle können Kurskorrekturen und falsche Abläufe erkannt werden und frühzeitige Korrekturen eingeleitet werden.

Zwischen der Projektsteuerung und den anderen Projektteilnehmern besteht keine Weisungsbefugnis oder Bevollmächtigung. Die Projektsteuerung ist aber auch keiner Organisation (außer dem Bauherren/Projektleiter) des Projektes unterstellt und kann daher die Meinung frei äußern ohne Sanktionen von Projektbeteiligten zu befürchten. ${ }^{24}$

Die Vorteile einer Projektsteuerung bestehen nicht nur für den Auftraggeber sondern auch bei den ausführenden Firmen. Durch die Aufbereitung und Verdeutlichung von Themen für den Auftraggeber können diese genauer abgegrenzt und vom Auftraggeber klare und realistische Vorgaben gemacht werden.

Besteht ein Vorhaben nicht nur aus einem Projekt, sondern versuchen verschiedene Projektgruppen ein gemeinsames Gesamtziel zu erreichen, so können die Aufgabengebiete der Projektsteuerung optimal ausgeschöpft werden.

Umso größer ein Gesamtprojekt (mehrere Teilprojekte) ist, desto größer und schwieriger wird der Aufgabenbereich der Projektorganisation. Bei Projekten die aus mehr als zwei Teilprojekten bestehen ist es ratsam eine übergeordnete Projektstruktur zu schaffen in der die Projektleiter untereinander Abklärungen tätigen können. Obwohl die Organisationsebene bei Installation einer übergeordneten Ebene rasch sehr aufwendig wird, empfiehlt es sich diese zusätzliche Organisation zu schaffen.

Bei dieser großen Projektstruktur ist es ratsam eine externe Projektsteuerung ins Boot zu holen. Die Entscheidungsfindung sowie die Formulierung des Bauherren-

\footnotetext{
${ }^{23}$ Vgl. Kalusche: Projektmanagement für Bauherren und Planer München/Wien 2005 S. 45

${ }^{24}$ Vgl. Kalusche: Projektmanagement für Bauherren und Planer München/Wien 2005 S. 62
} 
willens muss bei einer entsprechenden Größenordnung behutsam und exakt erfolgen. ${ }^{25}$

\subsubsection{Projektorganisation des Projektmanagements}

Für eine professionelle Abwicklung eines Projektes müssen verschiedene organisatorische Tätigkeiten durchgeführt werden. Im Folgenden werden im Punkt „Ablauforganisation" die wichtigsten Elemente dargestellt. Die Aufbauorganisation ist eine organisatorische Tätigkeit mit langfristigen Auswirkungen. Entscheidet man sich z.B. für eine Linienorganisation in einem Unternehmen, so wird dies für einen langen Zeitraum bei unterschiedlichen Projekten gleich bleiben.

\subsubsection{Aufbauorganisation}

„Die Aufbauorganisation stellt die Organisationsstruktur des Vorhabens dar.“26

Dabei geht es um die Grundfunktion eines Aufbaues. In der Abbildung 4 wird ein möglicher Aufbau dargestellt.

Dabei ist zu bedenken, dass die vertragliche Verbindung nicht mit der fachlichen Instanz identisch sein muss. Der Bauherr ist zum Beispiel der vertragliche Partner, der Architekt aber der fachlich Übergeordnete. Dies wird in der folgenden Darstellung von Greiner/Mayer/Stark verdeutlicht.

\footnotetext{
${ }^{25}$ Vgl. Sommer: Projektmanagement im Hochbau, Berlin/Heidelberg 2009 S. 101

${ }^{26}$ P. Greiner, P. E. Mayer, K. Stark :Baubetriebslehre- Projektmanagement, Wie Bauprojekte erfolgreich gesteuert werden, Wiesbaden ${ }^{3} 2005$ S. 37
} 


\section{Abbildung 4: Aufbauorganisation}

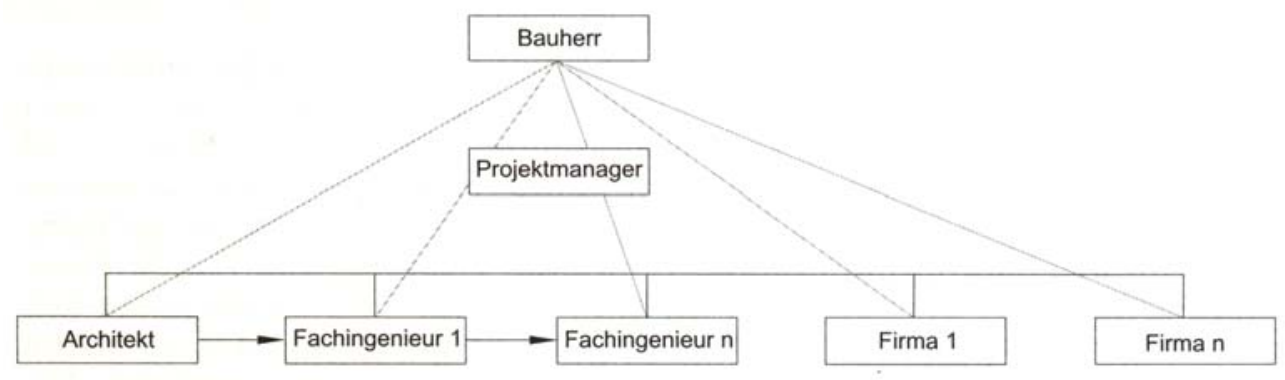

Quelle: P. Greiner, P. E. Mayer, K. Stark: Baubetriebslehre - Projektmanagement, Wie Bauprojekte erfolgreich gesteuert werden, Wiesbaden ${ }^{3} 2005$ S. 37

Die Vertragsverbindung führt vom Bauherren zum Architekten, vom Bauherren zum Fachingenieur 1, usw. Durch die Pfeile wird die fachliche Überordnung gekennzeichnet.

Im Folgenden werden nun die wichtigsten Bauprojektorganisationen ${ }^{27}$ dargestellt, die den Aufbau dieses Projekts maßgeblich mitbestimmen.

> Konventionelle Organisation: Darunter versteht man die Durchführung eines Projekts mit Einzelunternehmern.

> Generalplaner: Die Leistungen eines Generalplaners umfassen die gesamten Planungsleistungen eines Projektes. Meist werden diese Aufträge an Architekturbüros vergeben, die sich für die Detailplanung z.B. der Haustechnik oder der Bauphysik einen Sub-Unternehmer beauftragen. Der Vorteil liegt darin, dass die Koordinationsleistungen der Planung vom Generalplaner bewerkstelligt werden müssen. Mit dem Auftrag des Generalplaners ist ein fertiges vollständiges Planungswerk gefordert.

Generalunternehmer: Ähnlich wie bei dem Generalplaner auf der Planungsseite sind beim Generalunternehmer sämtliche Leistungen der Ausführungsseite in einer Hand. Für Leistungen, die nicht selbst erbracht werden können, werden Sub-Unternehmer beauftragt.

\footnotetext{
${ }^{27}$ P. Greiner, P. E. Mayer, K. Stark: Baubetriebslehre- Projektmanagement, Wie Bauprojekte erfolgreich gesteuert werden, Wiesbaden ${ }^{3} 2005$ S. 38-39
} 
$>$ Totalunternehmer: Ein Totalunternehmer wird ab einem bestimmten Projektfortschritt beauftragt. Ab diesem Zeitpunkt wird sowohl die Planung als auch die Bauausführung von diesem durchgeführt.

> Generalübernehmer: Der Generalübernehmer kann, ähnlich dem Totalunternehmer, definiert werden. Meist wird ein Generalübernehmer nicht wie der Totalunternehmer nach der Projektentwurfsphase beauftragt, sondern es werden häufig Projekte ausgehend von der Projektentwicklungsphase betrieben.

Bauträger: Bauträger sind ähnlich wie Generalübernehmer. Von diesen wird das Projekt bis zum Verkauf als Bauherr betreut. Häufig wird dieser Begriff im Zusammenhang mit Wohnbauträger verwendet.

Diese Projektorganisationen müssen der jeweiligen Bauphase größenmäßig angepasst werden. So wird der Projektaufbau zu Beginn und Ende eines Bauprojektes kleiner sein, als in der Hauptbauphase. Ein Element der Aufbauorganisation stellt auch der Nutzer dar, da dieser nicht zwingend mit dem Bauherren identisch ist. Nutzer können in unterschiedlichem Ausmaß integriert werden. Einerseits kann der zukünftige Nutzer noch nicht feststehen und daher nicht integriert sein, andererseits ist es wichtig die Bedürfnisse und den Bedarf des Nutzers zu kennen um gezielt danach zu planen und zu bauen.

Je nach Bedarf gibt es nun verschiedene Strukturen des Aufbaues beim Projektmanagement. Im Folgenden wird auf das reine Projektmanagement und das Matrixprojektmanagement eingegangen.

\subsection{Reines Projektmanagement}

Der Aufbau eines reinen Projektmanagements orientiert sich an der Linienorganisation. Dem Projektleiter unterstellt sind einzelne Abteilungen, die sich in weitere Stellen unterteilen. Dies veranschaulicht die folgende Abbildung. 


\section{Abbildung 5: Linienorganisation}

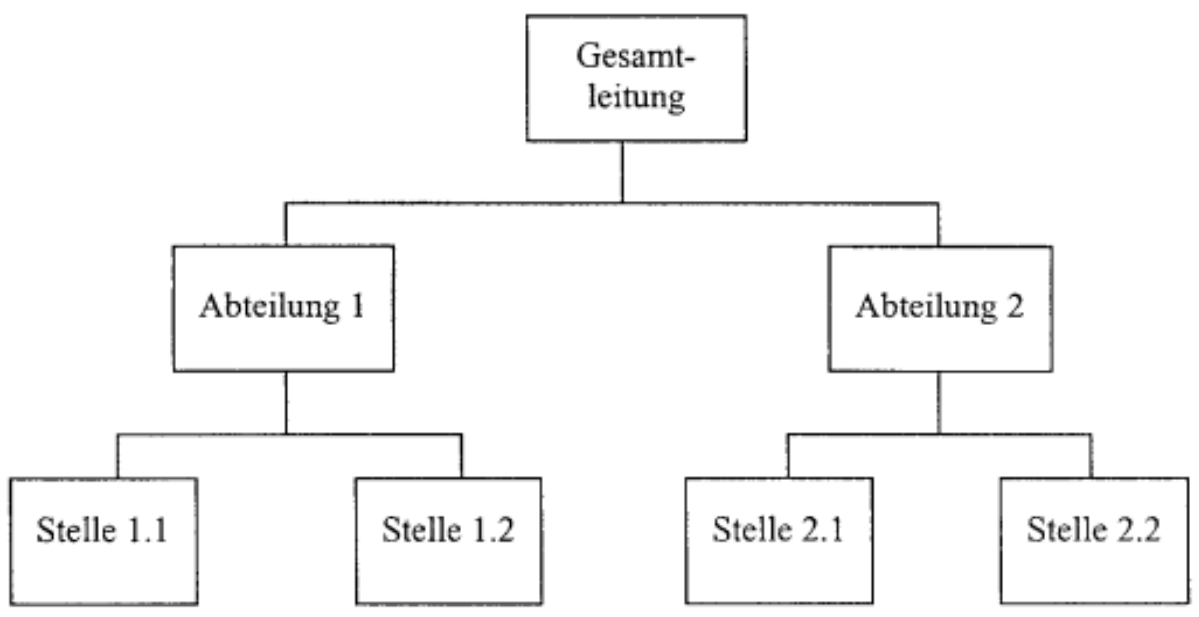

Quelle: Kalusche: Projektmanagement für Bauherren und Planer München/Wien 2005 S. 89

Hanser beschreibt dies folgendermaßen: „Bei dieser Organisationsform wird für ein Projekt eine praktisch eigenständige Organisation gebildet, die vom Projektleiter in voller Verantwortung selbstständig geleitet wird.“28

In der Baubranche ist dieses Management bei den Bauherren anzutreffen. ${ }^{29}$ Zum Beispiel unterteilt ein Bauherr ein Bauprojekt in einzelne Bereiche, wie Elektro, Installation, ... Hierfür beauftragt er einzelne Planer, die in der Linienorganisation in der Stufe der Abteilungen wären. Jeder dieser Bereiche, zum Beispiel Elektro, beauftragt nun im Namen des Bauherren einzelne Elektriker zur Durchführung. Diese sind auf der Ebene der Stellen angesiedelt.

Vorteile $^{30}$ dieser Organisationsform sind:

$>$ Eindeutige Weisungsbefugnis (der höheren Ebene)

Schnelle Reaktion auf Störungen

$>$ Klare, übersichtliche Verhältnisse

\footnotetext{
${ }^{28}$ Vgl. Litke: Projektmanagement München/Wien 2004 S. 69

${ }^{29}$ Vgl. Kalusche: Projektmanagement für Bauherren und Planer München/Wien 2005 S. 88

${ }^{30}$ Vgl. Kalusche: Projektmanagement für Bauherren und Planer München/Wien 2005 S. 69
} 
Ein Nachteil dieser Managementform ist die Einhaltung der langen Dienstwege bei einzelnen Schwierigkeiten, durch die vielen Zwischeninstanzen. ${ }^{31}$ Stellen Sie sich vor ein Elektriker hat ein Problem: Dieser geht zu seinem vorgesetzten Firmenchef. Dieser setzt sich nun in Verbindung mit dem Planungsbüro, das sich in weiterer Folge an den Bauherren wendet. In der Praxis könnten noch weitere Ebenen benötigt werden.

Für diese Form des Projektmanagements besteht die Möglichkeit einzelne Aufgaben herauszunehmen und eine extra eingesetzte Stelle damit zu beauftragen. Dies ist nur bei beratender Tätigkeit sinnvoll.

„Typische Stabfunktionen im Zusammenhang mit Bauvorhaben sind Bau- oder Projektcontrolling und die für die Dauer eines Bauprojektes eingerichtete und durch externe Fachleute besetzte Funktion der Projektsteuerung. ${ }^{\text {‘32 }}$

\subsection{Matrixprojektmanagement}

Die Matrixprojektorganisation bedeutet, dass nicht nur die Abteilungen, wie in der Linienorganisation verbunden sind, sondern eine zweite oder dritte Ebene der Verknüpfung eingeführt wird. Verdeutlicht wird dies auf der folgenden Abbildung:

\footnotetext{
${ }^{31}$ Vgl. Kalusche: Projektmanagement für Bauherren und Planer München/Wien 2005 S. 88

${ }^{32}$ Kalusche: Projektmanagement für Bauherren und Planer München/Wien 2005 S. 89
} 


\section{Abbildung 6: Matrixprojektorganisation}

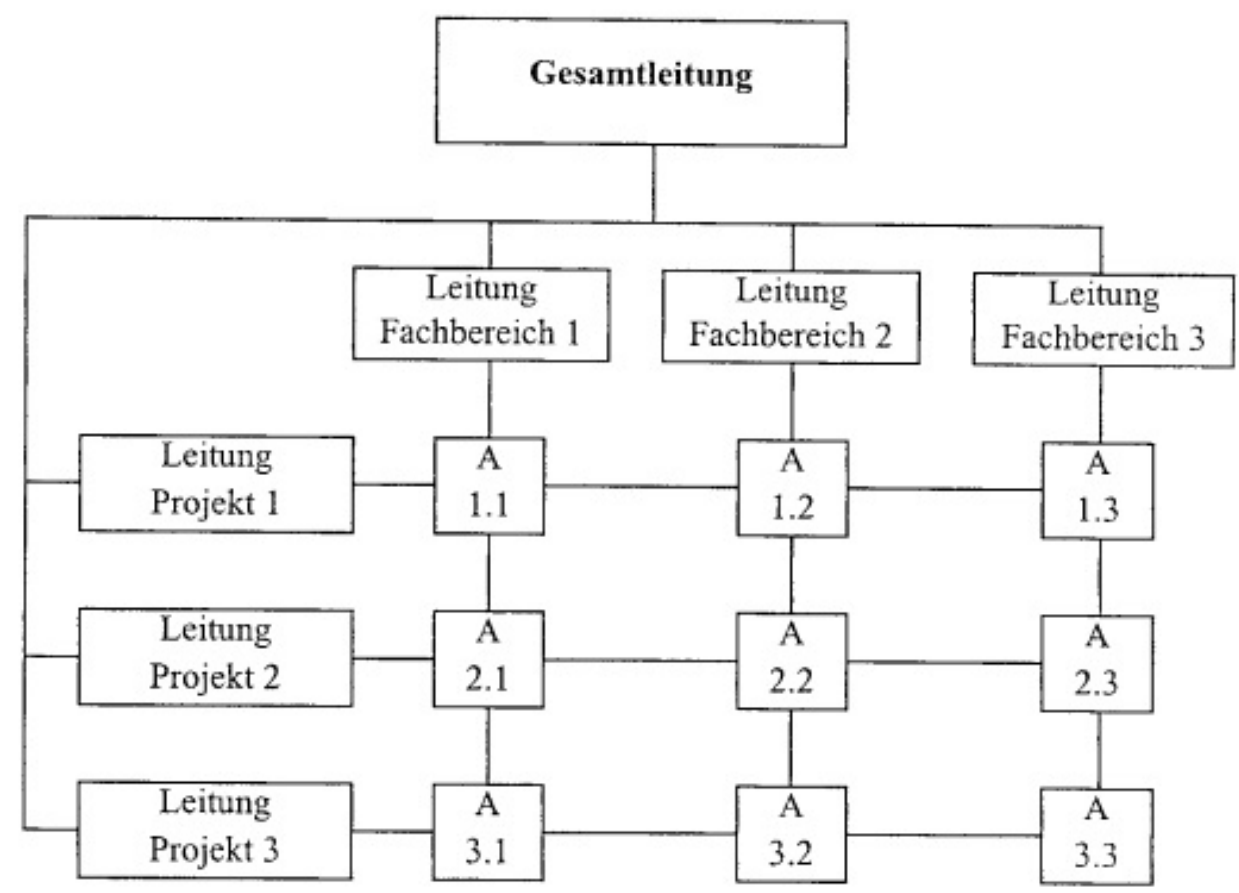

Quelle: Kalusche: Projektmanagement für Bauherren und Planer München/Wien 2005 S. 91

In der oben dargestellten Matrixprojektorganisation sind nun die einzelnen Firmen z.B. A1.1, A2.2 nicht mehr nur einer Weisungsinstanz unterstellt (z.B. Leitung Fachbereich 1), sondern noch einer weiteren Ebene (Leitung Projekt 2).

Ein Nachteil dieser Managementform ist die komplizierte nicht eindeutige Hierarchieform und daher sind zusätzliche Weisungskonflikte vorprogrammiert. ${ }^{33}$

\subsubsection{Ablauforganisation}

„Die Ablauforganisation regelt die projektbezogenen Abläufe, im Einzelnen die Abläufe von Aufgabenerledigungen, Zuständigkeiten für Abwicklungsschritte, Abstimmungsprozeduren, Büroorganisation, Besprechungswesen und Dokumentenlauf sowie Berichtorganisation. “34

\footnotetext{
${ }^{33}$ Kessler, H.: Winkelhofer, G.: Projektmanagement, Leitfaden zur Steuerung und Führung von Projekten Berlin 1997 S. 28 ${ }^{34}$ P. Greiner, P. E. Mayer, K. Stark: Baubetriebslehre - Projektmanagement, Wie Bauprojekte erfolgreich
gesteuert werden, Wiesbaden 2005 S. 41
} 
Die Ablauforganisation wird häufig mittels Diagrammen oder Tabellen dargestellt, da diese Formen schnell einen Überblick erlauben. Für große Projekte wird die Form des Flussdiagramms, wie es die folgende Abbildung zeigt, häufig angewendet.

\section{Abbildung 7: Flussdiagramm in der Ablauforganisation}

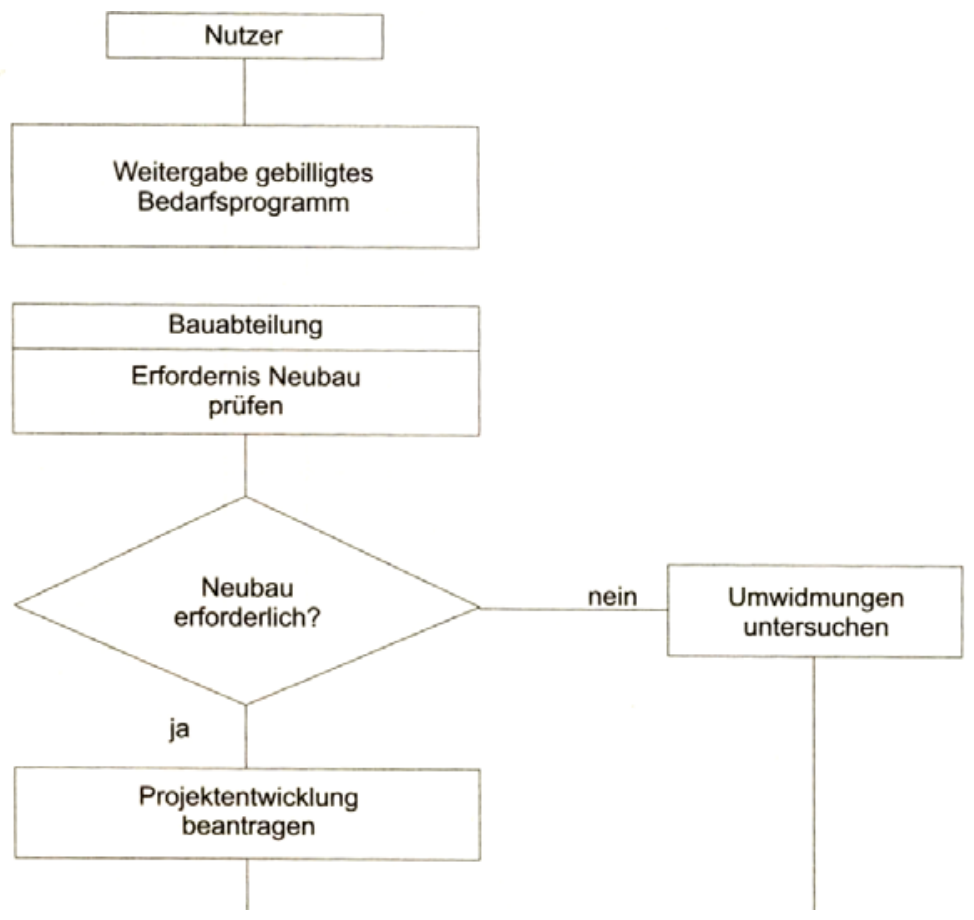

Quelle: P. Greiner, P. E. Mayer, K. Stark: Baubetriebslehre- Projektmanagement, Wie Bauprojekte erfolgreich gesteuert werden, Wiesbaden ${ }^{3} 2005$ S. 41

Bei der folgenden Abbildung ist ersichtlich, welche Schritte nacheinander durchgeführt werden müssen. Bei kleineren Projekten kann es ausreichend sein, die nächsten Schritte zu besprechen und im Protokoll festzuhalten. Bei großen Projekten wird die Erstellung und Abhandlung der dargestellten Abwicklungsmatrix empfohlen. 


\section{Abbildung 8: Abwicklungsmatrix}

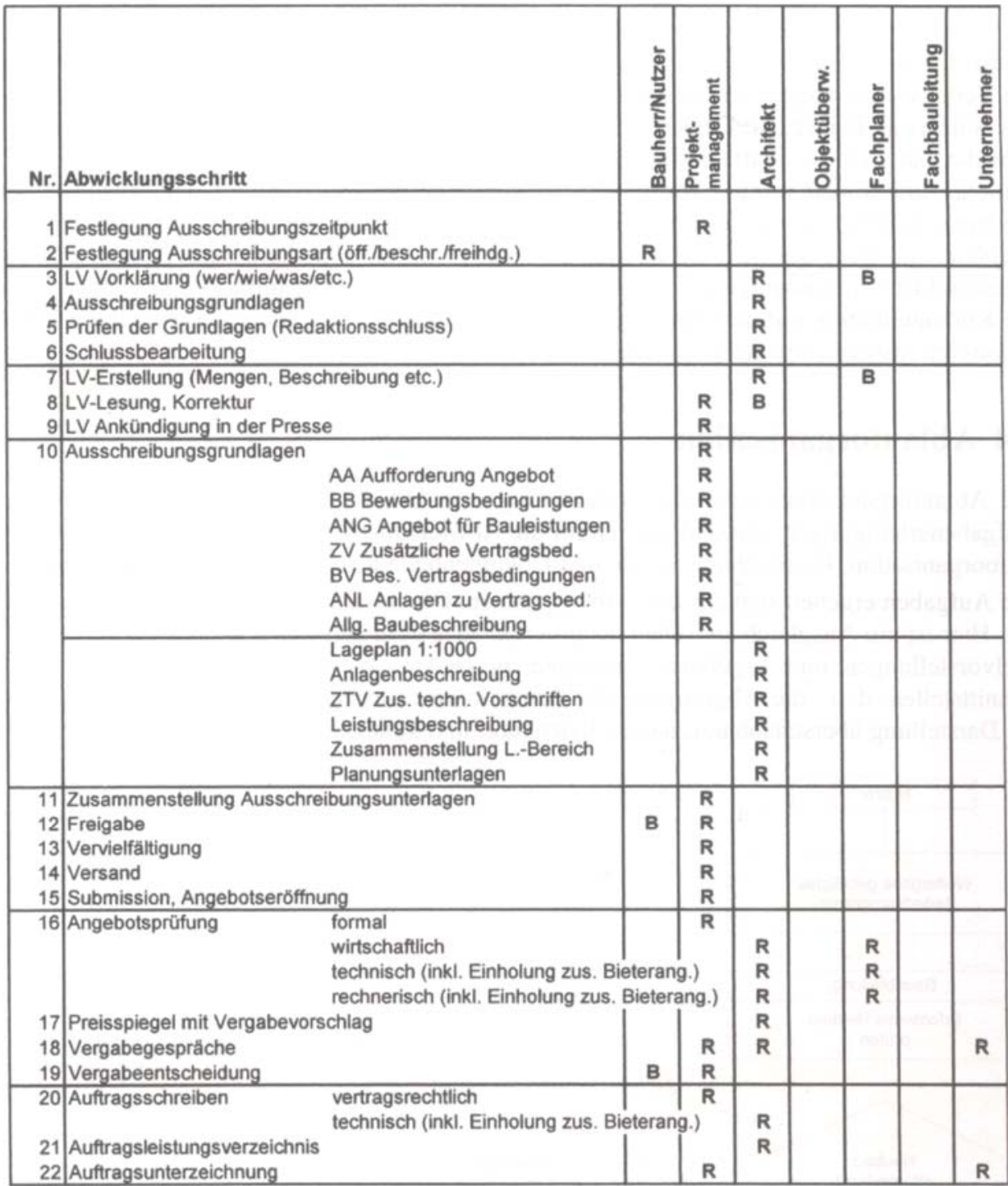

Legende: $\mathrm{B}=$ bei Bedarf; $\mathrm{R}=$ Regelfall

Quelle: P. Greiner, P. E. Mayer, K. Stark: Baubetriebslehre- Projektmanagement, Wie Bauprojekte erfolgreich gesteuert werden, Wiesbaden ${ }^{3} 2005$ S. 42

In dieser Abbildung ist klar aufgelistet, welche Aufgaben nacheinander geschehen müssen und wer für diese zuständig ist.

Von Nutzen ist es auch einen Besprechungsplan zu entwickeln. Mit diesem kann die Weitergabe von Informationen klar strukturiert werden. 


\section{Abbildung 9: Besprechungsplan}

\begin{tabular}{|c|c|c|c|c|c|c|c|}
\hline Art der Besprechung & \begin{tabular}{c|} 
Leitung und \\
Protokollführung
\end{tabular} & $\begin{array}{c}\text { Regel- } \\
\text { Rhythmus }\end{array}$ & Ort & $\begin{array}{c}\text { Regel- } \\
\text { Teilnehmer }\end{array}$ & $\begin{array}{l}\text { Mögliche } \\
\text { Teilnehmer }\end{array}$ & \begin{tabular}{c|} 
Verteilung, \\
Protokoll \\
spätestens
\end{tabular} & $\begin{array}{l}\text { Anforderung, } \\
\text { Einladung, } \\
\text { Tagesordnung }\end{array}$ \\
\hline Bauherr & PM & 1/4 Jahr & Amt & \begin{tabular}{c|} 
Amtsvertreter \\
nach Einladung \\
PM, Arch.
\end{tabular} & Fachplaner & nach 4 Wo. & 4 Wo. vorher \\
\hline Nutzergespräche intern & Nutzer & (intern) & Nutzer & & & & \\
\hline $\begin{array}{l}\text { Organisation, Qua lităt, } \\
\text { Kosten, Termine }\end{array}$ & PM & 14-tăgig & Amt & $\begin{array}{l}\text { PM, Planer, } \\
\text { Ausführende }\end{array}$ & \begin{tabular}{c|} 
Nutzer, \\
Sonderfachleute, \\
Fachbauleiter
\end{tabular} & nach 1 Wo. & 2 Wo. vorher \\
\hline $\begin{array}{c}\text { Fachtechnische } \\
\text { Koordination Planung }\end{array}$ & Architekt & 14-tăgig & Arch. & $\begin{array}{l}\text { PM, Planer, } \\
\text { Austührende }\end{array}$ & Sonderfachleute & nach 1 Wo. & 2 Wo. vorher \\
\hline \begin{tabular}{c|} 
Fachtechnische \\
Koordination Bauvorbereitung
\end{tabular} & Architekt & n. Bedarf & Planer & $\begin{array}{l}\text { PM, Planer, } \\
\text { Ausführende }\end{array}$ & & n. 3 Tagen & 1 Wo. vorher \\
\hline $\begin{array}{c}\text { Fachtechnische } \\
\text { Koordination Ausführung }\end{array}$ & Architekt & wőchentlich & vor Ort & $\begin{array}{l}\text { PM, Planer, } \\
\text { Ausführende }\end{array}$ & & nach 1 Wo. & 1 Wo. vorher \\
\hline Einzelbesprechungen & Initiator & nach Bedart & & & & n. 3 Tagen & n. Vereinbarung \\
\hline \multicolumn{8}{|c|}{$\begin{array}{l}\text { Grundsătzlich ist jede Besprechung (moglichst kurz) zu protokollieren. Protokolle gehen jeweils an Bauherm, PM, Architekt, Eingeladene und weitere It. Festlegeung in der } \\
\text { jeweiligen Besprechung. }\end{array}$} \\
\hline Projektmanagementbüro & & rganisation & von $\mathrm{Be}$ & sprechungen & & $\begin{array}{l}\text { Projekt: } \\
\text { Plan Nr. } \\
\text { Bearbeiter: } \\
\text { Stand: }\end{array}$ & \\
\hline
\end{tabular}

Quelle: P. Greiner, P. E. Mayer, K. Stark: Baubetriebslehre- Projektmanagement, Wie Bauprojekte erfolgreich gesteuert werden, Wiesbaden ${ }^{3} 2005$ S. 44

Die oben abgebildete Darstellung von Greiner/Mayer/Stark zeigt ein Beispiel eines Besprechungsplanes. In diesem müssen vor allem die Art der Besprechung, der Ort, der zeitliche Rhythmus, die Teilnehmer und die Vor- und Nacharbeiten geregelt sein.

Kalusche nennt neben den bereits aufgelisteten Formen noch das Ablaufschema als Mittel der Ablauforganisation. 


\section{Abbildung 10: Ablaufschema}

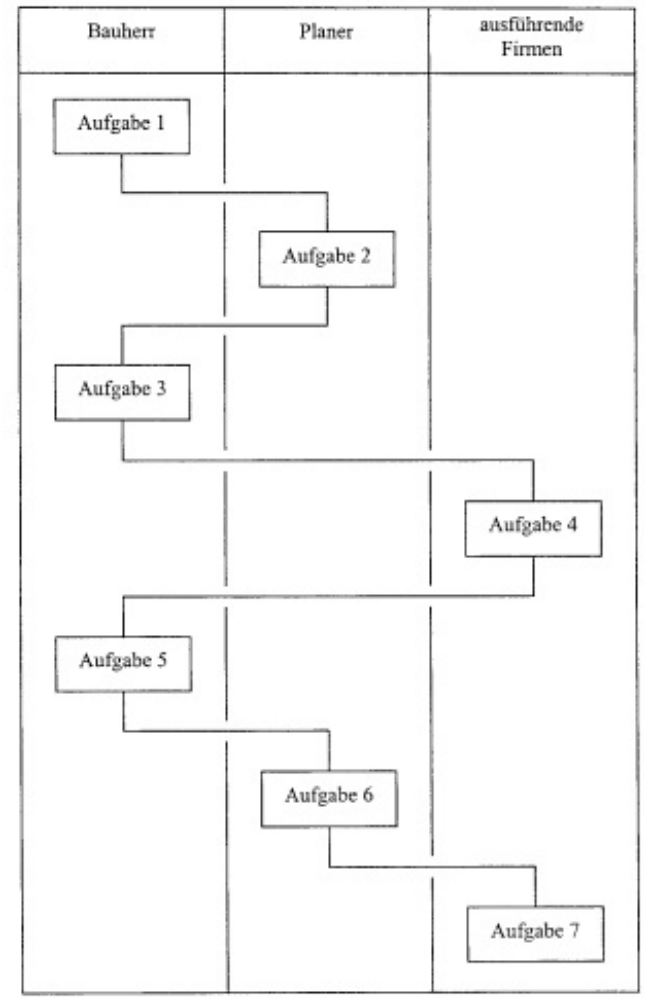

Quelle: Kalusche: Projektmanagement für Bauherren und Planer München/Wien 2005 S. 92

Die oben dargestellte Abbildung stellt ein Schema dar, in dem die Ablaufstruktur festgelegt ist. Dieser Ablauf muss von allen Beteiligten eingehalten werden. Entsprechend diesem strukturierten Plan müssen die Beteiligten ihre Aufgaben erledigen. Dieses Schema kann beispielsweise für Regelabläufe beim Verfahren für Ausschreibung und Vergabe eingesetzt werden. ${ }^{35}$

${ }^{35}$ Vgl. Kalusche: Projektmanagement für Bauherren und Planer München/Wien 2005 S. 91 


\subsection{Projektmanagement eines Bauprojektes}

Der zweite Teil des Punktes „Allgemeines Projektmanagement" beschreibt den Ablauf des Projektmanagements eines Bauprojektes. Dieser Punkt gliedert sich in vier Unterpunkte. Übergeordnet werden im ersten Punkt allgemeine Themen behandelt die sich auf den gesamten Projektablauf beziehen. Im zweiten Punkt wird der Projektbeginn mit der Projektentwicklung erläutert. Der dritte Punkt beschreibt das Projektmanagement in der Planung, und im vierten Punkt wird das Projektmanagement in der Ausführungsphase dargestellt.

\section{Abbildung 11: Beziehung des Bauherren zu den Vertragspartnern}

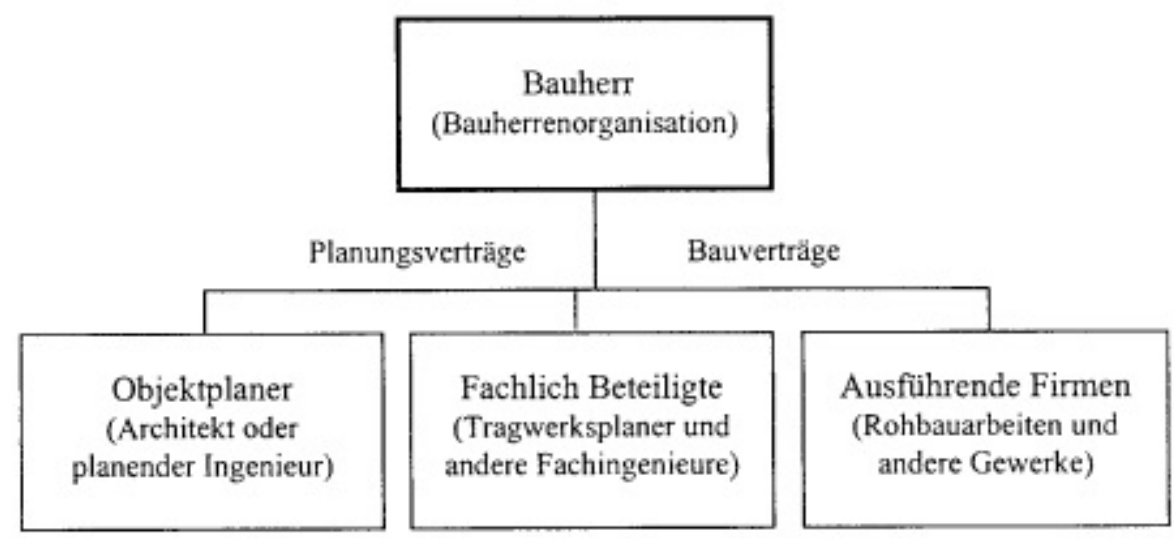

Quelle: Kalusche: Projektmanagement für Bauherren und Planer München/Wien 2005 S. 25

\subsubsection{Projektplanung}

Der Punkt „Projektplanung“ wird in dieser Arbeit vor den Punkten „Projektentwicklung“, „Projektmanagement in der Planung“ und „Projektmanagement in der Ausführungsphase" behandelt, da in diesem Kapitel wichtige Themen behandelt werden, die sich übergeordnet über die soeben genannten Themenbereiche erstrecken. Beispielsweise muss die Terminplanung zu Beginn des Projektes definiert und im gesamten Ablauf des Projektes verfolgt werden. ${ }^{36}$

\footnotetext{
${ }^{36}$ Vgl. Kalusche: Projektmanagement für Bauherren und Planer München/Wien 2005 S. 25
} 


\subsubsection{Strukturierung der Projektaufgaben / des Projektablaufs}

Zu Beginn eines Projektes ist es wichtig das Projekt in seinem Umfang zu erfassen und überschaubar zu machen. Dafür ist es ratsam das Projekt zu strukturieren und in einzelne Projektaufgaben aufzuteilen. Der erste Grundstein für die Planungsaufgaben ist damit geschaffen.

Um die einzelnen Teilaufgaben sowie den Projektumfang zu veranschaulichen wird in der Startphase eines Projektes ein Projektstrukturplan erstellt. Dieses Planungselement wird oft tabellarisch oder als Organigramm in Form einer Baumstruktur dargestellt. Im Baugewerbe wird die Unterteilung des Projektstrukturplanes häufig in die verschiedenen Bauabschnitte und weiters in logische Einheiten wie Bauteile oder Geschoße unterteilt. Der Umfang dieses Strukturplanes richtet sich jedoch stark nach dem Umfang des Projektes. ${ }^{37}$

\section{Abbildung 12: Projektstrukturplan}

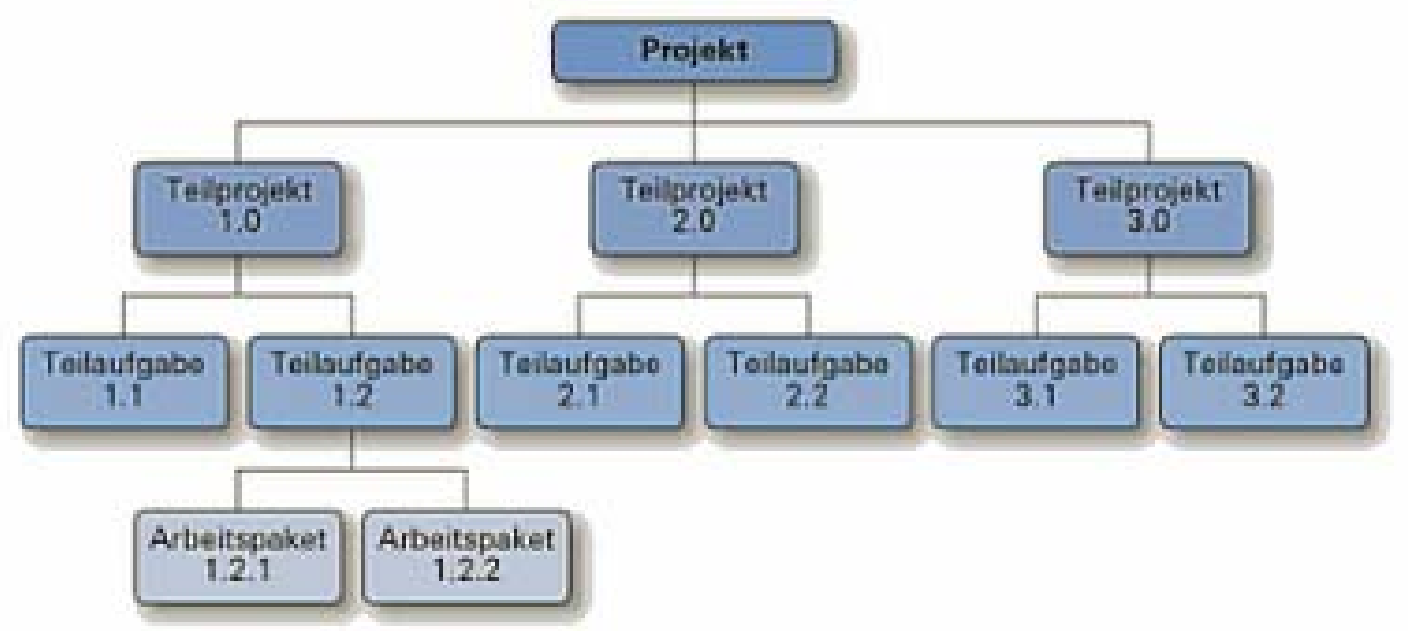

Quelle: A.Führer/R.Züger: Projektmanagement Management-Basiskompetenz, Zürich 2007 S. 74

Der Projektstrukturplan ist die Zerlegung einzelnen Arbeitsabläufe in Ihre Teilaufgaben. Die Einzelschritte werden dabei in Projektaufgaben dargestellt, und hierarchisch gegliedert. Der Zweck besteht also darin einen Überblick über das Projekt zu erlangen und die große unüberschaubare Gesamtaufgabe in kleinere Teilaufgaben zu unterteilen (Teilprojekte), um Zusammenhänge bzw. Synergien festzustellen und zu nutzen.

\footnotetext{
${ }^{37}$ A.Führer/R.Züger: Projektmanagement Management-Basiskompetenz, Zürich 2007 S. 74
} 
Der Projektstrukturplan stellt damit die optimale Basis für die Erstellung des Ablauf-, Termin-, und Kostenplanes dar. Die Vollständigkeit des Projektstrukturplanes ist von besonderer Bedeutung. Sämtliche nicht enthaltenen Elemente werden auch nicht ausgeführt. Die Einhaltung des Projektstrukturplanes wird meist von der Stelle „Projektcontrolling“ ausgeführt.

Die Vorteile des Projektstrukturplanes liegen in der klaren Strukturierung und in der Effizienzsteigerung bei der Planung und Durchführung des Projekts, da Ungereimtheiten über den Leistungsumfang zwischen Auftraggeber und Projektteam/Auftragnehmer bereits zu Beginn des Projektes ausgeräumt werden.

Bei der Projektstrukturierung und dem Erstellen eines Projektstrukturplanes muss auf Folgendes geachtet werden ${ }^{38}$ :

1.) Die Unterteilung des Projektes in Teilaufgaben sollte nur so weit betrieben werden, wie die unterste Einheit, also das Arbeitspaket, geschlossen an eine Organisationseinheit delegiert werden kann.

2.) Die Arbeitspakete untereinander sind möglichst klar abzugrenzen und jedes Paket für sich sollte ein als Zielgröße definiertes Ziel haben.

3.) Für die Erreichung der Ergebnisse des Arbeitspaketes sowie die Einhaltung der Kosten und Zeiten sind die zuständigen Projektmitglieder verantwortlich zu machen.

\subsubsection{Terminplanung}

Die Terminplanung eines Projektes ist eine der entscheidenden Größen über den Erfolg oder den Misserfolg eines Projektes. Er ist wesentlicher Bestandteil der strukturierten, ordentlichen und professionellen Abwicklung einer Baumaßnahme. Nur wenn ein Projekt zum vereinbarten Zeitpunkt fertig gestellt wird und es ab diesem Zeitpunkt nutzbar bzw. einsatzbereit ist, kann von einem erfolgreichen Projekt gesprochen werden. Bei nicht zeitgerechter Fertigstellung können hohe Geldstrafen in Form von z.B. Vertragsstrafen, Schadenersatzforderungen udgl. drohen.

\subsection{Grundsätze der Terminplanung}

\footnotetext{
${ }^{38}$ Vgl. T.Sperber: Aufbau einer Projektmanagementstruktur für Investitinsprojekte, Hamburg 2008 S. 65
} 
Die Terminplanung spielt eine wichtige Rolle und dient nicht zuletzt der Fortschrittskontrolle und der Terminabstimmung aller Beteiligten.

Ziel der Terminplanung ist die Festlegung sämtlicher Termine für alle Bereiche. Weiters sind in der Terminplanung eines Projektes wichtige Meilensteine, Termineckpunkte und die Ausführungsdauer verschiedener globaler Tätigkeiten enthalten. Pufferzeiten sowie kritische Zeitvorgaben aus der Aufwandsschätzung der Strukturplanung werden im Terminplan ebenfalls eingearbeitet. ${ }^{39}$

Bei großen und umfangreichen Projekten können in den Terminplan natürlich nicht sämtliche Einzeltätigkeiten aufgenommen werden. Es werden lediglich die Zeitspannen einzelner Gewerke bzw. Fachbereiche mit der auf die anderen Tätigkeiten abgestimmten Zeitspannen und Endtermine aufgenommen. Die Detailabstimmung über die Ausführung der jeweiligen Tätigkeit wird dann vom zuständigen Gewerk/Fachbereich in der vorgegebenen Zeitspanne unter Berücksichtigung und Abstimmung mit anderen Gewerken vorgenommen.

Grundsätzlich gibt es zwei Möglichkeiten der Terminplanerstellung, die Vorwärtsrechnung und die Rückwärtsrechnung.

Vorwärtsrechnung: Ausgehend vom Anfangstermin eines Projektes werden der früheste Endzeitpunkt sowie die Anfangszeitpunkte der Zwischenvorgänge ermittelt.

Rückwärtsrechnung: Bei der Rückwärtsrechnung geht man gegengleich zur Vorwärtsrechnung vor. Es wird vom Fertigstellungszeitpunkt (meist mit dem Auftraggeber vereinbart) ausgegangen und anhand dieses Zeitpunktes wird der spätest mögliche Projektstartpunkt festgelegt.

Die zeitliche Planung eines Projektes beginnt mit der offiziellen Ankündigung des Projektes und endet mit der Übergabe an den Nutzer.

${ }^{39}$ Vgl. K. Zering: Terminplanung im Projektmanagement, Norderstedt 2008 S. 5 
Je nach Komplexität der Baumaßnahme und nach Projektfortschritt ist eine unterschiedliche Detailliertheit des Terminplanes erforderlich. ${ }^{40}$

Ein Projektablaufplan, der sämtliche Abläufe vom Beginn der Projektentwicklungsphase bis zum endgültigen Fertigstellungstermin enthält, kann zwar theoretisch erstellt werden, ist jedoch für sämtliche Projektteilnehmer unübersichtlich und verbraucht unnötige Ressourcen bei der Erstellung und der Aktualisierung. Weiters enthält dieser unzählige Informationen, die zum jeweiligen Projektstand nicht erforderlich sind. So ist es beispielsweise nicht zielführend in der Projektstartphase den genauen Termin sowie die Ausführungsdauer z.B. des Fenstereinbaues festzulegen.

In der Praxis haben sich daher folgende Terminpläne durchgesetzt: der Rahmenterminplan/Meilensteinplan, der Generalterminplan, der Steuerungsterminplan, der Detailterminplan, und die Checkliste. ${ }^{41}$

In der unten stehenden Abbildung werden die Terminplantypen anhand ihres Umfanges und dem Grad der Detaillierung aufgelistet. ${ }^{42}$

${ }^{40}$ Vgl. M. Mohrmann: Bauvorhaben mithilfe von Lean Projektmanagement neu denken 4. , Norderstedt ${ }^{4} 2011$ S. 319

${ }^{41}$ Vgl. P. Greiner, P. E. Mayer, K. Stark :Baubetriebslehre- Projektmanagement Erfolgreiche Steuerung von Bauprojekten, Wiesbaden ${ }^{4} 2009$ S. 120

${ }^{42}$ K. Bisani, Fachhochschule München, Fachbereich 02 Bauingenieurwesen: Bauproduktionsplanung, -steuerung, Terminplanung: http://w3-mediapool.hm.edu/mediapool/media/fk02/fk02_lokal/professoren_7/ bisani/downloads_2/terminplanung/fhm_skript_terminplanung_kapitel_3.pdf 01.02.2012 S. 49 


\section{Abbildung 13: Plantypen der Terminplanung}

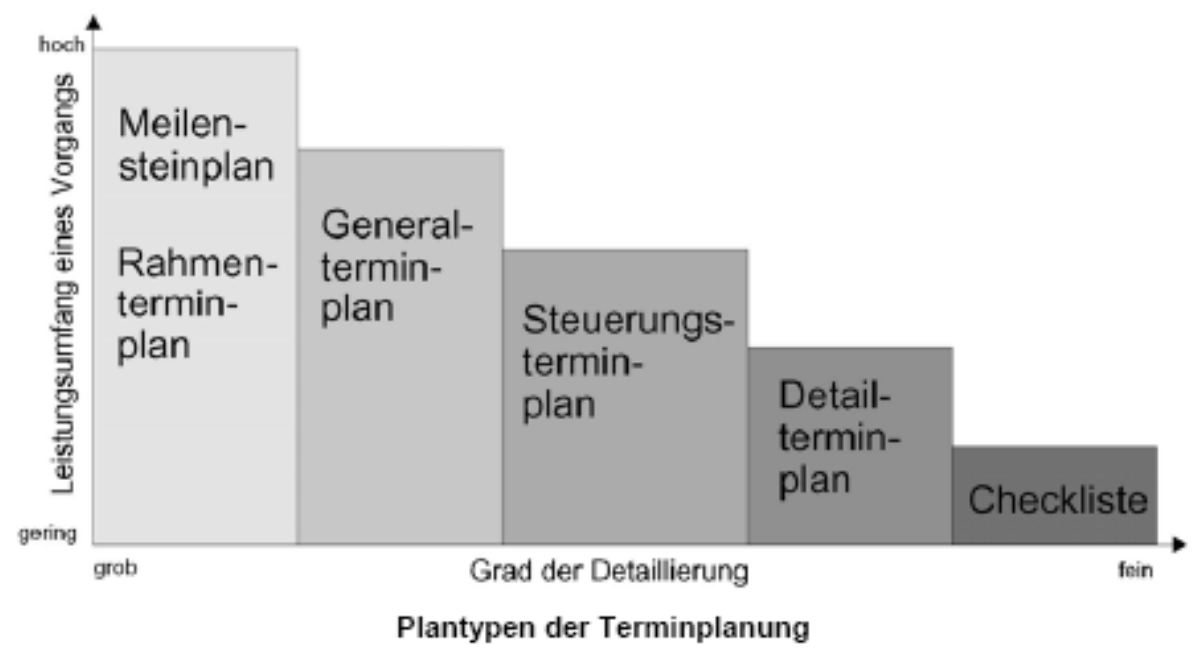

Quelle: P. Greiner, P. E. Mayer, K. Stark: Baubetriebslehre- Projektmanagement Erfolgreiche Steuerung von Bauprojekten, Wiesbaden ${ }^{4} 2009$ S. 120

Es werden zwei Formen der Terminplanung unterschieden:

\section{Der projektorientierte Terminplan ${ }^{43}$}

Der projektorientierte Terminplan wird meist von der Bauherrenseite oder von der Bauherrenvertretung erstellt. Dieser Terminplan beinhaltet die gesamte Projektdauer von der Projektidee bis zur endgültigen Fertigstellung bzw. Projektübergabe. Die Darstellung und Betrachtung ist in diesem Terminplan sehr ganzheitlich. Es werden keine Details beschrieben. Es werden vielmehr die einzelnen Bereiche dem Grunde nach in die Terminschiene aufgenommen. Dieser Zeitplan umfasst sowohl den Tätigkeitsbereich des Bauherren als auch des Projektsteuerers, sämtlicher „Sub“-Projektteams und selbstverständlich auch der ausführenden Unternehmen.

\section{Der produktorientierte Terminplan ${ }^{44}$}

Bei diesem Terminplan wird der beauftragte Leistungsumfang in den Mittelpunkt gestellt. Die einzelnen Leistungen des Bauprozesses werden im Terminplan dar-

\footnotetext{
${ }^{43}$ K. Bisani, Fachhochschule München, Fachbereich 02 Bauingenieurwesen: Bauproduktionsplanung, steuerung, Terminplanung: http://w3-mediapool.hm.edu/mediapool/media/fk02/fk02_lokal/professoren_7/ bisani/downloads_2/terminplanung/fhm_skript_terminplanung_kapitel_3.pdf 01.02.2012 S. 49

${ }^{44}$ K. Bisani, Fachhochschule München, Fachbereich 02 Bauingenieurwesen: Bauproduktionsplanung, steuerung, Terminplanung: http://w3-mediapool.hm.edu/mediapool/media/fk02/fk02 lokal/professoren_7/ bisani/downloads_2/terminplanung/fhm_skript_terminplanung_kapitel_3.pdf 01.02.2012 S. 49
} 
gestellt. Der produktorientierte Terminplan umfasst meist nur einen Teil der Projektphase und nur selten den gesamten zeitlichen Abschnitt des Projektes. Sämtliche anderen Projektteilnehmer können ausgehend vom produktorientierten Terminplan über die Rückwärtsrechnung die eigenen Termine abstimmen. Von den aus dem Terminplan abgeleiteten Daten können Unternehmen den Organisationsplan ableiten.

\subsubsection{Rahmenterminplan}

Der Rahmenterminplan ist in der Regel der erste Terminplan eines Bauprojektes in dem die grundsätzlichen Terminvorgaben wie z.B. Projektbeginn und gewünschter Fertigstellungstermin eingetragen werden. Die Projektabwicklung wird erstmals in einzelnen Phasen eingeteilt. Der Rahmenterminplan dient ebenfalls als Grundlage bei der Besprechung mit den jeweiligen Finanzgebern um die Finanzierungsmittelplanung und die damit erforderlichen Finanzflüsse in den groben Umrissen einzutakten. Dieser Terminplan wird meist vom Bauherr oder einem Bauherrenvertreter erstellt und gehört in die Gruppe der projektorientierten Terminpläne.

Im Rahmenterminplan werden für das Gesamtprojekt terminkritische Vorgänge wie z.B. Genehmigungsverfahren bei Behörden udgl. eingetragen. Weiters werden die wichtigsten Haupt-Abläufe des Projektes in den Planungszeitraum und den Ausführungszeitraum unterteilt. Entscheidende Zwischentermine von beispielsweise Teilfertigstellungen oder unterschiedlichen Bauteilen werden ebenfalls angeführt. Der Rahmenterminplan sollte jedoch nicht mehr als ca. 20 Vorgänge beinhalten. ${ }^{45}$

\footnotetext{
${ }^{45}$ Vgl. B. Kochendörfer, J. H. Liebchen, M. G. Viering: Bau-Projekt-Management Grundlagen und Vorgehensweisen, Wiesbaden ${ }^{4} 2010$ S. 114
} 


\section{Abbildung 14: Beispielhafter Rahmenterminplan}

\begin{tabular}{|c|c|c|c|c|c|}
\hline Rahmenterminpla & altung & băude & & & \\
\hline Vorgang & Jahr 1 & Jahr 2 & Jahr 3 & Jahr 4 & Jahr 5 \\
\hline Projektentwicklung & & & & & \\
\hline Architektenwettbewerb & & & & & \\
\hline Vorplanung & & & & & \\
\hline Entwurfsplanung u. Baug & & & & & \\
\hline Genehmigungsverfahren & & & & & \\
\hline Werkplanung Rohbau & & & & & \\
\hline Ausschreibung Rohbau & & & & & \\
\hline Rohbauarbeiten & & & & & \\
\hline Gebåudetechnik & & & & & \\
\hline Ausbau & & & & & \\
\hline Mängelbeseitigung & & & & & \\
\hline Inbetriebnahme/Umzug & & & & & \\
\hline
\end{tabular}

Quelle: U. Schütz: Projektentwicklung von Verwaltungsgebäuden, Renningen-Malmsheim ${ }^{1} 1994$ S. 51

\subsection{Generalablaufplan (Generalablaufterminplan)}

Als Basis für die Erstellung des Generalablaufplanes werden die Festlegungen des Rahmenterminplanes herangezogen. Dieser Terminplan dient der mittelfristigen Zeitplanung, in dem Vorgänge angeführt werden die sich ausführenden Firmen oder Planern zuordnen lassen. Daraus lassen sich auch Abhängigkeiten zwischen den Firmen oder auch zwischen den Firmen und der Planung (Planlieferungen) ablesen. Wichtiger Bestandteil dieses Terminplanes ist die Darstellung der einzelnen Vergabepakete mit jeweiligem Start- und Fertigstellungstermin. Wichtige Termine wie z.B. Abnahmen, Mängelbehebungen, gemeinsame Inbetriebnahmen, Probebetriebe udgl. sind ebenfalls Bestandteil dieser Vorgabe.

Die Leistungen sind in Balken, die über mehrere Wochen bzw. Monaten reichen dargestellt. Es können bereits wichtige Verbindungen und kritische Leistungen abgeleitet werden. Ein Generalablaufplan umfasst rund 40 Vorgänge. Für die Ausführung einzelner Tätigkeiten ist dieser Terminplan allerdings noch zu ungenau. 
Da dieser (wie auch der Rahmenterminplan) meist von der Bauherrenseite erstellt wird, wird dieser der Gruppe der projektorientierten Terminpläne zugeordnet. ${ }^{46}$

\section{Abbildung 15: Beispielhafter Generalablaufplan}

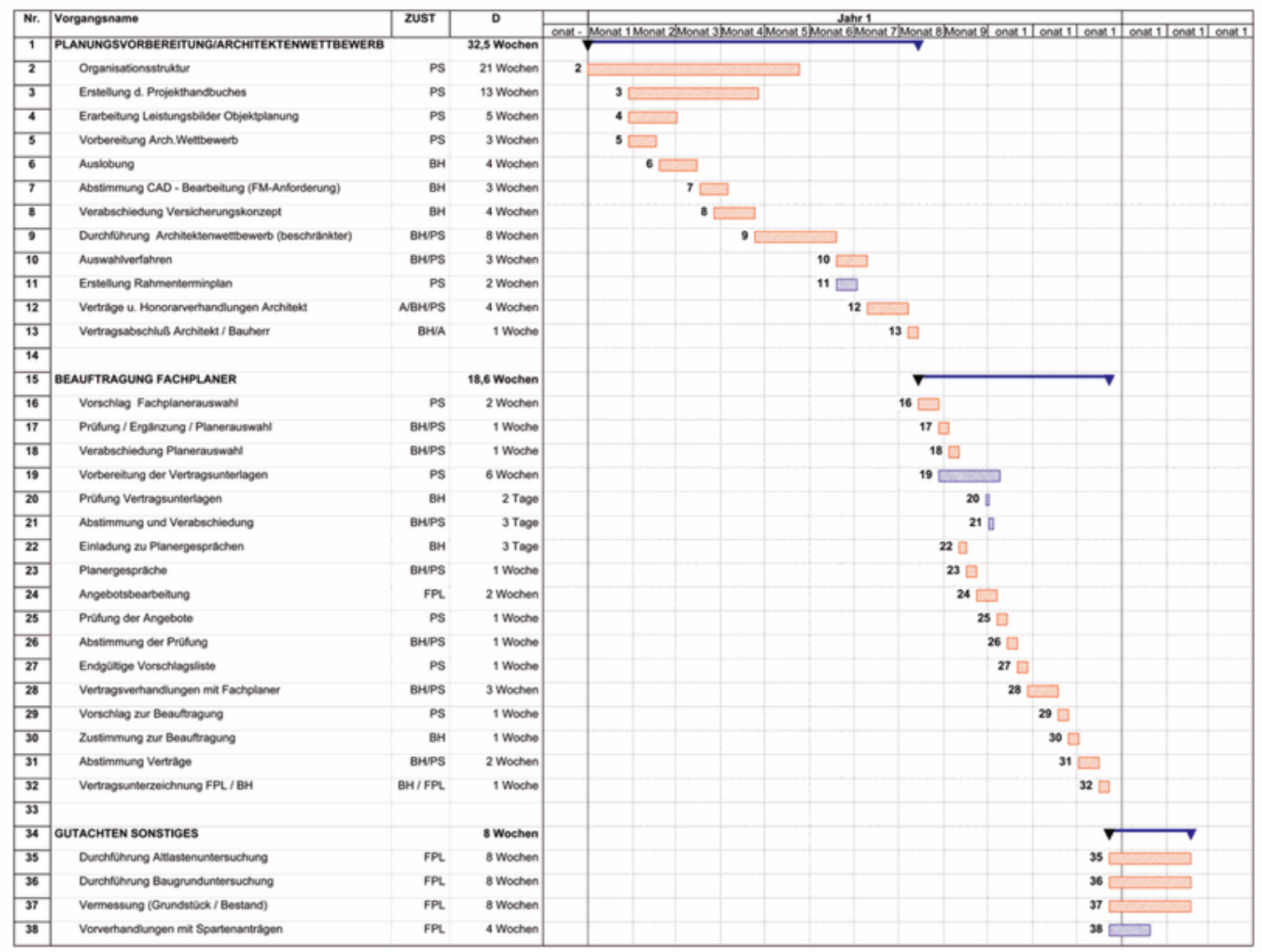

Quelle: N. Preuß: Projektmanagement von Immobilienprojekten, Entscheidungsorientierte Methoden, Berlin/Heidelberg ${ }^{1} 2011$ S. 204

\subsection{Steuerungsterminplan}

Der Steuerungsterminplan wird in die einzelnen Abläufe wie z.B. Vorplanung, Entwurfsplanung, Ausführungsplanung und Ausführung unterteilt. Meist werden für jeden dieser Abschnitte eigene Terminpläne erstellt. Dieser Terminplan enthält im Vergleich zum Generalablaufplan weit mehr Informationen, die aufgrund des fortgeschrittenen Projektstandes auch im Terminplan dargestellt werden. Der Inhalt dieses Terminplanes ist bereits so weit verfeinert, dass dieser zur Koordination

\footnotetext{
${ }^{46}$ http://w3-mediapool.hm.edu/mediapool/media/fk02/fk02_lokal/professoren_7/ bisani/downloads_2/terminplanung/fhm_skript_terminplanung_kapitel_3.pdf 01.02.2012 S. 51
} 
und als Basis der Überwachung und Steuerung des Projektablaufes verwendet werden kann.

Anhand des Steuerungsterminplanes können die vereinbarten Termine verfolgt, kontrolliert und dokumentiert werden. Weiters dient dieser als Grundlage für Besprechungen und ermöglicht eine Leistungsvorschau und damit eine vorausblickende Steuerung des Projektablaufes.

Dieser Terminplan muss spätestens mit Abschluss der Vorplanung geführt und regelmäßig aktualisiert werden. Für alle Projektbeteiligten sind damit die erforderlichen Termine einzelner Teilleistungen (z.B. Planlieferungen, Einreichungen, udgl.) definiert. Der Steuerungsterminplan gehört zu den produktorientierten Terminplänen. ${ }^{47}$

\footnotetext{
${ }^{47}$ Vgl. B. Kochendörfer, J. H. Liebchen, M. G. Viering: Bau-Projekt-Management Grundlagen und Vorgehensweisen, Wiesbaden ${ }^{4} 2010$ S. 114
} 


\section{Abbildung 16: Steuerungsterminplan mit den Elementen der Vorentwurfs- planung}

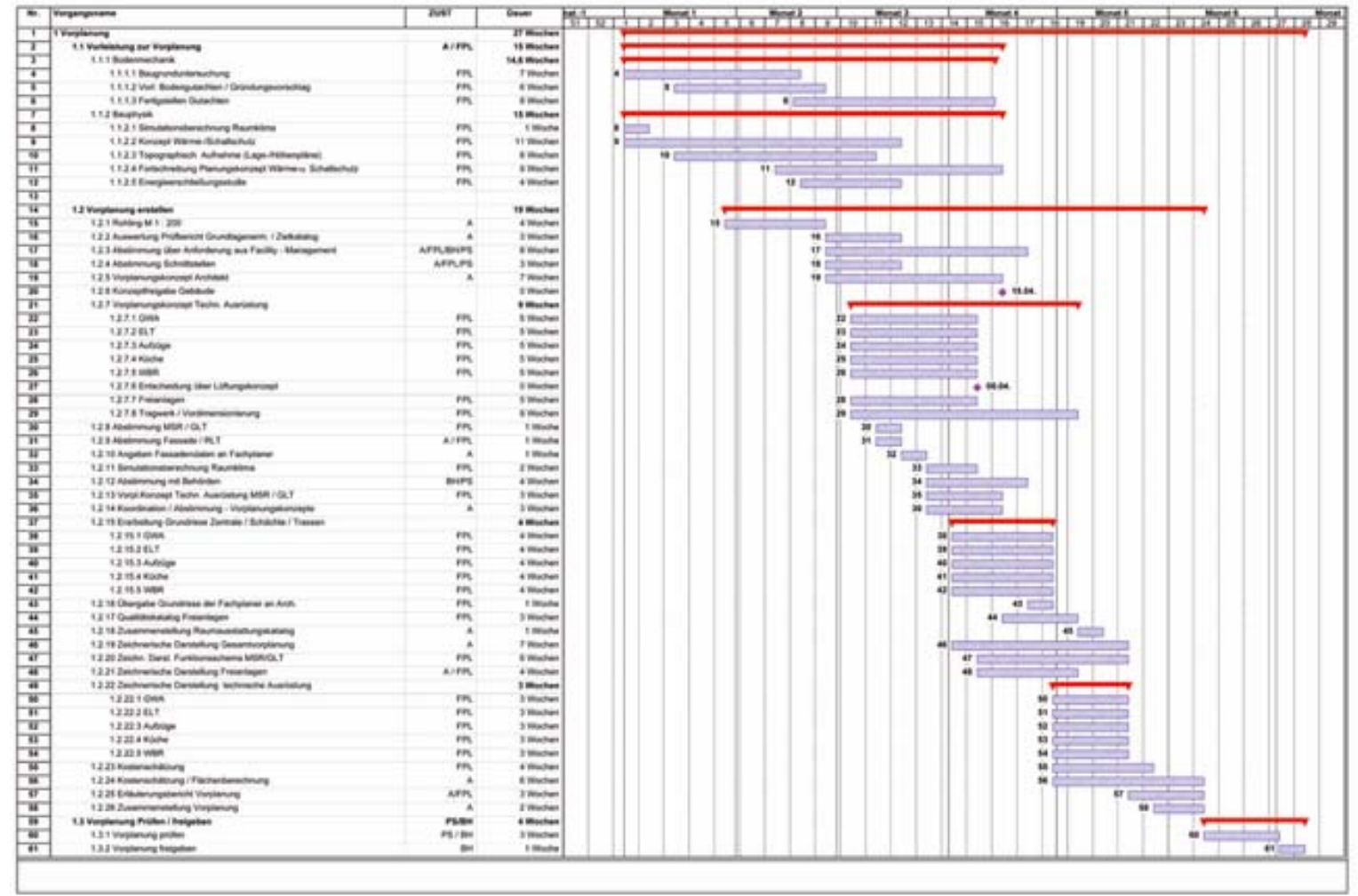

Quelle: N. Preuß: Projektmanagement von Immobilienprojekten, Entscheidungsorientierte Methoden, Berlin/Heidelberg ${ }^{1} 2011$ S. 207

\subsection{Detailterminplan}

Die Basis des Detailterminplanes bildet der Steuerungsterminplan. Der Detailterminplan umfasst jedoch typischerweise nur einen Zeitraum von ca. drei Wochen. Dieser Terminplan muss wöchentlich an die aktuellen Gegebenheiten und Vereinbarungen angepasst werden. Es werden nach Möglichkeit einzelne Arbeitsschritte mit Zeitangaben erfasst, daher kann dieser Terminplan zur tagesgenauen Steuerung des Projektes verwendet werden. Aufgrund der detaillierten Ausführung wird auch dieser der produktorientierten Terminplanung zugerechnet. ${ }^{48}$

\footnotetext{
${ }^{48}$ Vgl. B. Kochendörfer, J. H. Liebchen, M. G. Viering: Bau-Projekt-Management Grundlagen und Vorgehensweisen, Wiesbaden ${ }^{4} 2010$ S. 115
} 


\subsection{Feinterminplan}

Der Feinterminplan stellt die genaueste Betrachtung und Ausführung eines Terminplanes dar. Dieser wird erstellt wenn besonders kritische Abläufe geplant oder koordiniert werden müssen. Es werden einzelne Arbeitsschritte mit einer definierten Dauer, einem Start- und einem Endzeitpunkt dargestellt. Häufig werden auch die betreffenden Firmen oder handelnde Personen eingetragen. Aufgrund des hohen Genauigkeitsgrades beträgt die Zeitspanne des Feinterminplanes wenige Tage bis eine Woche. ${ }^{49}$

\subsection{Terminverfolgung/Terminkontrolle im Projektablauf}

Mit dem Begriff „Projektmanagement“ (siehe Begriffsdefinition) sind auch Leitungsund Kontrollfunktionen verbunden. Terminverfolgung und Terminüberwachung stellen entscheidende Faktoren für die positive Abwicklung eines Projektes dar.

Um den reibungslosen Ablauf zwischen den Firmen (unter Berücksichtigung der vorgegebenen Termine) zu gewährleisten, ist eine strikte Einhaltung der (unter Punkt 2.2.1.1.1 bis 2.2.1.1.4) angeführten Terminpläne erforderlich. Wird von einer projektbeteiligten Partei ein Terminverzug z.B. zu Beginn des Projekts verursacht, so hat das Auswirkungen auf alle Firmen bis zum letzten Tag des Projektes. Ein Aufholen einer Verzögerung im Projektablauf ist sehr schwierig und meist mit Kosten verbunden. Da ein nachfolgendes Gewerk ebenfalls die vereinbarte Zeit für das eigene Werk benötigt. Die Engpassfaktoren „Arbeitsleistung“ und „Maschinen“ stehen meist nicht uneingeschränkt frei zur Verfügung und auch aufgrund der Platzverhältnisse sind diese oft nicht parallel einsetzbar. Das Aufholen einer „verIorenen Zeit" ist meist nur durch zusätzlichen Aufwand, wie z.B. Überstunden udgl. möglich und damit mit zusätzlichen Kosten verbunden.

Aus Eigeninteresse muss die Terminverfolgung von sämtlichen beteiligten Firmen, wie beispielsweise dem Architekten, dem Generalplaner bis hin zur ausführenden Firma, verfolgt werden. Übergeordnet wird die Terminverfolgung und Terminkon-

\footnotetext{
${ }^{49}$ Vgl. B. Kochendörfer, J. H. Liebchen, M. G. Viering: Bau-Projekt-Management Grundlagen und Vorgehensweisen, Wiesbaden ${ }^{4} 2010$ S. 115
} 
trolle von der Projektsteuerung, dem Projektcontrolling, dem Projektleiter und dem Bauherren durchgeführt.

Zu den Aufgaben der Terminkontrolle und -steuerung gehören im Einzelnen: ${ }^{50}$

$>$ regelmäßiger Soll-Ist-Vergleich durch Datenerhebung in Besprechungen sowie bei Baustellenbegehungen

$>$ Bericht an den Bauherren sowie Informierung weiterer Projektbeteiligter

$>$ fortlaufende Aktualisierung der Terminplanung besonders auf der Ebene der Detailterminplanung nach Abstimmung mit Fachplanern, Behörden, ausführenden Firmen usw. sowie mit dem Bauherren

> bei erkennbaren oder eingetretenen Abweichungen Entwicklung von Terminsteuerungsmaßnahmen sowie deren Abstimmung und Bewertung, beispielsweise in Bezug auf Vertragsänderungen oder Kosten

$>$ Dokumentation der Terminentwicklung.

\subsubsection{Budgetplanung/Kostenplanung}

Die Budget oder Kostenplanung kann beschrieben werden mit:

Kostenermittlung für einzelne Aktivitäten

$>$ Kostenermittlung für das Gesamtprojekt

Diese ermittelten Kosten stellen die Basis für die Finanzierung, die Budgetierung und die Überprüfung (Controlling) in der Projektphase dar.

Die Qualität und der Zeitablauf eines Projektes haben entscheidenden Einfluss auf die Kosten, da beispielsweise bei Zeitverzug mit zusätzlichen finanziellen Mittel die versäumten Zeiten wieder aufgeholt werden können. Bei der Kostenfeststellung in der Kostenplanung werden die Kosten in Abhängigkeit der vorgegebenen Termine und Qualitäten ermittelt und regelmäßig angepasst. Hauptziel jeder Kostenplanung ist, dass die prognostizierten Kosten mit den endgültigen Kosten der

\footnotetext{
${ }^{50}$ Kalusche: Projektmanagement für Bauherren und Planer München/Wien 2005 S. 201
} 
Endabrechnung übereinstimmen, denn wesentlicher Faktor eines Projekterfolges ist die Einhaltung der budgetierten Kosten.

\subsection{Ziele der Kostenplanung}

Von Aichele werden die Ziele der Projektkostenplanung als Erfassung und Dokumentation der Projektkosten bezeichnet. Die errechneten Kosten können folgendermaßen eingesetzt werden: ${ }^{51}$

Als Dispositionsgrundlage, z.B. bezüglich der Entscheidung der Projektdurchführung, oder der Festlegung der Angebotspreise

> Als Bestandteil der geplanten Kosten des Unternehmens im Rahmen der Zusammenstellung eines Wirtschaftsplanes

> Als Möglichkeit eines anschließenden Soll-Ist-Vergleiches und somit der Gegenüberstellung der geplanten Kosten mit den tatsächlich entstandenen Kosten

Von Seiten des Bauherren, des Projektmanagements, des Projektcontrollings oder der Projektsteuerung sind laufend Soll-Ist-Vergleiche durchzuführen oder durchführen zu lassen. Anhand dieser Vergleiche können wichtige Informationen und damit kostenentscheidende Informationen gewonnen werden. Der Projektverantwortliche kann anhand dieser Fakten Vorgaben ändern bzw. Entscheidungen treffen. Folgende Erhebungen werden durchgeführt: ${ }^{52}$

$>$ Frühwarnung bei Kostenüberschreitungen: Aufgrund der laufenden Kostenverfolgungen wird eine Überschreitung der Projektkosten rasch erkannt. Es können von Bauherrenseite Gegenmaßnahmen eingeleitet werden.

$>$ Kostenprognose für die Folgephasen des Projektes: Ähnlich des Systems der Frühwarnung können bei der Kostenprognose die gemachten Erfahrungen in die weitere Prognose eingearbeitet werden.

\footnotetext{
${ }^{51}$ Vgl. C. Aichele: Intelligentes Projektmanagement, Stuttgart ${ }^{1} 2006$ S. 135

${ }^{52}$ Vgl. C. Aichele: Intelligentes Projektmanagement, Stuttgart ${ }^{1} 2006$ S. 135
} 
Schwachstellenanalyse bisheriger Projektarbeit: Resultate der Kostenverfolgung können auf Fehlabläufe oder Schwachstellen des Systems hinweisen. Zusätzliche Schulungen, Änderungen in der Projektabwicklung udgl. können Maßnahmen zur Eliminierung dieser Schwachstellen sein.

Wirtschaftlichkeitsanalyse: Kontrolle über die wirtschaftliche Abwicklung des Projektes

\subsection{Phasen der Kostenplanung ${ }^{53}$}

Frühzeitige Kostenplanung und -verfolgung hat eine hohe Bedeutung, da Fehlentwicklungen schnell erkannt werden und korrigierende Maßnahmen eingeleitet werden können. Betrachtet werden alle kostenverursachenden Positionen des Projektstrukturplanes. Die Strukturen des Projektstrukturplanes und des Budgets/Kostenplanes sind ident.

Im Laufe des Projektes wird die Kostenplanung in denselben Phasen wie auch die Terminplanung abgewickelt. Von Abschnitt zu Abschnitt werden die Inhalte immer detaillierter. In der ÖNORM 1801-1 werden die einzelnen Phasen der Kosten denen der Projektabschnitte gegenübergestellt.

\section{Abbildung 17: Kostenplanung laut ÖNORM B1801-1:2009}

\begin{tabular}{|c|c|c|c|c|c|c|c|c|}
\hline & & & $\begin{array}{l}\text { Entwicklungs- } \\
\text { phase }\end{array}$ & $\begin{array}{l}\text { Vorbereitungs- } \\
\text { phase }\end{array}$ & $\begin{array}{l}\text { Vorentwurfs- } \\
\text { phase }\end{array}$ & $\begin{array}{l}\text { Entwurfs- } \\
\text { phase }\end{array}$ & $\begin{array}{l}\text { Ausführungs- } \\
\text { phase }\end{array}$ & $\begin{array}{l}\text { Abschluss- } \\
\text { phase }\end{array}$ \\
\hline \multirow{2}{*}{ 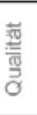 } & Qualităt & \multirow{4}{*}{ 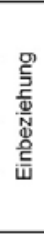 } & $\begin{array}{c}\text { Qualitäts- } \\
\text { ziel }\end{array}$ & $\begin{array}{l}\text { Qualitäts- } \\
\text { rahmen }\end{array}$ & $\begin{array}{l}\text { Vorentwurfs- } \\
\text { beschreibung }\end{array}$ & $\begin{array}{c}\text { Entwurfs- } \\
\text { beschreibung }\end{array}$ & $\begin{array}{l}\text { Ausführungs- } \\
\text { beschreibung }\end{array}$ & $\begin{array}{c}\text { Qualitäts- } \\
\text { dokumentation }\end{array}$ \\
\hline & Quantität & & $\begin{array}{l}\text { Quantitäts- } \\
\text { ziel }\end{array}$ & $\begin{array}{c}\text { Raum- } \\
\text { programm }\end{array}$ & $\begin{array}{c}\text { Vorentwurfs- } \\
\text { planung }\end{array}$ & $\begin{array}{l}\text { Entwurfs- } \\
\text { planung }\end{array}$ & $\begin{array}{l}\text { Ausführungs- } \\
\text { planung }\end{array}$ & $\begin{array}{c}\text { Planungs- } \\
\text { dokumentation }\end{array}$ \\
\hline \multirow{2}{*}{ 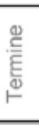 } & Termine & & $\begin{array}{c}\text { Termin- } \\
\text { ziel }\end{array}$ & $\begin{array}{l}\text { Termin- } \\
\text { rahmen }\end{array}$ & $\begin{array}{c}\text { Grob- } \\
\text { terminplan }\end{array}$ & $\begin{array}{l}\text { Genereller } \\
\text { Ablaufplan }\end{array}$ & $\begin{array}{c}\text { Ausführungs- } \\
\text { terminplan }\end{array}$ & $\begin{array}{c}\text { Termin- } \\
\text { feststellung }\end{array}$ \\
\hline & Ressourcen & & $\begin{array}{c}\text { Ressourcen- } \\
\text { ziel }\end{array}$ & $\begin{array}{c}\text { Ressourcen- } \\
\text { rahmen }\end{array}$ & \multicolumn{4}{|c|}{ Ressourcenplan } \\
\hline \multirow{2}{*}{ 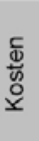 } & Kosten & \multirow{2}{*}{ 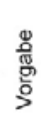 } & $\begin{array}{l}\text { Kosten- } \\
\text { ziel }\end{array}$ & $\begin{array}{l}\text { Kosten- } \\
\text { rahmen }\end{array}$ & $\begin{array}{l}\text { Kosten- } \\
\text { schătzung }\end{array}$ & $\begin{array}{l}\text { Kosten- } \\
\text { berechnung }\end{array}$ & $\begin{array}{l}\text { Kosten- } \\
\text { anschlag }\end{array}$ & $\begin{array}{l}\text { Kosten- } \\
\text { feststellung }\end{array}$ \\
\hline & Finanzierung & & $\begin{array}{c}\text { Finanzierungs- } \\
\text { ziel }\end{array}$ & $\begin{array}{l}\text { Finanzierungs- } \\
\text { rahmen }\end{array}$ & \multicolumn{4}{|c|}{ Finanzierungsplan } \\
\hline
\end{tabular}

Quelle: ÖNORM B1801-1 Ausgabe 2009-06-01 Österreichisches Normungsinstitut S. 8

In der ÖNORM 1801-1 wird definiert welche Kostenberechnung in welcher Projektphase durchzuführen ist, welche Vorgaben verwendet werden, welche Fakto-

\footnotetext{
${ }^{53}$ Vgl. ÖNORM B1801-1 Ausgabe 2009-06-01 Österreichisches Normungsinstitut S. 8
} 
ren einzubeziehen sind, und welche Gliederung als Grundlage verwendet werden kann. $^{54}$

\section{Kostenziel/Finanzierungsziel:}

Phase: Entwicklungsphase

Vorgabe: individuell

Einbeziehung: Qualitätsziel, Quantitätsziel, Terminziel, Ressourcenziel

Gliederung: Gliederung frei wählbar

\section{Kostenrahmen/Finanzierungsrahmen:}

Phase: Vorbereitungsphase

Vorgabe: Kostenziel, Finanzierungsziel

Einbeziehung: Qualitätsrahmen, Raumprogramm, Terminrahmen, Ressourcenrahmen

Gliederung: 1 . Ebene = Gliederung in Grobleistungsgliederung

\section{Kostenschätzung/Finanzierungsplan:}

Phase: Vorentwurfsphase

Vorgabe: Kostenrahmen, Finanzierungsrahmen

Einbeziehung: Vorentwurfsbeschreibung, Vorentwurfsplanung, Grobterminplan, Ressourcenplan

Gliederung: 2. Ebene = Gliederung in Leistungsgruppen

\section{Kostenberechnung/Finanzierungsplan:}

Phase: Entwurfsphase

Vorgabe: Kostenschätzung, Finanzierungsplan

${ }^{54}$ Vgl. ÖNORM B1801-1 Ausgabe 2009-06-01 Österreichisches Normungsinstitut S. 8/9 
Einbeziehung: Entwurfsbeschreibung, Entwurfsplanung, genereller Ablaufplan, Ressourcenplan

Gliederung: 3 . Ebene $=$ Gliederung in Unterleistungsgruppen

\section{Kostenanschlag/Finanzierungsplan:}

Phase: Ausführungsphase

Vorgabe: Kostenberechnung, Finanzierungsplan

Einbeziehung: Ausführungsbeschreibung, Ausführungsplanung, Ausführungsterminplan, Ressourcenplan

Gliederung: Baugliederung oder Leistungsgliederung in Leistungspositionen

\section{Kostenfeststellung/Finanzierungsplan:}

Phase: Abschlussphase

Vorgabe: Kostenanschlag, Finanzierungsplan

Einbeziehung: Qualitätsdokumentation, Planungsdokumentation, Terminfeststellung, Ressourcenplan

Gliederung: Baugliederung oder Leistungsgliederung in Leistungspositionen

\subsubsection{Kapazitätsplanung}

Bei der Kapazitätsplanung wird zuerst auf Allgemeines und dann auf einzelne Schritte des Ablaufes eingegangen.

\subsection{Grundsätze der Kapazitätsplanung}

Ein Teilbereich des Projektmanagements ist die Kapazitätsplanung. Um in der wirtschaftlichen Situation des Termin- und Kostendruckes bestehen zu können, ist eine Kapazitätsplanung unumgänglich. Die zur Verfügung stehenden Ressourcen der Arbeitskräfte, der Maschinen und der Materialien müssen optimal eingesetzt werden um eine möglichst hohe Effizienz und Effektivität zu erreichen. Das Problem besteht darin, dass eine Vielzahl an Projekten mit verschiedenen Zwischenund Endterminen bestehen, bei denen zu unterschiedlichen Zeitpunkten unter- 
schiedliche Arbeits-, Material- und Maschineneinsätze erforderlich sind. Unten stehend wird ein Kapazitätsauslastungsdiagramm beispielhaft dargestellt. Es wird die Auslastung von z.B. Personal pro Kalenderwoche dargestellt. ${ }^{55}$

\section{Abbildung 18: Kapazitätsauslastungsdiagramm}

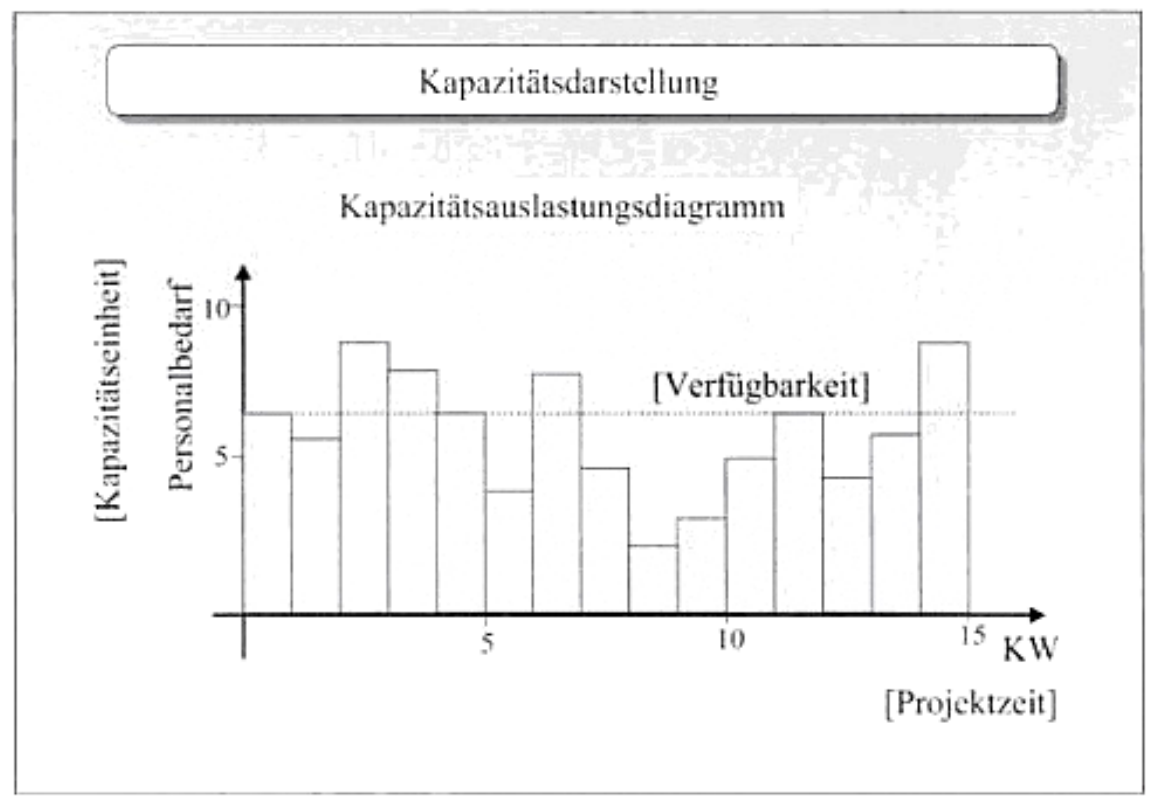

Quelle: R. Hahn: Projektmanagement für Ingenieure Weinheim 2002 S. 91

Ziel der Kapazitätsplanung ist es, Engpässe der knappen Ressourcen zu vermeiden bzw. frühzeitig gegenzusteuern. Durch die Kapazitätsplanung ist es außerdem möglich, eine möglichst gleichmäßige, ausgewogene Auslastung der Ressourcen zu erzielen. ${ }^{56}$

Mit der Kapazitätsplanung wird daher eine

zeitliche

qualitative

quantitative

lokale und

\footnotetext{
${ }^{55}$ Vgl. A.Preißner: Projekte budgetieren und planen München/Wien 2003 S. 93

${ }^{56}$ Vgl. Litke: Projektmanagement München/Wien 2004 S. 107
} 
organisatorische

Planung der Kapazitäten durchgeführt. ${ }^{57}$

\subsection{Schritte der Kapazitätsplanung}

Für eine Kapazitätsplanung eines Projektes werden zuerst alle erforderlichen Arbeiten definiert und aufgelistet. Die Zeitdauer der einzelnen Arbeiten wird errechnet, oder es werden die aus der Erfahrung bekannten Ausführungsdauern zugewiesen. Weiters muss geprüft werden, ob alle erforderlichen Arbeitspakete selbst ausgeführt werden können. Anschließend werden die zur Verfügung stehenden Kapazitäten (z.B. Maschinen, Personal udgl.) ebenfalls aufgelistet. Die Ablaufpläne der Arbeiten werden eingearbeitet und entsprechend ihrer Priorität gereiht. Dann werden die Arbeiten den Kapazitäten zugeordnet. Sämtliche Kapazitätsanforderungen werden zusammengezählt, um den Gesamtbedarf mit den verfügbaren Kapazitäten abzustimmen. Die einzelnen Arbeiten werden in ein Belastungsdiagramm eingetragen. ${ }^{58}$

Im Belastungsdiagramm können nun die Belastungsspitzen abgelesen werden. In der Praxis wird zu diesem Zeitpunkt meist festgestellt, dass deutliche Belastungsspitzen und Belastungslücken im Ablauf vorhanden sind.

Die Kapazitätsspitzen müssen geglättet werden um eine gleichmäßigere Kapazitätsauslastung zu erhalten. Litke ${ }^{59}$ listet in seinem Buch folgende Maßnahmen zur Glättung der Belastung auf:

- Verschiebung und/oder zeitliche Dehnung von nicht kritischen Aktivitäten innerhalb der vorhandenen Pufferzeit

- Einstellung von neuem Personal

- Personalverschiebung innerhalb des Bereiches oder der Unternehmung

\footnotetext{
${ }^{57}$ Vgl. R. Hahn: Projektmanagement für Ingenieure Weinheim 2002 S. 91

${ }^{58}$ Vgl. Litke: Projektmanagement München/Wien 2004 S. 108

${ }^{59}$ Vgl. Litke: Projektmanagement München/Wien 2004 S. 108
} 
- Verschiebung und/oder zeitliche Dehnung von kritischen Aktivitäten unter Inkaufnahme einer Verschiebung des Endtermines

- Auftragsvergabe an Fremdfirma

Ergänzend zu den möglichen Maßnahmen die Litke in seinem Buch auflistet, gehören noch die innerbetrieblichen Leistungssteigerungsmaßnahmen, wie zum Beispiel Überstunden der Mitarbeiter in der Zeit der Überbelastung und Überstundenabbau im Zeitraum mit geringerer Arbeitsauslastung.

Nachstehend wird ein Kapazitätsauslastungsdiagramm dargestellt in dem in der zweiten bis vierten Periode und in der neunten und zehnten Periode eine überdurchschnittlich hohe Kapazitätsauslastung vorherrscht. Ziel der Kapazitätsplanung und Optimierung ist eine möglichst gleichmäßige Auslastung zu schaffen und verschiebbare Leistungen des Personales in die 5., 6., und 8. Woche sowie in die 11., 12., und 14. Woche zu verschieben, in der eine niedrige Auslastung vorherrscht. Weiters könnte versucht werden Leistungen die vorzeitig ausgeführt werden können von der 2., 3., und 4. Woche in die 1. Woche vorzuziehen. Hierbei wird vor allem an vorbereitende Arbeiten gedacht, die unabhängig vom Auftrag vorzeitig ausgeführt werden können. Dazu zählen zum Beispiel Arbeiten, die in der innerbetrieblichen Werkstätte zusammengebaut und auf der Baustelle nur mehr montiert/eingebaut werden. ${ }^{60}$

${ }^{60}$ Vgl. R. Hahn: Projektmanagement für Ingenieure Weinheim 2002 S. 91 


\section{Abbildung 19: Kapazitätsverlauf ohne Anpassung}

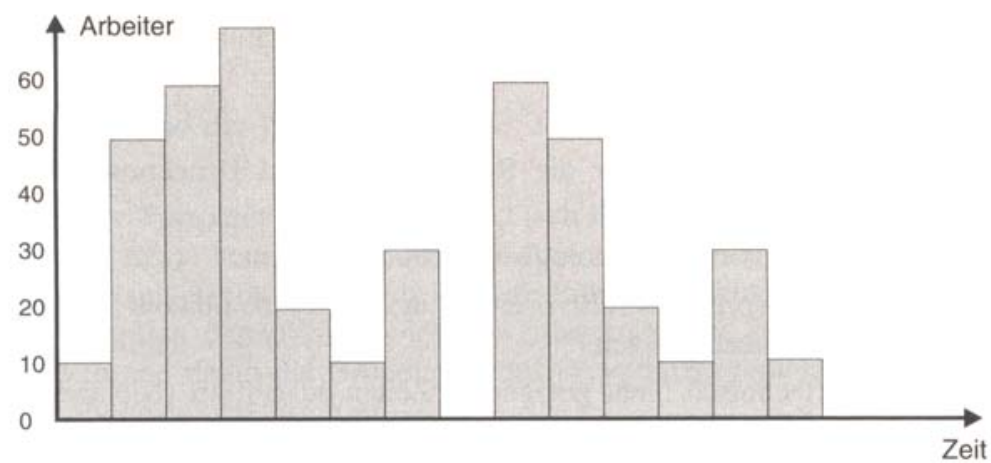

Quelle: R. Hahn: Projektmanagement für Ingenieure Weinheim 2002 S. 91

\section{Abbildung 20: Kapazitätsverlauf unter Ausnützung der Pufferzeiten}

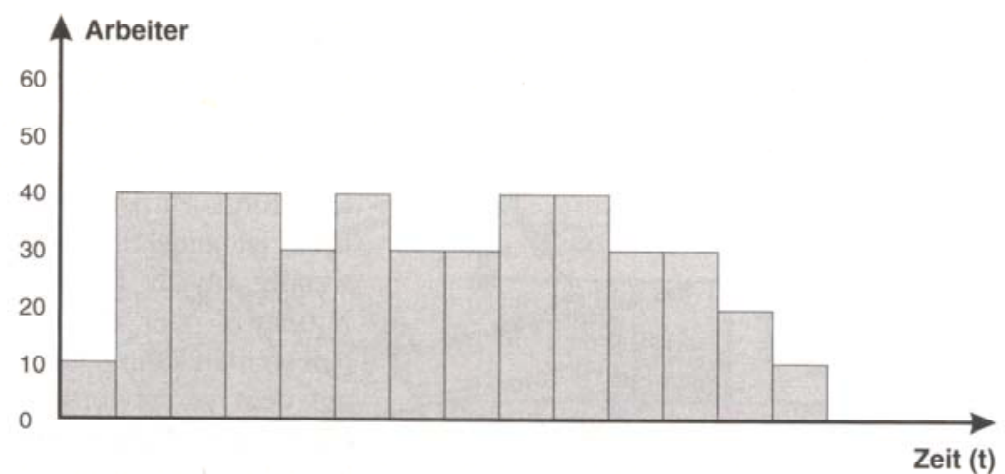

Quelle: R. Hahn: Projektmanagement für Ingenieure Weinheim 2002 S. 91

\subsubsection{Logistik}

Der Fachbereich "Logistik" ist mittlerweile auch in der Baubranche vorzufinden. Um die Leerzeiten von z.B. Maschinen und Personal zu reduzieren und damit die nicht wertschöpferischen Tätigkeiten zu verringern. Dafür ist es erforderlich die Grundelemente der Logistik wie folgt zu berücksichtigen: ${ }^{61}$

die richtige Menge der erforderlichen Maschinen, Grundstoffe udgl.

die richtigen Typen, Fabrikate, Maschinen, oder Objekte

${ }^{61}$ D. Arnold, H. Isermann, A. Kuhn, H. Tempelmeier, K. Furmans: Handbuch Logistik Berlin, Heidelberg 2008 S. 371 
$>$ am richtigen Ort

zum richtigen Zeitpunkt

in der richtigen Qualität

zu den richtigen Kosten

Damit die oben angeführten Punkte von allen Beteiligten ohne weitere Hindernisse eingehalten werden können, muss seitens des Bauherren bzw. der Projektsteuerung ein logistisches Konzept für die Themen „Infrastruktur“, „mögliche Lagerflächen" und „Transportwege" bereits in der Projektvorbereitung erstellt werden. Diese Rahmenbedingungen können einen wesentlichen Einfluss auf die Kosten, die Termine und die Kapazitäten des Projektes haben. Ist beispielsweise ein Projekt nicht von einer allgemeinen Straße erreichbar, werden die Kosten sämtlicher Produkte eine Erschwerniszulage enthalten.

\subsubsection{Projektentwicklung}

Die Projektentwicklung ist meist, wie auch die Projektleitung, ein Aufgabengebiet das vom Projektmanagement ausgeführt bzw. organisiert/gesteuert wird. Das Themengebiet „Projektentwicklung“ wird auch häufig als Projektvorbereitung bezeichnet. Die Aufgabe des Projektentwicklers ist es den Bauherren zu unterstützen. Weiters sollte dieser Themen aufbereiten, sodass auch ein Bauherr ohne Erfahrungen im Bauwesen Entscheidungen treffen kann. Die Projektentwicklung wird vorrangig bei größeren Bauprojekten eingesetzt. Die Leistungen des Projektentwicklers reichen bis zur Mithilfe bei der Vermarktung.

International wird für die Projektentwicklung der Begriff „Development" verwendet. Development bedeutet sowohl Entwicklung von Bauland im Sinne der Erschließung, als auch Entwicklung von Gebäuden im Sinne der Bestands- bzw. Nutzungsverbesserung. ${ }^{62}$

${ }^{62}$ Vgl. Kalusche: Projektmanagement für Bauherren und Planer München/Wien 2005 S. 210 


\subsubsection{Definition der Projektentwicklung}

In der Bau- und Immobilienwirtschaft bestehen sehr unterschiedliche Auffassungen zum Überbegriff „Projektentwicklung“. Die Abgrenzung zu weiterführenden Tätigkeiten von Projektteilleistungen ist nicht eindeutig abgegrenzt, was die Definition weiter erschwert. In der Praxis hat sich daher keine einheitliche Definition durchgesetzt. ${ }^{63}$

Die im deutschsprachigen Raum verbreitete Definition stammt von Diederichs ${ }^{64}$. Er definiert Projektentwicklung folgendermaßen:

„Durch Projektentwicklung sind die Faktoren Standort, Projektidee und Kapital so miteinander zu kombinieren, dass einzelwirtschaftlich wettbewerbsfähige, arbeitsplatzschaffende und sichernde sowie gesamtwirtschaftlich sozial- und umweltverträgliche Immobilienprojekte geschaffen und dauerhaft rentabel genutzt werden können."

Von Diederichs wird der wirtschaftliche Erfolg als Hauptgrund für Baumaßnahmen von nicht staatlichen Bauherren definiert. Bei der Errichtung von Immobilien muss darauf geachtet werden, dass diese schlussendlich gewinnbringend (rentabel) eingesetzt werden können. Diese Vorraussetzung ist sowohl bei staatlichen als auch bei gewerblichen Bauherren/Investoren gültig.

Weiterführend zur Definition von Diederichs muss eine entscheidende Größe ergänzt werden und zwar die Wünsche bzw. Erfordernisse der Nutzer. Harlfinger stellt in seinem Buch die vier Grundpfeiler der Ausgangssituation der Projektentwicklung in folgender Grafik dar:

\footnotetext{
${ }^{63}$ Vgl. K. Schulte: Immobilien Ökonomie München ${ }^{4} 2008$ S. 223

${ }^{64}$ CJ Diederichs: Grundlagen der Projektentwicklung/Teil 1, in: Bauwirtschaft,1994, Heft 11, S. 43-49
} 


\section{Abbildung 21: Vier Grundpfeiler der Projektentwicklung}

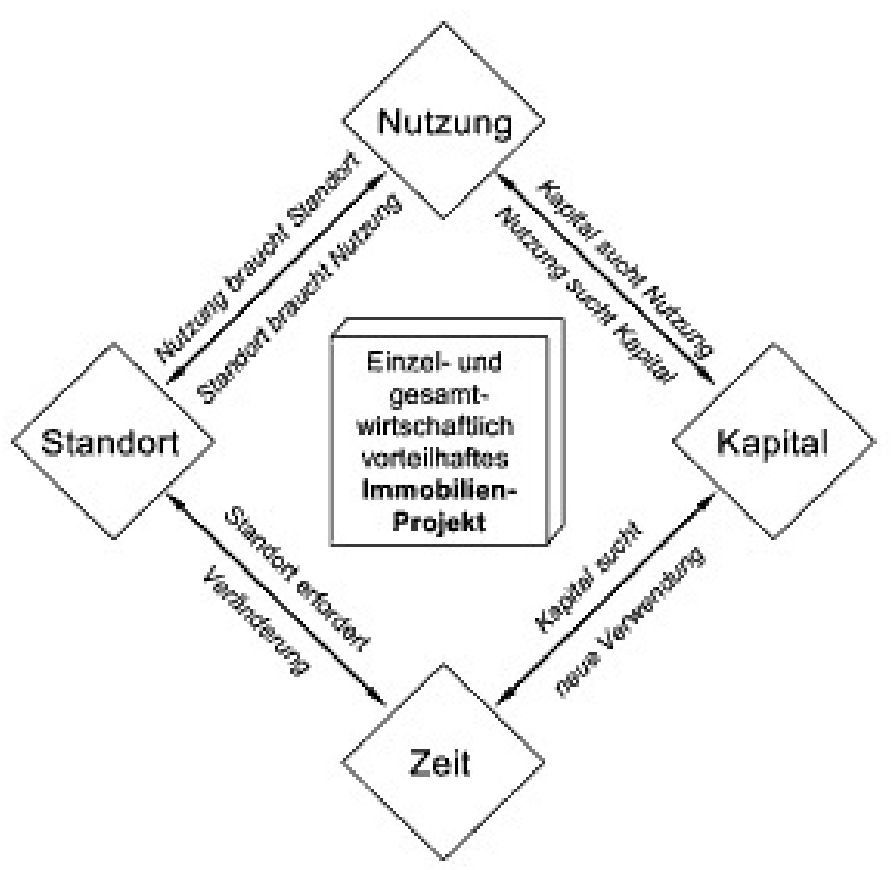

Quelle: T.Harlfinger: Referenzvorgehensmodell zum Redevelopment von Bürobestandsimmobilien, Norderstedt 2010 S. 16

Der wirtschaftliche Nutzen eines Projektes, und damit seine spätere Marktfähigkeit hängen sehr stark vom Nutzerwunsch bzw. den Nutzeranforderungen ab. Wird beispielsweise vom Nutzer eine Fabrik für Produktionszwecke benötigt, sollte diese in der Nähe einer guten Verkehrsanbindung errichtet werden und nicht in einem verlassenen unwegsamen Gelände.

\subsubsection{Beteiligte und Objekte}

Die Projektentwicklung umfasst grundsätzliche alle Arten von Immobilien. Mögliche Projektformen können dabei sein:

- Objekte die vom Errichter in weiterer Folge auch genutzt oder weitervermietet werden, wie z.B. Vermietung von Wohnbaugesellschaften, Kapitalanlagegesellschaften, Versicherungen

- Objekte die schnellstmöglich veräußert werden sollen, wie z.B. Eigentumswohnungen, Reihenhäuser, Gewerbeimmobilien

Bei der Projektentwicklung sind in der Regel eine Vielzahl an Personen beteiligt. Der Aufgabenbereich des Projektentwicklers umfasst vor allem die Koordinierung 
der erforderlichen Aufgaben. Sämtliche Aufgaben die vom Projektentwickler aus Zeitmangel oder aus mangelnder Fachkenntnis nicht erledigt werden können, werden an Dritte weiter gegeben. Diese Aufgaben sind vom Projektentwickler so zu steuern, dass eine effiziente Zusammenarbeit des „Projektentwicklerteams“ gewährleistet ist.

Nachstehend wird eine Auflistung der möglichen Beteiligten eines Projektentwicklungsprozesses dargestellt.

\subsection{Grundstückseigentümer ${ }^{65}$}

Es gibt drei verschiedene Arten von Grundstückseigentümer:

Als erste Gruppe können die öffentlichen Grundstückseigentümer genannt werden. Diese Gruppe umfasst den gesamten öffentlichen Sektor wie Bund, Länder, Städte, Gemeinden. Zu dieser Gruppe werden auch größere mit Öffentlichkeitscharakter behaftete Glaubensgemeinschaften wie z.B. die Kirche und ähnliche Einrichtungen gezählt.

Die zweite Gruppe der möglichen Grundstückseigentümer umfasst die Unternehmer für die Grund und Boden ein Produktionsfaktor darstellt.

Die dritte Gruppe bilden die privaten Grundstückseigentümer. Diese können ein Grundstück sowohl zur Befriedigung der persönlichen Bedürfnisse als auch als Kapitalanlage nutzen.

Jeder dieser drei oben genannten Grundstückseigentümer kann der Auslöser einer Projektentwicklung sein. Die Haltung des Eigentümerskann entweder unterstützend oder sogar aktiv mitarbeitend sein, in dem er sein Grundstück anbietet, bzw. ein Projekt auf diesem errichten möchte. Weiters kann die Haltung der Eigentümer zu einem neuen Projekt passiv bzw. ablehnend sein, sodass Entscheidungen oder Zustimmungen nur sehr schwierig erreicht werden können.

\footnotetext{
${ }^{65} \mathrm{Vgl.}$ W. Schulte: Projektentwicklung Immobilienökonomie Betriebswirtschaftliche Grundlagen, München, 2008 S. 262
} 


\subsubsection{Nutzer NG $^{66}$}

Der Nutzer nimmt grundsätzlich die Nachfrageposition in einem Projektentwicklungsprozess ein. Wie die Grundstückseigentümer kann auch der Nutzer eine öffentliche Person, ein Unternehmer oder eine Privatperson sein.

Wird die Immobilie vom späteren Nutzer selbst errichtet, so ist dieser meist in den Projektentwicklungsprozess von der Geburtsstunde an eingebunden. Dieser Sachverhalt ist günstig, da der Bauherr seine Wünsche und Vorgaben von Beginn an in das Projekt einfließen lassen kann. Der Nutzer (Bauherr) hat die Entscheidung zu treffen, ob er das Projekt selbst erstellt, oder ob er sich externe Hilfe besorgen muss (make or buy - Entscheidung). Es können auch Teilleistungen fremd vergeben werden. Ob und in welchem Umfang Leistungen von Dritten ausgeführt werden sollen, muss vom Bauherren unter Berücksichtigung seiner Berater und seiner eigenen Kompetenzen selbst entschieden werden.

Wird das Bauvorhaben nicht vom Nutzer selbst als Bauherr errichtet, sind die endgültigen Anforderungen der Nutzung nicht bekannt. Vom Errichter der Anlage müssen bei der Projektentwicklung Entscheidungen über die möglichen Nutzungen des Objektes getroffen werden. Es muss beispielsweise festgelegt werden ob eine Wohnimmobilie oder eine Immobilie für den Wirtschaftsbereich (Büro, Fabrik, Hotel udgl.) errichtet werden soll. Bei dieser Entscheidung ist die Marktanalyse und die Standortanalyse des Objektes und des dazu gehörenden Umfeldes sowie die örtlichen Anforderungen entscheidend.

\subsection{Financiers ${ }^{67}$}

In der Projektentwicklungsphase muss auch die Finanzierung der Immobilie abgeklärt werden. Die meisten Bauherren haben nicht das entsprechende Eigenkapital um ein gesamtes Bauvorhaben während der Bauphase, bzw. bei Eigennutzung auch dauerhaft, aus eigener Tasche zu finanzieren. Diejenige Institution die dem

\footnotetext{
${ }^{66}$ Vgl. W. Schulte: Projektentwicklung Immobilienökonomie Betriebswirtschaftliche Grundlagen, München, 2008 S. 262

${ }^{67}$ Vgl. M. Dziomba: Städtebauliche Großprojekte der urbanen Renaissance, Münster 2006 S. 72
} 
Bauherren Kapital zur Verfügung stellt, wird als Financier bezeichnet. Es gibt eine kurzfristige und eine langfristige Finanzierung:

Kurzfristige Financiers:

Die kurzfristige Finanzierung wird häufig von Bauträgern und Errichtern von Immobilienobjekten in Anspruch genommen, um die Bautätigkeiten bis zur Fertigstellung des Objektes finanzieren zu können. Das bedeutet, dass von den jeweiligen Geldgebern wie Geschäftsbanken, Hypothekenbanken, udgl. die Finanzierung der Bauleistungen entsprechend dem Baufortschritt mit vereinbarten Zwischenschritten bis zur Fertigstellung erfolgt. Je nach Vereinbarung mit den Geldgebern wird die Finanzierung bis zum Vermarktungszeitpunkt erweitert. Die jeweiligen Konditionen hängen vom Risiko und von der jeweiligen Qualifikation und Bonität des Bauherren und seiner Partner ab. Da die Tranchen der Gelder entsprechend dem Baufortschritt ausbezahlt werden, beschränkt sich das Risiko der Geldgeber dabei auf die nicht termin- oder zeitgerecht fertig gestellten Bauwerke.

\section{Langfristige Financiers:}

Die langfristige Finanzierung wird in Anspruch genommen wenn die Immobilie nicht vor Fertigstellung (bzw. dem vorher definierten Vermarktungszeitpunkt) verkauft werden kann, oder die Immobilie in den eigenen Bedarf übernommen wird. Das Risiko des jeweiligen Kreditinstituts ist bei einem langfristigen Kreditmodell wesentlich höher als bei einem kurzfristigen Modell. Das Kreditinstitut wird die Zusage zum Kreditgeschäft maßgeblich von der Konzeption des Projektes und dessen Fähigkeit zur Erwirtschaftung des Kapitaldienstes, sowie von den Marktanalysen und den Rentabilitätsuntersuchungen abhängig machen. Weiters wird bei der Kreditentscheidung natürlich die Bonität des Kapitalnehmers berücksichtigt.

\subsection{Investoren ${ }^{68}$}

Ergänzend zu den am freien Wirtschaftsmarkt möglichen Investitionsalternativen besteht auch die Möglichkeit in Immobilien zu investieren. Als Investor wird eine Person oder eine Gesellschaft bezeichnet, die mit einer Vermögensanlage in Form

\footnotetext{
${ }^{68}$ Vgl. M. Dziomba: Städtebauliche Großprojekte der urbanen Renaissance, Berlin 2009 S. 72
} 
einer Immobilie einen Gewinn erzielen möchte. Der Investor tritt in diesem Fall als Nachfrager in unserem Projektsystem auf.

Der Käufer einer Immobilie wird als Endinvestor bezeichnet. Der Unterschied zwischen einem Eigentümer und einem Endinvestor ist lediglich, dass der Eigentümer der Immobilie bereits vor Projektstart Besitzer dieser war.

\subsection{Bauunternehmen}

Das Auftragsverhältnis zu den Bauunternehmen kann mit Einzelverträgen erfolgen, wobei bei dieser Ausführungsform die gesamte Koordinierung, sowie das Detailwissen über die einzelnen Gewerke beim Auftraggeber liegen.

Die weiteren Varianten sind die Beauftragung eines Generalunternehmers oder eines Generalübernehmers für die Bauleistungen. Der Vorteil bei diesen Vertragsformen liegt darin, dass das Know-How der Detailgewerke, Schnittstellenprobleme, Koordinationsleistungen und ähnliche Gewerke übergreifende Leistungen vom Hauptauftragnehmer (Generalunternehmer/Generalübernehmer) organisiert und einer Lösung zugeführt wird. Weitere Vorteile liegen darin, dass die Gesamtbaukosten sowie der Fertigstellungstermin bei Auftragvergabe bereits fixiert und in den Verträgen verankert werden können.

\subsubsection{Formen der Projektentwicklung}

Bei der Projektentwicklung unterscheidet man drei unterschiedliche Formen:

1. Projektentwicklung für den Eigenbestand

2. Projektentwicklung für Investoren

3. Projektentwicklung als Consultingleistung

Die Projektentwicklung für den Eigenbestand wird betriebsintern mit den firmeneigenen Mitarbeitern oder mit einer externen Projektentwicklungsfirma ausgeführt.

Bei der Projektentwicklung für Investoren werden meist von einem Unternehmen die Entwicklungsleistungen übernommen und von einem anderen „Investitionsunternehmen“ die Sicherung des Kapitals. Häufig werden für solche Kooperationen 
„Joint Ventures“ ${ }^{69}$ zwischen den Entwicklern und den Kapitalgebern geschlossen. ${ }^{70}$

Unter Projektentwicklung als Consultingleistung wird die beratende Tätigkeit einer externen Person oder einem externen Unternehmen bezeichnet. Diese Consultingleistung kann sowohl bei dem Punkt 1 „Projektentwicklung für den eigenen Bestand“ als auch bei dem Punkt 2 „Projektentwicklung für Investoren“ zur Anwendung gebracht werden.

Bei der Projektentwicklung unterscheidet man zwei unterschiedliche Formen ${ }^{71}$ :

Projektentwicklung im weiteren Sinn umfasst den gesamten Werdegang eines Objektes beginnend bei der Projektidee, über die Projektvermarktung, der Projekterrichtung, der Projektnutzung, bis zum endgültigen Abriss einer Immobilie.

In dieser Arbeit wird die Projektentwicklung im engeren Sinn behandelt. Diese umfasst die Phase ausgehend von der Projektidee oder des Projektanstoßes bis zu Entscheidung über die Fortführung des Projektes oder der Verwerfung der Projektidee. Als Ergebnis wird eine umfassende schriftliche Aufgabenstellung formuliert, die bei Weiterführung des Projektes als Basis für die Beauftragung des Planungsteams dient.

\footnotetext{
${ }^{69}$ Duden (http://www.duden.de/rechtschreibung/Joint_Venture) 14.03.2012: Zusammenschluss von Unternehmen zum Zweck der gemeinsamen Durchführung von Projekten

${ }^{70}$ Vgl. C. Diederichs: Immobilienmanagement Im Lebenszyklus, Berlin, Heidelberg 2006 S. 8

${ }^{71}$ Vgl. C. Diederichs: Immobilienmanagement Im Lebenszyklus, Berlin, Heidelberg 2006 S. 6
} 


\section{Abbildung 22: Abgrenzung der Projektentwicklung}

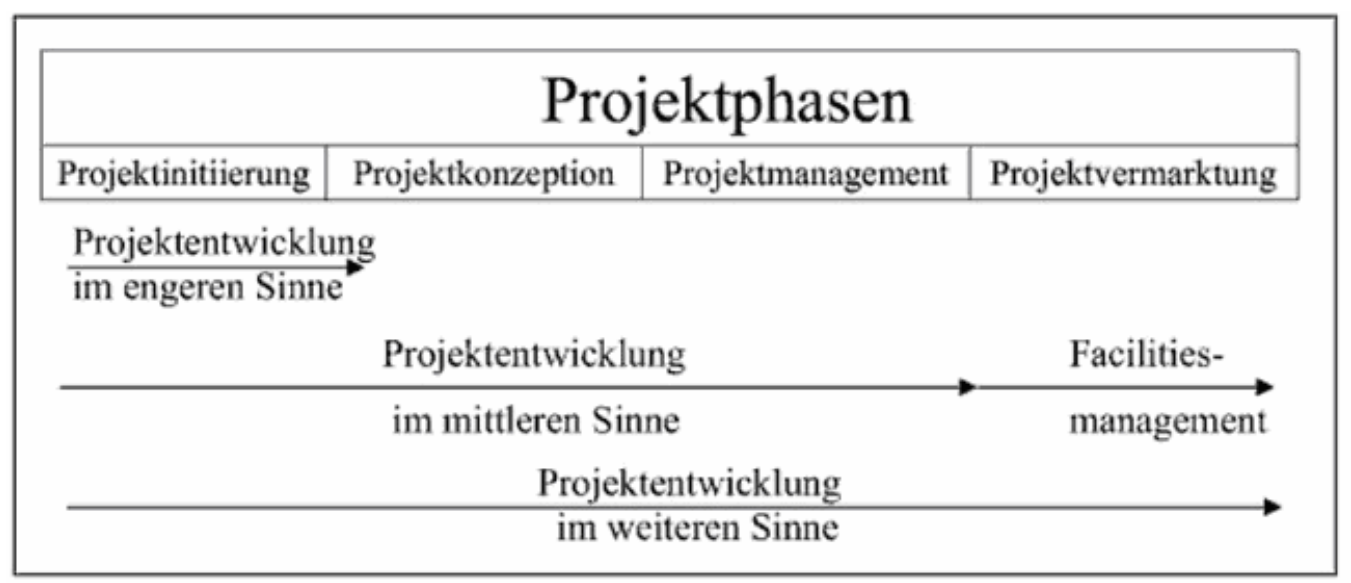

Quelle: S. Ullmann Projektentwicklung nach dem 4-Phasen-Modell, Hamburg ${ }^{1} 2007$ S. 10

Ein Anreiz zur Durchführung einer umfangreichen Projektentwicklung kann für Unternehmen auch der strategische Ansatz zum Aufbau von Konkurrenzvorteilen und Wettbewerbsvorteilen sein, sodass die Immobilie später einen höheren Nutzen für den Unternehmer hat. Dieser Vorteil kann gegenüber der Konkurrenz gezielt eingesetzt werden.

Dem Startschuss eines Projektes können zwei Ursachen zu Grunde liegen. Erstens kann ein Bedarf oder eine Projektidee den Auslöser für ein Projekt darstellen. Eine weitere Möglichkeit liegt darin, dass jemand von einem Grundstück einen höheren Nutzen erzielen möchte und daher ein Gebäude errichtet. ${ }^{72}$

\subsubsection{Faktoren der Projektentwicklung}

Entsprechend der Definition von Diederichs (siehe Pkt. 2.2.2.1 Definition Projektentwicklung) sind die Faktoren „Standort“, „Projektidee“ und „Kapital“ optimal miteinander zu verknüpfen.

Nicht-staatliche Bauherren verfolgen meist das ökonomische Prinzip ${ }^{73}$ (Minimalprinzip/Maximalprinzip). Das bedeutet, dass ein Immobilienprojekt dem Bauherren

\footnotetext{
72 T. Held: Immobilien-Projektentwicklung Wettbewerbsvorteile durch strategisches Projektmanagement, Berlin, Heidelberg ${ }^{1} 2010$ S. 89

${ }^{73}$ Minimalprinzip (auch Sparsamkeitsprinzip): Mit möglichst wenigen Mitteln (Input) ein bestimmtes Ziel (Output) erreichen.
} 
einen positiven Nutzen bringen muss. Bei Immobileninvestoren und Bauträgern ist dieser Nutzen meist monetär. Das Bauvorhaben muss daher einzelwirtschaftlich effizient sein, um wettbewerbsfähig in der Immobilienbranche bestehen zu können.

Im Gegensatz dazu sind staatliche Bauherren (gemeinnützige Bauherren) zusätzlich dem Allgemeinwohl verpflichtet. Auf die genaueren Hintergründe, Richtlinien und Ziele der staatlichen Bauträger wird in dieser Arbeit nicht weiter eingegangen.

Die drei wichtigen Projektentwicklungsfaktoren, entsprechend der gängigen deutschsprachigen Definition, werden in den nachstehenden Punkten erörtert:

\subsection{Projektidee ${ }^{74}$}

Bei der Projektentwicklung muss zur passenden Projektidee auch das passende Grundstück sowie die entsprechenden Geldgeber gefunden werden. Dafür wird eine Standortanalyse und eine Nutzwertanalyse durchgeführt, um die Auswahl des am besten geeigneten Grundstücks zu treffen. Die Standortfaktoren, die in die Berechnung einfließen, können entsprechend der Nutzung unterschiedlich gewichtet und entsprechend dem Zielerfüllungsgrad bestimmt werden. Durch die Nutzwertanalyse lässt sich der optimale Nutzungs-Standort bestimmen.

Im Zuge der Projektentwicklung muss diese „Projektidee“ weiter verfeinert werden, sodass eine konkrete Vorstellung dieses Objektes formuliert werden kann. Diese Beschreibung muss je nach Objekt unterschiedliche Kenngrößen enthalten. Bei einem Shoppingcenter stellen z.B. die Anzahl der Arbeitsplätze sowie die Besucherzahlen pro Monat und die Größe der Grundfläche solche Kennzahlen dar. Weiters müssen in dieser Beschreibung erforderliche Kenndaten und Grundlagen

\footnotetext{
Maximalprinzip (auch Ergiebigkeitsprinzip): Mit gegebenen Mitteln (Input) möglichst großen Nutzen (Output) erzielen.

http://de.wikipedia.org/wiki/\%C3\%96konomisches_Prinzip 26.02.2012

${ }^{74}$ Vgl. W. Schulte: Projektentwicklung Immobilienökonomie Betriebswirtschaftliche Grundlagen, München, 2008 S. 246
} 
der Planung für die Erstellung eines Vorentwurfs durch ein Planungsteam enthalten sein. Kalusche ${ }^{75}$ führt in seinem Buch folgende Bereiche an:

eine Bedarfsplanung mit Zielvorstellungen für die Nutzung

> ein Raumprogramm, in Form der Zusammenstellung vorgesehener Räume, nach Größe und Zweckbestimmung

$>$ ein Funktionsprogramm zur Festlegung der im Raumprogramm festgelegten Räume oder Flächen.

Die Projektentwicklung kann aus der Vorgabe der Projektidee die erforderlichen Größen der Gesamtfläche und der Gesamtkosten ermitteln. Entsprechend der festgelegten Grundfläche und der Art und Nutzung des Gebäudes kann die erforderliche Gesamtfläche ermittelt werden. Die entscheidende Größe der Gesamtkosten lässt sich über die Bruttogesamtfläche anhand der Vorgabe ermitteln.

\subsection{Standort}

Es werden für ein bestehendes Grundstück eine Projektidee sowie ein Kapitalgeber gesucht. Diese Form ist sehr häufig nach einer Umwidmung von Grünflächen in Gewerbegebiete oder Bauflächen zu finden. Der Grundstückbesitzer oder der zukünftige Käufer der Grundstücksfläche errichtet zu Selbstzwecken oder zum Verkauf ein Objekt. ${ }^{76}$

Das Objekt und das Grundstück sollen dauerhaft rentabel genutzt werden. Um diese Nutzung bereits in der Projektentwicklung kalkulieren zu können, ist (wie bereits im Kapitel „Projektidee“ beschrieben) eine umfangreiche Markt und Standortanalyse durchzuführen. ${ }^{77}$

\footnotetext{
${ }^{75}$ Vgl. Kalusche: Projektmanagement für Bauherren und Planer München/Wien 2005 S. 222

${ }^{76}$ Vgl. S. Ullmann Projektentwicklung nach dem 4-Phasen-Modell, Hamburg ${ }^{1} 2007$ S. 6

${ }^{77}$ Vgl. P. Greiner, P. E. Mayer, K. Stark :Baubetriebslehre- Projektmanagement Erfolgreiche Steuerung von Bauprojekten, Wiesbaden ${ }^{4} 2009$ S. 199
} 


\subsection{Kapital}

Oft wird die Projektentwicklung ausgehend von einem Kapitalgeber gestartet. Da$\mathrm{zu}$ ist es hilfreich die grundsätzliche Sichtweise eines Investors zu verstehen. Denn ein Investor sieht das Bauobjekt nicht als persönliche Verwirklichung, sondern als Investition, aus der ein zusätzlicher Nutzen gezogen werden kann. Die zur Verfügung stehenden Mittel werden eingesetzt. Es wird dafür eine Immobilie (Grund und Boden) erworben, auf der ein Objekt errichtet wird. Das Kapital ist somit gebunden und steht für keine weitere Kapitalanlage zu Verfügung. Die Nachteile bei der Investition in Immobilien, im Vergleich zu anderen Investitionsformen, liegen in der meist sehr hohen Laufzeit, in der großen Kapitalmenge, in den höheren Risiken (im Vergleich zu Sparbriefen) und in der schweren und trägen Revidierbarkeit der Investition. Aus diesen Gründen wird von Investoren die Wirtschaftlichkeit einer Investition sehr genau unter die Lupe genommen.

Bei der Projektentwicklungsrechnung muss die Wirtschaftlichkeit einer Investition überprüft werden. Dafür stehen einige Verfahren zur Verfügung, wie z.B. die Amortisationsrechnung oder die Annuitätenmethode. Die Rechnung baut großteils auf Erfahrungswerten auf. Diese sind für eine Vorabkalkulation wichtig, damit eine vorab Wirtschaftlichkeitsberechnung durchgeführt werden kann. Entsprechend dieser Analyseergebnisse können einzelne Modalitäten angepasst und verbessert werden, sodass die Wirtschaftlichkeit steigt. Wird bei der Rechnung und der Verbesserung der Projektidee bzw. des Standorts kein positiver wirtschaftlicher Ertrag errechnet, ist dringend vom Vorhaben Abstand zu nehmen. Die bis zu diesem Zeitpunkt angefallenen Kosten müssen von einem anderen weiteren Projekt mitgetragen werden. ${ }^{78}$

Für die Berechnung der Wirtschaftlichkeit wird meist die einfache Projektentwicklungsrechnung angewendet. Mit diesem statischen Verfahren ist es möglich, die Rendite eines Immobilienprojektes zu ermitteln. Bei der Berechnung sind zwei Methoden zur Projektentwicklungskalkulation möglich ${ }^{79}$ :

\footnotetext{
${ }^{78}$ Vgl. W. Schulte: Projektentwicklung Immobilienökonomie Betriebswirtschaftliche Grundlagen, München, 2008 S. 246

${ }^{79}$ Hierzu wurden diese beiden Quellen verwendet:
} 


\section{Frontdoor-Approach}

\section{Backdoor-Approach}

Beim Frontdoor-Approach wird die erforderliche Miete pro $\mathrm{m}^{2}$ unter Berücksichtigung der gewünschten Rendite berechnet. Beim Backdoor-Approach hingegen werden, ausgehend von der maximal erzielbaren Bruttomiete pro $\mathrm{m}^{2}$, die maximalen Kosten des Grundstückes ermittelt.

Eine entscheidende Einflussgröße auf das Projekt und damit auf die Wettbewerbsfähigkeit wird in der ersten Projektphase im Zuge der Projektentwicklung durchgeführt. Je später die kontrollierte Beeinflussung und Steuerung der Projektstartphase beginnt, umso mehr nimmt die mögliche Beeinflussung ab. ${ }^{80}$

Vgl. S. Ullmann Projektentwicklung nach dem 4-Phasen-Modell, Hamburg ${ }^{1} 2007$ S. 23

Vgl. W. Schulte: Projektentwicklung Immobilienökonomie Betriebswirtschaftliche Grundlagen, München, 2008 S. 281

${ }^{80}$ Vgl. T. Held: Immobilien-Projektentwicklung Wettbewerbsvorteile durch strategisches Projektmanagement, Berlin, Heidelberg ${ }^{1} 2010$ S. 88 


\section{Abbildung 23: Kostenbeeinflussbarkeit in der Projektphase}

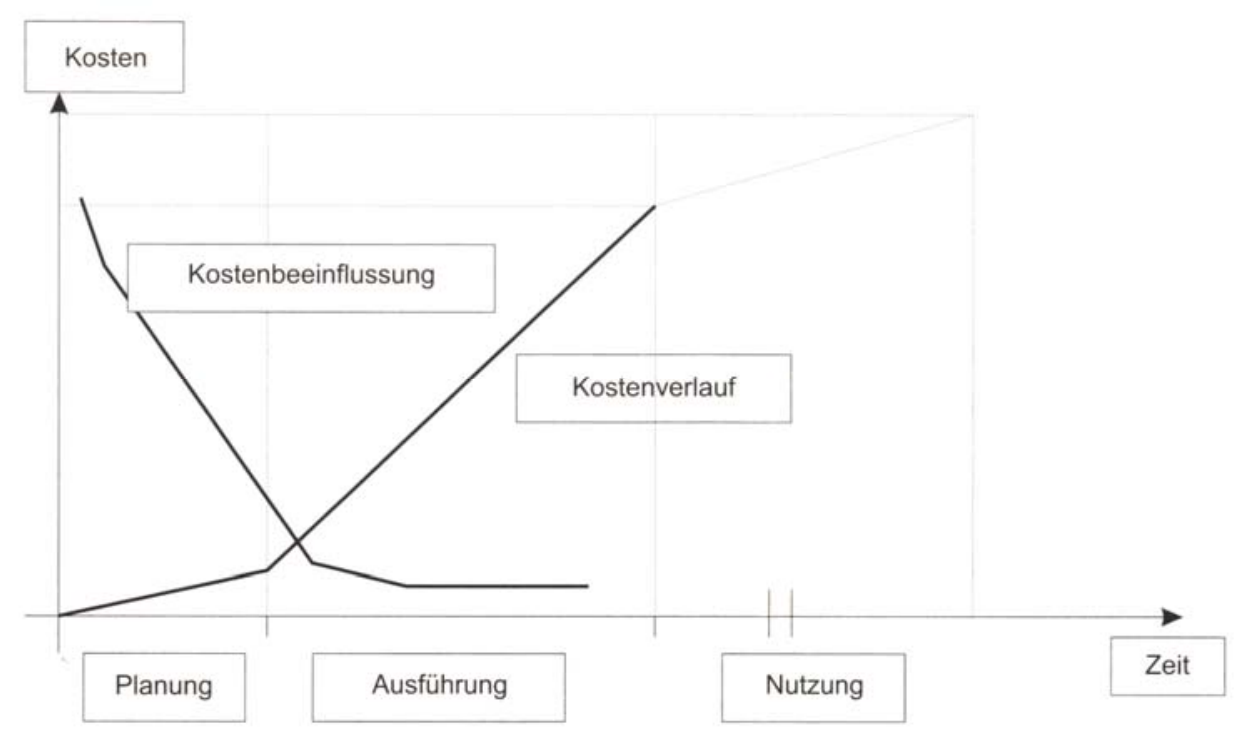

Quelle: P. Greiner, P. Mayer, K. Stark: Baubetriebslehre - Projektmanagement, Wiesbaden ${ }^{3} 2005$ S. 196

Vor Allem ist die Beeinflussung durch den Bauherren in dieser Projektphase entscheidend. Hier wird die Projektidee in Zahlen und Formen gegossen. Es müssen die entscheidenden Eckdaten, wie z.B. die Grundform des Objektes, die Kosten einzelner Bereiche, das Erscheinungsbild, und weitere maßgebende Definitionen erarbeitet und mit Kosten beziffert werden, damit mit dem Auftraggeber die weitere Richtung des Projektes abgestimmt werden kann.

\subsubsection{Projektkonzeption}

Das Thema „Projektkonzeption“ beschäftigt sich mit Aufgaben, Zielen und Analysen. Die bis zu diesem Status erfolgten Projektkonzeptionen und Projektumrisse werden nun weiteren Analysen unterzogen. Für diese hat sich der Begriff „Feasibility Analysen“81 durchgesetzt.

Ist ein Projekt nicht wirtschaftlich wird das Projekt, trotz der bereits getätigten Aufwendungen, abgebrochen. Denn ein Projekt in dieser Phase abzubrechen ist immer noch besser, als ein unwirtschaftliches Bauvorhaben zu realisieren.

\footnotetext{
${ }^{81}$ Duden: Feasibility Analysen: „Untersuchung über die Durchführbarkeit eines technischen Projekts“ http://www.duden.de/rechtschreibung/Feasibility_Studie 23.03.2012
} 


\section{Standort- und Marktanalyse $e^{82}$}

Auf Basis der Standort- und Marktanalyse werden in der Immobilienbranche die meisten Entscheidungen gefällt.

Mit der Marktanalyse soll abgeschätzt werden wie der Vermietungs- bzw. Verkaufserfolg für eine festgelegte Nutzung eines Grundstückes oder einer Projektidee kurz und mittelfristig sein wird.

Bei der Angebotsanalyse werden bestehende vergleichbare Objekte, und die davon ausgehenden Angebote analysiert, in verschiedene Gruppen eingeteilt (Lage, genaue Örtlichkeit, udgl.) und mit Flächenangeboten, Preisen, NutzerFluktuationen und Leerstandstagen belegt.

Bei der Nachfrageanalyse wird der derzeitige Bedarf an z.B. Wohnungen oder Geschäftsflächen in einem Bereich, einem Sektor, oder einem Bezirk analysiert. Ausgehend von diesem Wert werden Prognosen über den zusätzlichen Bedarf errechnet. Anhand dieser Ergebnisse kann ein Bedarf oder ein Überangebot an Nutzflächen prognostiziert werden. Ein zusätzlicher Bedarf an Nutzflächen lässt die Projektentwicklung zum nächsten Schritt übergehen, ein Überangebot an Nutzflächen erfordert eine Projektanpassung. Mögliche Anpassungen sind unter anderem eine andere Nutzung, ein anderes Klientel an Nutzern (z.B. bei Wohnhausanlagen), oder ein anderer Standort für die Immobilie.

\section{Analyse des Nutzungskonzeptes}

Bei der Analyse des Nutzungskonzeptes wird zwischen der Projektentwicklung und dem planenden Architekten das Nutzungskonzept abgestimmt. Dafür werden vom Projektentwickler sämtliche bereits getroffenen Festlegungen sowie Ergebnisse von Analysen festgehalten, sodass ein beauftragter Architekt das Nutzungskonzept in einem Grundrissplan darstellen kann. Das Nutzungskonzept kann auch mittels Ausschreibung an unterschiedliche Planer verteilt werden, wobei der beste Grundrissentwurf unter Abstimmung auf das Nutzungskonzept weitergeführt wird.

\footnotetext{
${ }^{82}$ Vgl. W. Schulte: Projektentwicklung Immobilienökonomie Betriebswirtschaftliche Grundlagen, München, 2008 S. 248
} 
Im Nutzungskonzept werden sowohl die gewonnen Erkenntnisse im Speziellen der Standort- und Marktanalyse berücksichtigt. Das Objekt wird daher auf die Ergebnisse der Nachfrageanalyse der Angebotsanalyse und der Marktanalyse angepasst. ${ }^{83}$

3. Wettbewerbsanalyse ${ }^{84}$

Die Wettbewerbsanalyse stellt zwei konkurrierende Immobilien im direkten Vergleich aus Sicht des Nutzers dar. Bestimmt wird die relative Marktsituation einer Immobilie im Vergleich zum Mitbewerber.

4. Risikoanalysen

Im Rahmen der Feasibility Analysen wird auch das bestehende Risiko analysiert und bewertet. Auch mit der Feasibility Analyse kann der Erfolg einer Projektentwicklung nicht garantiert werden, es können jedoch die Entwicklungsrisiken aufgezeigt und entsprechend bewertet werden.

In der Aufstellung der Risiken von Allendorf/Schulte ${ }^{85}$ werden die Investitionsrisiken dargestellt:

${ }^{83}$ Vgl. W. Schulte: Projektentwicklung Immobilienökonomie Betriebswirtschaftliche Grundlagen, München, 2008 S. 249

${ }^{84}$ Vgl. S. Ertle-Straub: Standortanalyse für Büroimmobilien, Leipzig, 2002 S. 73

${ }^{85} \mathrm{Vgl.} \mathrm{W}$. Schulte: Projektentwicklung Immobilienökonomie Betriebswirtschaftliche Grundlagen, München, 2008 S. 253 


\section{Abbildung 24: Risiken der Projektentwicklung}

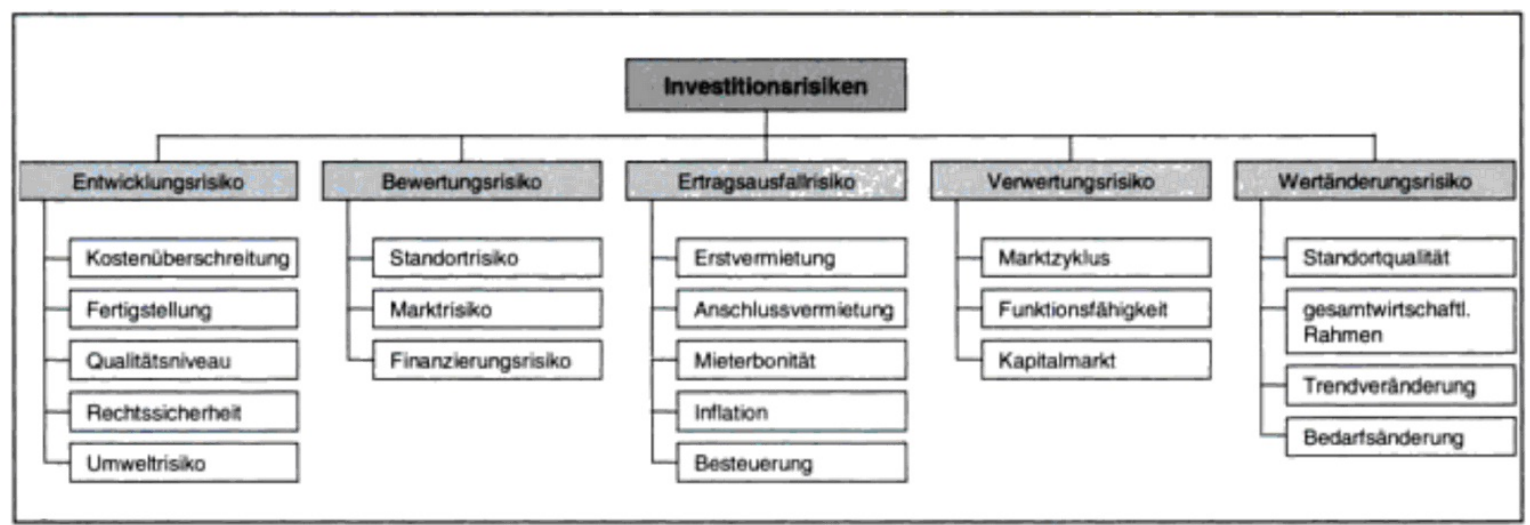

Quelle: W. Schulte: Projektentwicklung Immobilienökonomie Betriebswirtschaftliche Grundlagen, München, 2008 S. 249

Ergänzend zu dieser Aufstellung von Schulte ${ }^{86}$ sind im Bereich des Entwicklungsrisikos folgende Risiken zu ergänzen:

$>$ Zeitrisiko

$>$ Genehmigungsrisiko

Boden und Baugrundrisiko

Kostenentwicklungsrisiko

In der Praxis wird die Bewertung der Risiken mit Kosten sehr zurückhaltend durchgeführt, da diese Reserven meist den Kostenrahmen sprengen. Vielmehr wird versucht die Risiken im Vorfeld zu überprüfen und diese möglichst auszuschließen. Beispielsweise werden beim Baugrundrisiko frühzeitig Bohrungen durchgeführt, um ein späteres „böses Erwachen“ zu vermeiden. Die übrig bleibenden Restrisiken müssen vom Trading Profit (Handelsgewinn) beglichen werden. In der Praxis werden die Risiken, um Projektentwicklungskosten zu sparen, oft mit Erfahrungswerten angesetzt.

\footnotetext{
${ }^{86}$ Vgl. W. Schulte: Projektentwicklung Immobilienökonomie Betriebswirtschaftliche Grundlagen, München, 2008 S. 249
} 


\subsubsection{Projektmanagement in der Planung}

Der nächste Schritt des Projektablaufes nach der Projektentwicklungsphase ist die Projektplanungsphase. Dieser Projektabschnitt benötigt wieder viele beteiligte Personen. Der meist wichtigste Auftragnehmer dieser Phase ist das Architekturbüro. Vom Architekturbüro können jedoch meist nicht sämtliche Bereiche der Planung abgedeckt werden. Die erforderliche Unterstützung erhält dieses von den Sonder- bzw. Detailplanern. Diese decken die Bereiche ab, die nicht vom Architekturbüro geplant werden können, wie z.B. Statik, Haustechnik, Bauphysik udgl..

Die Aufgaben der Planung werden grundsätzlich vom Bauherren in den jeweiligen Aufträgen der Planer definiert. Sämtliche Leistungen, die nicht vom Bauherren wahrgenommen werden können, werden an externe Planer vergeben. Im Leitfaden zur Kostenabschätzung von Planungsleistungen der Bundesinnung $\mathrm{Bau}^{87}$ wird die übliche Sphäre des Bauherren und des Planers folgendermaßen definiert:

\section{Abbildung 25: Übersicht der Planungsleistungen}

\section{SPHÄRE BAUHERR}

\section{A.1. Projektleitung}

A.2. Projektentwicklung

A.3. Projektsteuerung

A.4. Begleitende Kontrolle

A.5. Planungs- \& Baust.koordinator

A.6. Sonstige Fachgebiete

\section{SPHÄRE klass. PLANER}

B.1. Objektplanung

B.2. Örtliche Bauaufsicht

B.3. Tiefbauplanungen

B.4. Tragwerksplanung

B.5. Sonstige Fachgebiete

Quelle: WKO Bundesinnung Bau: Leitfaden zur Kostenabschätzung: Band 1 Grundlagen, Stand 30.04.2006 S. 7

\footnotetext{
${ }_{7}^{87}$ Vgl. WKO Bundesinnung Bau: Leitfaden zur Kostenabschätzung: Band 1 Grundlagen, Stand 30.04.2006 S. 7
} 
Das Projektmanagement in Form der Bauherrenvertretung ist sowohl in der Planung als auch in der Bauleitung maßgeblich involviert. Sämtliche Entscheidungen, Richtungsvorgaben und Freigaben erfolgen, abhängig von der Organisationsform, über das Projektmanagement vom Bauherren oder direkt vom Projektmanagement.

Die Leistungsgruppe der örtlichen Bauaufsicht ist keine typische Planungsleistung. Die Abgrenzung zwischen den Leistungen der örtlichen Bauaufsicht (ÖBA) und der Planung wird in Kapitel 2.2.4 dargestellt. Thematisch wird diese Leistung jedoch meist zu den Planungsleistungen gezählt, da dieser Leistungsumfang ebenfalls zu den Bauherren unterstützenden Leistungen zählt.

\subsubsection{Objektplaner und fachliche Beteiligte ${ }^{88}$}

In der Planung gibt es viele sehr unterschiedliche Projektbearbeiter bzw. Planungsbeteiligte. Die Themengebiete sind sehr unterschiedlich und reichen von der Architekturplanung, über die technische Gebäudeausstattung, zur Statik, der Bauphysik bis hin zur Einrichtungsplanung. Da die einzelnen Fachbereiche sehr komplex sind, werden diese meist von eigenständigen Ingenieurbüros/Planungsbüros bearbeitet. Sämtliche Planungsleistungen werden vom Bauherren beauftragt.

\subsection{Objektplaner}

Üblicherweise werden Architekten und Ingenieure als Objektplaner bezeichnet. Diese Bezeichnung wird sowohl in der $\mathrm{HOAl}^{89}$ in Deutschland, wie auch im Leitfaden zur Kostenabschätzung der Wirtschftskammer Österreich ${ }^{90}$ verwendet. Der Objektplaner ist nicht nur für die räumliche und bauliche Gestaltung des Objektes zuständig, sondern diesem obliegt auch die Koordination und Abstimmung mit den anderen beteiligten Planern.

\footnotetext{
${ }^{88}$ Vgl. U. Blecken, B. Bielefeld: Bauen in Deutschland: Handbuch Für Architekten und Ingenieure, Basel, 2005 S. 41

${ }^{89} \mathrm{HOAl}$, Honorarordnung für Architekten und Ingenieure Ausgabe 01.1996

${ }^{90}$ Vgl. WKO Bundesinnung Bau: Leitfaden zur Kostenabschätzung: Band 2 Objektplanung, Stand 30.04.2006
} 


\subsection{Tragwerksplaner}

Unter Tragwerksplaner wird die Berufgruppe der Statiker verstanden. Diese müssen in enger Abstimmung mit dem planenden Architekten arbeiten. Der Statiker trägt die Verantwortung über die Tragekonstruktion und die Standsicherheit des Planungsobjektes. Häufig wird vom Architekturbüro als Entwurf ein Gebäude ohne statische Einflussnahme vorab entworfen. Dieser Entwurf wird dann durch statische Erfordernisse ergänzt, bevor dieser an die übrigen Planer verteilt wird.

\subsection{Planer der technischen Gebäudeausrüstung}

Die technische Gebäudeausrüstung umfasst sämtliche Anlagen, die für die gewünschte Funktion des Gebäudes erforderlich sind. Es müssen Anlagen wie z.B. Heizungsanlage, Stromversorgung und Verteilung udgl. aufbereitet, dimensioniert und in baulicher Hinsicht mit dem Architekturbüro abgestimmt werden. In Anlehnung an die Auflistung von Blecken und Bielefeld ${ }^{91}$ werden folgende Gebiete der technischen Gebäudeausrüstung angeführt:

$>$ Gas-, Wasser-, Abwasser- und Feuerlöschtechnik

Wärmeversorgungs-, Brauchwasserwärmungs- und Raumlufttechnik

$>$ Elektrotechnik

$>$ Aufzugs-, Förder- und Lagertechnik

$>$ Küchen-, Wäscherei- und chemische Reinigungstechnik

Medizin- und Labortechnik

\subsection{Sonstige Projekt- und Planungsbeteiligte}

In der Kategorie „Sonstige Projekt- und Planungsbeteiligte“ sind sämtliche Gewerke enthalten, die keine technische Gebäudeeinrichtung, keine Statik und keine architektonische Planung ausführen. Beispielhaft können in dieser Planungsgruppe die Bauphysiker angeführt werden, die den Architekten in der Detailausbildung

\footnotetext{
${ }^{91}$ Vgl. U. Blecken, B. Bielefeld: Bauen in Deutschalnd Handbuch für Architekten und Ingenieure, Basel, 2005 S. 41
} 
von Wänden und Decken beraten. Weitere erforderliche Leistungen werden von der Berufsgruppe der Vermessungstechniker, der Geologen udgl. ausgeführt.

\subsubsection{Leistungsphasen/Aufgaben der Planung}

Jeder der Objektplaner, wie auch sämtliche fachlich Beteiligten, müssen entsprechend ihrer Beauftragung, die sie vom Bauherren erhalten haben, ihre Leistungen erbringen. Die Gruppen der Leistungen sind bei allen Planern ähnlich und entsprechen dem typischen Planungsablauf. Nachstehend wird eine Übersicht der Teilleistungen anhand der Objektplanung dargestellt. ${ }^{92}$

1. Vorleistungen / Grundlagenermittlung (siehe Kapitel 2.2.3.2.1)

2. Vorentwurfsplanung (siehe Kapitel 2.2.3.2.2)

3. Entwurfsplanung (siehe Kapitel 2.2.3.2.3)

4. Einreichplanung und Genehmigungsverfahren (siehe Kapitel 2.2.3.2.4)

5. Ausführungsplanung und Details (siehe Kapitel 2.2.3.2.5)

6. Ausschreibungsunterlagen (siehe Kapitel 2.2.3.2.6)

7. Oberleitung (siehe Kapitel 2.2.4.1.1)

7.1. Oberleitung bei der Vergabe

7.2. Oberleitung bei der Bauphase

7.3. Künstlerische Oberleitung

8. Dokumentation und Nachbetreuung (siehe Kapitel 2.2.4.1.2)

9. Sonstige Teilleistungen (siehe Kapitel 2.2.4.1.3)

Die oben angeführten Grundleistungen wurden mit einer Nummerierung versehen. In dieser dargestellten Abfolge werden die Leistungen der Planung im Planungs-

\footnotetext{
92 Vgl. WKO Bundesinnung Bau: Leitfaden zur Kostenabschätzung: Band 2 Objektplanung, Stand 30.04.2006 S. 6
} 
ablauf sowie im Bauablauf ausgeführt. Die Punkte eins bis sechs werden typischweise als Planungsleistungen, die Punkte sieben bis neun als Tätigkeiten der Bauausführung beschrieben. Die Punkte sieben bis neun werden im Kapitel „Projektmanagement in der Ausführungsphase" näher erläutert. Werden nicht alle Teilleistungen eines Gewerk vom Bauherren bei einer Stelle beauftragt, müssen diese von einer anderen Stelle ausgeführt werden. Für ein besseres Verständnis werden nun noch einzelne Teilleistungen weiter beschrieben. ${ }^{93}$

Die folgende Auflistung der Leistungen ist in Deutschland (entsprechend der $\mathrm{HOAI}^{94}$ ) und in Österreich (geregelt im Leitfaden der $\mathrm{WKO}^{95}$ ) nahezu ident. Nachstehend wird die österreichische Darstellung beschrieben.

\subsection{Vorleistungen Grundlagenermittlung}

Diese Teilleistung überschneidet sich im Aufgabenumfang mit den Leistungen der Projektentwicklung. Wird vom Bauherren eine Projektentwicklung durchgeführt, wird der Punkt 01 (Vorleistungen/Grundlagenermittlung) nicht zusätzlich bei den Planungsleistungen beauftragt. Im Aufgabenumfang dieses Punktes ist die Klärung der Aufgabenstellung, die Analyse der Grundlagen, die Klärung der Rahmenbedingungen und die Erhebung von Bebauungsvorgaben enthalten.

\subsection{Vorentwurfsplanung}

Die Vorentwurfsplanung beinhaltet die Klärung der Aufgabenstellung und der Rahmenbedingungen. In dieser Projektphase werden Lösungsvorschläge für die bekannten Probleme erarbeitet und in Planform (Maßstab 1:200) dargestellt. Diese Planunterlagen werden mit den einzelnen zuständigen Behörden vorbesprochen und vorverhandelt. Weiters wird in dieser Planungsphase ein Terminrahmen mit entsprechenden Meilensteinen zusammengestellt. Parallel zu den einzelnen Leistungen müssen die Ergebnisse stets mit den anderen, an der Planung beteiligten, koordiniert und abgestimmt werden. Das Ende jeder Planungsphase stellt ein

\footnotetext{
${ }^{93}$ Eine detaillierte Beschreibung dieser Leistungen können bei folgender Quelle eingesehen werden: WKO Bundesinnung Bau: Leitfaden zur Kostenabschätzung: Band 2 Objektplanung, Stand 30.04.2006 S. 7-15

${ }^{94}$ Vgl. HOAI, Honorarordnung für Architekten und Ingenieure Ausgabe 01.1996

${ }^{95}$ Vgl. WKO Bundesinnung Bau: Leitfaden zur Kostenabschätzung: Band 2 Objektplanung, Stand 30.04.2006 S. 7-15
} 
Gespräch mit dem Bauherren dar, in dem der vorliegende Vorentwurfsstand besprochen und vom Bauherren befürwortet werden muss.

\subsection{Entwurfsplanung}

In der Entwurfsplanung werden die Vereinbarungen mit den Behörden eingearbeitet, sodass ein genehmigungsfähiger Vorentwurf entsteht. Parallel zu den Vorbereitungsplänen der Genehmigung werden die Entwurfspläne zeichnerisch dargestellt und an alle Planungsbeteiligten verteilt, damit dieser aktuelle Planungsstand als Grundlage und Basis für die einzelnen Teilleistungen verwendet werden kann. Der in der Vorentwurfsphase erstellte Terminrahmen wird zum Grobterminplan verfeinert und ergänzt. Wie auch in der Vorentwurfsphase müssen sämtliche Ergebnisse stets mit den anderen an der Planung Beteiligten koordiniert und abgestimmt werden. Am Ende der Entwurfsplanung wird der Entwurf dem Bauherren präsentiert und mit den zusätzlichen Wünschen des Bauherren verfeinert, sodass die Freigabe zur Weiterführung der Planung vom Bauherren erteilt werden kann.

\subsection{Einreichplanung und Genehmigungsverfahren}

Die in der Entwurfsplanung erstellten und mit den Behörden vorbesprochenen Pläne werden zur Bewilligung der Behörde vorgelegt. Zu dieser Planungsphase gehören unter anderem die Mitwirkung und Erläuterungen der Behörde sowie die Beratung und Vertretung des Bauherren aus planungstechnischer Sicht.

\subsection{Ausführung und Detailplanung}

Sämtliche von den Behörden gewünschten/geforderten Anmerkungen und Ergänzungen werden in der Detailplanung in die Pläne eingearbeitet und in Planform dargestellt. Das Hauptaugenmerk der Ausführungs- und Detailplanung liegt jedoch darauf, den Planungsstand so weit zu verfeinern, dass alle für die Ausführung notwendigen Unterlagen und Informationen in den Plänen enthalten sind. Weiters müssen sämtliche Detailzeichnungen, Schnitte, Perspektiven, Einrichtungspläne Haustechnikangaben, Elektroangaben udgl. abgestimmt und in den Plänen dargestellt werden. Die Ausführungsunterlagen dienen den ausführenden Firmen als Basis für die Leistungserbringung. Um ein späteres böses Erwachen des Bauherren zu verhindern, ist die nochmalige Abklärung und endgültige Freigabe dieser Unterlagen absolut entscheidend, da darin die spätere Endleistung dargestellt ist. 


\subsection{Ausschreibungsunterlagen}

Um den Leistungsumfang der ausführenden Firmen zu definieren und einen konkurrenzfähigen Preis für die einzelnen Gewerke zu erhalten, werden Ausschreibungen für jedes Gewerk vom zuständigen Planer erstellt. Diese Ausschreibungen enthalten sowohl eine Baubeschreibung wie auch eine Leistungsbeschreibung, in der die Teilleistungen in Umfang und Qualität genau definiert sind. Ergänzt werden diese beschreibenden Positionen mit den benötigten Stückzahlen. Von den ausführenden Firmen werden diese Positionen mit Einzelpreisen versehen, sodass nach Aufsummierung aller Leistungen eine Endsumme für die beschriebenen Leistungen angeboten werden kann.

\subsubsection{Planungsabläufe}

Grundsätzlich gibt es drei verschiedene Abläufe nach denen eine Planung ausgeführt werden kann.

Konventionelle Planung

Synchrone Planung

Neutrale Planung 


\section{Abbildung 26: Grundsätzliche Planungsabläufe}

\section{konventionelle Planung}

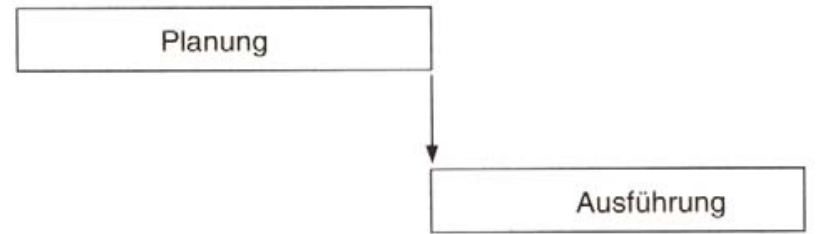

Synchronplanung

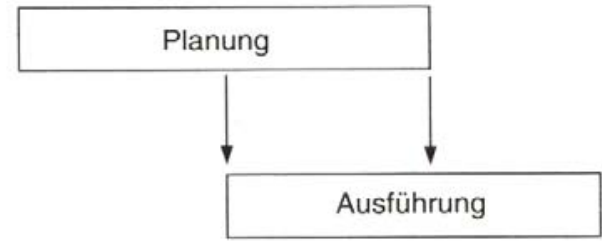

Neutralplanung

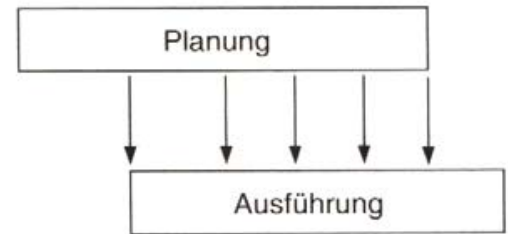

Quelle: P. Greiner, P. E. Mayer, K. Stark: Baubetriebslehre- Projektmanagement, Wie Bauprojekte erfolgreich gesteuert werden, Wiesbaden ${ }^{3} 2005$ S. 15

Die konventionelle Planung ist die einfachste Form der Planungsarbeit. Bei dieser wird zuerst die gesamte Planung abgeschlossen und dieses gesamte Konvolut der ausführenden Firma als Basis der Ausführung zur Verfügung gestellt. Der Vorteil dieses Ablaufes liegt darin, dass die Planung exakt bei Auftragsvergabe bekannt ist. Das bedeutet genau definierte Leistungen und damit eine Kostensicherheit. Die Nachteile liegen im relativ hohen Zeitaufwand und einer mangelnden Flexibilität.

Die Synchronplanung lässt sich dadurch charakterisieren, dass sich der Planungsablauf mit der Ausführungsphase überschneidet. Zum Zeitpunkt der Ausschreibung wird die Planung des Objekts nur soweit vorangetrieben, dass die Ausführungsleistungen definiert werden können. Die restliche Detailplanung erfolgt parallel zur Ausführungsplanung. Der Vorteil dieses Ablaufes liegt in der reduzier- 
ten Zeit des Gesamtablaufes. Ein weiterer Vorteil liegt darin, dass mögliche Änderungen oder neue Erkenntnisse noch in der Planung berücksichtigt werden können. Der Nachteil der Synchronplanung besteht darin, dass die Definition der auszuführenden Leistungen nicht exakt sind, da ein Teil der Probleme erst in der Detailplanung erarbeitet wird.

Bei der Neutralplanung wird die Gesamtzeit der Planung und Ausführung nochmals reduziert. Es werden keine später auszuführenden Gewerke berücksichtigt. Die Objekte werden so geplant, dass eine hohe spätere Nutzungsflexibilität gewährleistet ist. Das Objekt wird nutzungsneutral errichtet. Es wird noch nicht definiert, ob die Räumlichkeit als Arztpraxis, als Büro oder als Fitnessstudio genutzt wird. Der Vorteil liegt in der bereits erwähnten kürzeren Bauzeit im Vergleich zur Synchronplanung. Die Nachteile liegen in den höheren Errichtungskosten, da für die flexible Nutzung bei der Errichtung ein höherer Standard mit verschiedenen Ausführungsvarianten angedacht werden muss. ${ }^{96}$

\subsubsection{Leistungsträger in der Planung}

Das Auftragsverhältnis zwischen dem Bauherren und den Planern kann entweder mittels Einzelaufträgen (an jeden Planer separat) oder als Gesamtauftrag abgeschlossen werden. Bei der Beauftragung eines Gesamtauftragnehmers holt sich dieser die weiteren erforderlichen Planer als Sub-Auftragnehmer mit ins Planungsteam.

\subsection{Einzelleistungsträger}

Bei der Projektstruktur mit Einzelleistungsträgern muss sich der Bauherr die Frage stellen welche Planer er zu welchem Zeitpunkt und in welchem Umfang benötigt. Der Bauherr muss jede Planungsleistung separat ausschreiben, mit jedem Anbieter verhandeln, einen eigenen Werkvertrag erstellen und schlussendlich für jedes Gewerk die Rechnung prüfen und bezahlen. ${ }^{97}$

\footnotetext{
${ }^{96}$ Vgl. P. Greiner, P. E. Mayer, K. Stark :Baubetriebslehre- Projektmanagement, Wie Bauprojekte erfolgreich gesteuert werden, Wiesbaden ${ }^{3} 2005$ S. 14

${ }^{97}$ Vgl. Kalusche: Projektmanagement für Bauherren und Planer München/Wien 2005 S. 236
} 


\subsection{Gesamtleistungsträger}

Der Vorteil bei der Beauftragung der gesamten Planungsleistung an einen Generalplaner liegt darin, dass die gesamte Planungsleistung aus einer Hand kommt und man nur einen Ansprechpartner hat. Sämtliche Koordinierungsaufgaben und Schnittstellenprobleme werden vom Generalplaner gelöst. Der Generalplaner schuldet dem Auftraggeber (Bauherren) die gesamte Planungsleistung und ist für alle internen Koordinierungs-, Abstimmungs- und Problemlösungsleistungen der Planung verantwortlich. Weiters reduziert sich der Aufwand des Bauherren deutlich, da er nur mehr einen Auftrag erteilen und eine Rechnung prüfen muss. ${ }^{98}$

${ }^{98}$ Vgl. Kalusche: Projektmanagement für Bauherren und Planer München/Wien 2005 S. 238 


\subsubsection{Projektmanagement in der Ausführungsphase}

Von einem erfolgreichen Projekt kann nur gesprochen werden, wenn die entscheidenden Größen „Kosten“, „Termine“ und „Qualität", entsprechend der Planungsvorgabe eingehalten werden. Diese drei maßgeblichen Faktoren sind vor allem in der Bauausführung entscheidend. Das Projektmanagement, als übergeordnete Instanz zur Bauleitung und auch die Bauleitung im Eigeninteresse, ist an der Kontrolle und Verfolgung dieser Größen interessiert und verpflichtet. Für diese Kontrolle sind laufende soll/ist Vergleiche erforderlich, die im Laufe der Bauausführung durchgeführt werden.

Die Schnittstelle zwischen der ÖBA, dem Projektmanagement und auch der Projektsteuerung ist in der Literatur nicht eindeutig definiert. Entscheidend bei der Abgrenzung dieser Aufgabenbereiche ist der Auftrag vom Bauherren. Laut Greiner/Mayer/Stark werden die wesentlichen Spielregeln vom Projektmanagement bzw. -steurer definiert und bestehen üblicherweise aus folgenden Spielregeln ${ }^{99}$ :

> Basisleistungen der technischen Objektüberwachung, der Fachplanerkoordination, der Feinkoordination der Arbeiten auf der Baustelle und der Rechnungsprüfung sind originäre Aufgaben der Objektüberwachung.

Ebenso obliegt der Objektüberwachung die Feinkoordination von Planern und Ausführenden (beispielsweise wann welche Montage-Kolonnen eingesetzt und wann welche Mängelbeseitigung vorgenommen werden).

\subsubsection{Leistungsphasen/Aufgaben des Planungsteams in der Ausführung}

Die unter Pkt. 2.2.3.2 „Leistungsphasen/Aufgaben der Planung" dargestellten Phasen betreffen die gesamten von der Planungsseite geforderten Leistungen.

\footnotetext{
${ }^{99}$ P. Greiner, P. E. Mayer, K. Stark :Baubetriebslehre- Projektmanagement, Wie Bauprojekte erfolgreich gesteuert werden, Wiesbaden ${ }^{3} 2005$ S. 244
} 
Die Leistungen der nachstehend angeführten Punkte sieben bis neun, werden von der Planung in der Ausführungsphase durchgeführt. ${ }^{100}$

\subsection{Oberleitung}

Die Teilleistung „Oberleitung“ wird entsprechend der Übersicht der Teilleistungen in drei Untergruppen unterteilt.

\section{1.) Mitwirkung bei der Vergabe}

Die Angebotsergebnisse der im Punkt 2.2.3.2.6 erstellten Ausschreibung werden von der ausschreibenden Stelle (Planer) einer Prüfung unterzogen, in der Rechen-, Qualitäts-, Preis- und Plausibilitätsprüfungen durchgeführt werden. Erforderliche Klärungen werden von der ausschreibenden Stelle direkt mit dem Bieter durchgeführt.

Die geprüften Angebotsergebnisse werden entsprechend der Best- und Billigstbieter zusammengefasst und mit einem Vergabevorschlag versehen. Die gesammelten Unterlagen werden dem Bauherren bzw. dem Projektmanager zur Vergabe übermittelt. Die ausführenden Firmen werden vom Bauherren beauftragt.

Die angebotenen Leistungen der einzelnen Firmen können nun vom Bauherren für die Ausführung mit einer definierten Summe beauftragt werden. Vom Bauherren bzw. dem Projektmanagement werden nun in einer Kostenverfolgung die aktuellen Werte der einzelnen Teilgewerke erfasst und mit den in der Planung bekannt gegebenen Kostenschätzungen/Kostenberechnungen verifiziert.

\section{2.) Oberleitung in der Bauphase}

Die ausführenden Firmen sind mit der Beauftragung zur Ausführung von Werkzeichnungen und zur Erstellung von ergänzenden, konstruktiven Details beauftragt. Diese müssen von den jeweiligen Firmen vor Ausführung zur Freigabe der jeweiligen Bauleitung und dem Projektmanagement vorgelegt werden. Ergänzend zu der Überprüfung und Freigabe der Werkzeichnungen

\footnotetext{
${ }^{100}$ Vgl. WKO Bundesinnung Bau: Leitfaden zur Kostenabschätzung: Band 2 Objektplanung, Stand 30.04.2006 S. 6
} 
der ausführenden Firmen muss von der Oberleitung der Bauphase oder vom Projektmanagement ein Bauablaufplan für die Bauphase erstellt werden.

Ebenfalls zu den Leistungen der Oberbauleitung oder des Projektmanagements zählen die Kostenverfolgung und die Rechnungskontrolle der Teil- und Schlussrechnungen.

\section{3.) Künstlerische Oberbauleitung in der Bauphase}

Die künstlerische Oberbauleitung betrifft nicht, wie die Punkte 1 und 2 alle unter Punkt 2.2.3.1 fachlich Beteiligten, sondern wird in den meisten Fällen vom planenden Architekturbüro ausgeführt. Von diesem wird geprüft ob das errichtete Objekt mit den in der Planung definierten gestalterischen Vorgaben übereinstimmt. Zusätzlich ist es üblich, dass in der Ausführungsphase noch einzelne Details und funktionelle Einheiten mit dem Bauherren oder dem Projektmanagement abgestimmt werden. Zu diesem Zeitpunkt können sich auch unerfahrene Bauherren die Ideen und Vorschläge des Bauherren besser vorstellen, da Teilbereiche des Bauwerkes bereits besichtigt werden können.

\subsection{Dokumentation und Nachbetreuung}

Nach Abschluss der Bauphase müssen die ausgeführten Leistungen dokumentiert werden, um Wartungsarbeiten und spätere Änderungen oder Erweiterungen zu ermöglichen. Es werden die Ausführungspläne mit zusätzlichen Informationen ergänzt und Änderungen in der Bauphase korrigiert. Weiters sind Angaben über z.B. im Erdreich verlegte Leitungen, Datenblätter über Verschleißteile udgl. in der Dokumentation abzulegen.

Zu den Planungs- und Bauleitungstätigkeiten gehören nicht nur die Leistungen vor und nach der Bauzeit. Das Planungsteam überprüft auch die Werte der Betriebskosten mit den in der Planung errechneten Werten. Weiters gehören zu den Aufgaben der Nachbetreuung des Planungsteams auch die Unterstützung des Bauherren bei möglichen Rechtsstreitigkeiten sowie die Unterstützung bei der Mängelfeststellung (meist nach 3 Jahren).

\subsection{Sonstige Teilleistungen}

Sonstige Teilleistungen der Planung sind gewünschte Teilleistungen, die nicht in den oben (Unterpunkt 2.2.3.2.1 bis 2.2.4.1.2) angeführten Teilleistungen enthalten 
sind oder in einer anderen Leistungsgruppe (z.B. Fluchtwegplanung, Brandschutzplanung, udgl.) als eigene Leistung angeführt werden.

\subsubsection{Leistungsphasen/Aufgaben der örtlichen Bauaufsicht in der Ausführung}

Die Leistungen der örtlichen Bauaufsicht (ÖBA) werden in der Kostenabschätzung für Planungsleistungen der WKO in folgende Teilleistungen eingeteilt ${ }^{101}$. Die unten angeführten Teilleistungen wurden mit einer Nummerierung versehen, in der die Leistungen im Bauablauf ausgeführt werden. ${ }^{102}$

1. Bauüberwachung \& Koordination

2. Termin- \& Kostenverfolgung

3. Qualitätskontrolle

4. Rechnungsprüfung

5. Bearbeitung von Mehr- \& Minderkostenforderungen

6. Übernahme \& Abnahme

7. Mängelfeststellung \& -bearbeitung

8. Prüfung und Mängelfeststellung der Dokumentation in den Phasen der Ausführungsvorbereitung, der Ausführung und des Projektabschlusses.

9. sonstige Teilleistungen

\footnotetext{
${ }^{101}$ Vgl. WKO Bundesinnung Bau: Leitfaden zur Kostenabschätzung: Band 3 ÖBA örtliche Bauaufsicht, Stand 30.04.2006 S. 4

102 Eine detaillierte Beschreibung dieser Leistungen kann in folgender Quelle nachgelesen werden: WKO Bundesinnung Bau: Leitfaden zur Kostenabschätzung: Band ÖBA-Örtliche Bauaufsicht, Stand 30.04.2006 S. 7-10
} 


\section{Abbildung 27: Teilleistungen der ÖBA in Abhängigkeit der Bauphasen}

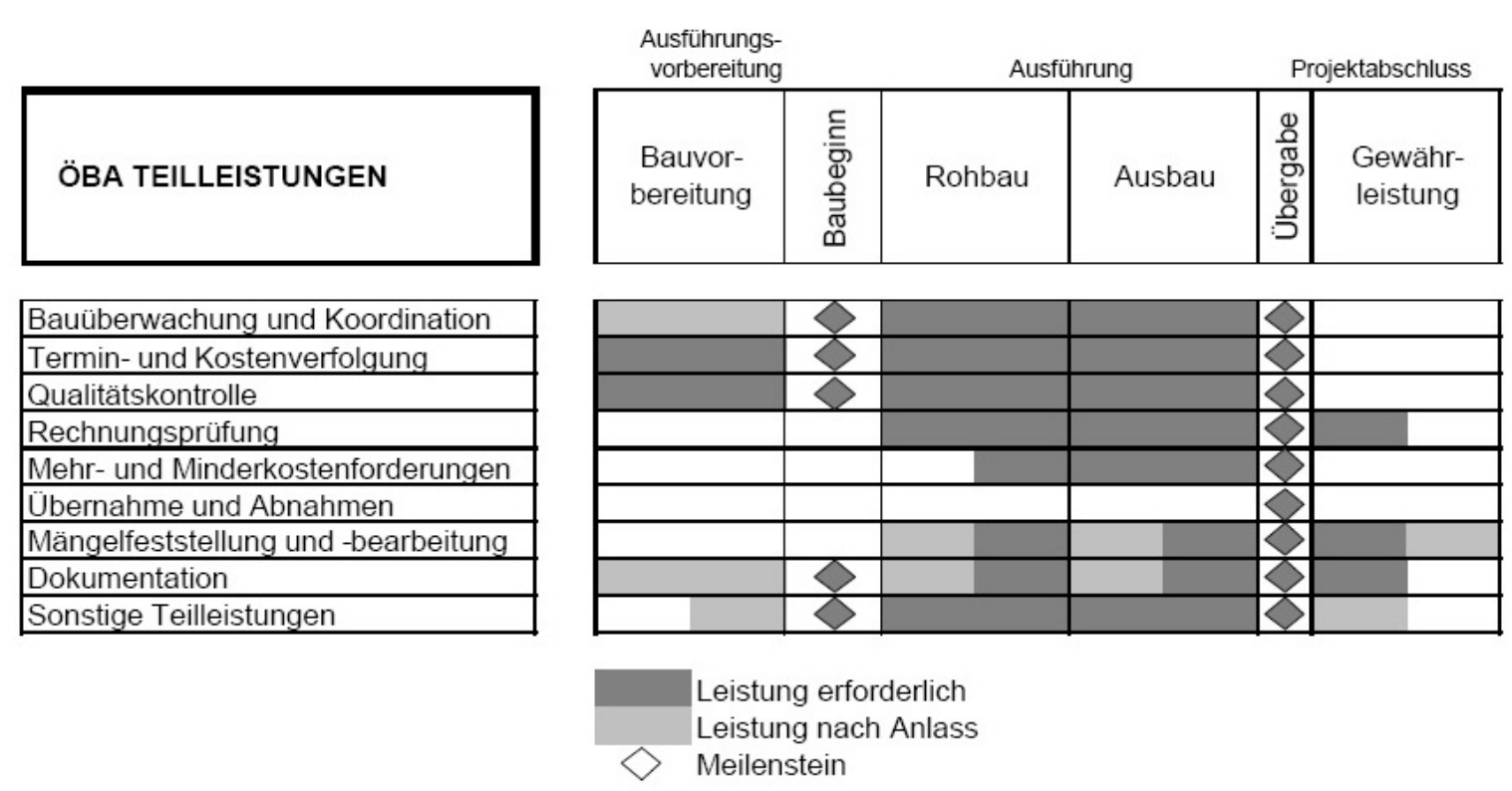

Quelle: WKO Bundesinnung Bau: Leitfaden zur Kostenabschätzung: Band 3 ÖBA örtliche Bauaufsicht, Stand 30.04.2006 S. 13

In der dargestellten Abbildung werden die Teilleistungen den Ausführungsabschnitten zugeordnet. Einzelleistungen können vom Bauherren, vom Projektmanagement oder von Dritten ausgeführt werden. Häufig werden diese Leistungen jedoch als Folgeleistung der Planung beim jeweiligen Planungsverantwortlichen beauftragt. Der Vorteil liegt darin, dass der Planer bereits Kenntnisse über Vorgaben und die Vereinbarungen, auf Basis derer die Planung erstellt wurde, hat. Darüber hinaus sind dem Planer auch die Hintergründe vieler Entscheidungen udgl. bekannt, auf Basis derer der Bauablauf positiv beeinflusst werden kann. Der Nachteil bei der Beauftragung des Planers mit den ÖBA-Leistungen liegt darin, dass eine zusätzliche Kontrolle (Vier-Augen-Prinzip) der ausgeführten Leistungen entfällt.

\subsection{Bauüberwachung \& Koordination}

Die örtliche Bauüberwachung (ÖBA) ist grundsätzlich die Vertretung des Bauherren in der Ausführungsphase und vertritt dessen Interessen. Die ÖBA hat daher unter anderem die Aufgabe zu kontrollieren, dass die Leistungen des Unternehmens entsprechend dem Bauauftrag und den Behördenvorschreibungen ausgeführt werden. Weiters werden die Arbeiten auf Übereinstimmung mit den Leis- 
tungsbeschreibungen, den Ausführungsplänen und selbstverständlich auf die Errichtung nach dem neuesten Stand der Technik überprüft

Ein weiterer wichtiger Aufgabenpunkt der überwachenden Stellen (ÖBA Projektleitung, Projektmanagement udgl.) ist die Koordination der Leistungen der ausführenden Firmen zu steuern bzw. diese zu veranlassen, sodass die Leistungen in Abstimmung zueinander ungestört ausgeführt werden können. Die Terminabläufe der Leistungserbringung müssen mit den Firmen festgelegt werden.

Von der Bauleitung müssen die Besprechungsabwicklung geleitet und die erforderlichen Rahmenbedingungen (z.B. Räumlichkeiten udgl.) für die Besprechungen geschaffen werden.

\subsection{Termin- und Kostenverfolgung}

Ein entscheidender Punkt jeder Bauausführung ist die Kosten- und Terminverfolgung. Bei dieser Verfolgung muss ein regelmäßiger Soll-Ist-Vergleich durchgeführt werden. Um die Terminverfolgung durchzuführen, wird in kontinuierlichen Abständen (meist bei der wöchentlichen Baubesprechung, beziehungsweise nach Erfordernis) der tatsächliche Projektfortschritt mit dem von der ÖBA erstellten Detailterminplan verglichen. Abweichungen von diesem Terminplan in Form von noch nicht oder verspätet ausgeführten Leistungen, werden mit der betreffenden Firma besprochen. Der Verzug muss unverzüglich wieder aufgeholt werden, da ansonsten sämtliche Termine der Folgegewerke nicht fristgerecht erfüllt werden können. Sollte der Verzug nicht aufgeholt werden, besteht für die ÖBA die Möglichkeit Verzugstrafen (PÖNALEN udgl.) einzuheben.

Der Ist-Stand der Kosten des Bauvorhabens wird von der ÖBA entsprechend des Baufortschrittes und/oder anhand der vorliegenden Teilrechnungen der ausführenden Firmen ermittelt. Der Ist-Stand wird der Kostenprognose und den jeweiligen Aufträgen der Firmen gegenübergestellt. Anhand dieser Maßnahme können die zu erwartenden Kosten des gesamten Bauvorhabens laufend überprüft werden. Bei einer Kostenüberhöhung muss die Ursache (Art und Umfang) der Kosten eruiert werden, damit Gegenmaßnahmen eingeleitet werden können. Bei Unterschreitung der Kosten muss ebenfalls der Kontakt zum Bauherren hergestellt werden, dann möglicherweise möchte dieser das übrig bleibende Budget in Form einer Standarderhöhung/Ausstattungserhöhung einsetzen. 


\subsection{Qualitätskontrolle}

In der Planung und in den Auftrags- und Ausschreibungsunterlagen wird die Ausführung und die Qualität der Produkte definiert. Im Zuge der Bauüberwachung muss von der ÖBA überprüft werden, ob die Firmen die vertraglich geschuldete Leistung erbringen. Dafür sind Überprüfungen und Messungen während der Ausführung erforderlich. Gegebenenfalls ist das jeweilige Unternehmen aufzufordern die Leistung zu korrigieren und den vertraglich vereinbarten Standard herzustellen. Weiterer Bestandteil der Qualitätskontrolle durch die ÖBA ist die Prüfung der Ausführungs- und Montagepläne. Diese sind auf Übereinstimmung mit den übergebenen Unterlagen der Planung zu überprüfen.

\subsection{Rechnungsprüfung}

Die wesentlichen Bestandteile einer Rechnungsprüfung bestehen aus der Kontrolle der Aufmaße, die von den ausführenden Firmen laufend erstellt werden müssen und der Prüfung der Rechnung. Bei der Prüfung der vorgelegten Rechnung sind folgende Punkte zu beachten:

1. Überprüfung auf Übereinstimmung mit dem Vertrag, hinsichtlich Vergütungsberechtigung

2. Überprüfung der Rechnungsbestandteile auf Richtigkeit des Vergütungsumfangs, der Einheitspreise und der Menge der verrechneten Leistungen. Weiters muss eine Leistungsabgrenzung zu früheren Teilrechnungen bzw. zu anderen Gewerken (Schnittstellen) geprüft werden.

3. Überprüfung der formalen Anforderungen wie z.B. Fristen, Empfängerdaten (UID-Nummer, udgl.)

4. Überprüfung der Preisanpassungen z.B. bei veränderlichen Preisen.

Weiters ist die Vergütungsberechtigung von Regieleistungen hinsichtlich Art und Umfang zu überprüfen.

Jede Rechnungskontrolle wird mit einer anweisbaren Endsumme für die vorgelegte Teil- oder Schlussrechnungssumme abgeschlossen. 


\subsection{Bearbeitung von Mehr- und Minderkostenforderungen}

Werden von einem ausführenden Unternehmen Mehr- und Minderkostenanforderungen gestellt, benötigt der Bauherr die fachliche Unterstützung. Die Forderung muss daher dem Grunde nach überprüft werden. Ist diese nicht gerechtfertigt muss der Bauherr bei der Verhandlung mit dem Forderungssteller fachlich unterstützt werden, sodass eine Entscheidung getroffen werden kann. Lässt sich die Meinungsverschiedenheit nicht außergerichtlich lösen, müssen die Interessen des Bauherren auch im Rechtsstreit in beratender Funktion vertreten werden.

\subsubsection{6 Übernahme und Abnahme}

Die Übernahme und die Abnahme stellen den letzten auf der Baustelle operativen Tätigkeitsbereich der ÖBA dar. Gemeinsam mit der Projektleitung und dem Bauherren müssen die Leistungen der Unternehmen abgenommen werden. Dafür sind folgende Schritte erforderlich:

Abstimmung der errichteten Anlage mit den geplanten Vorgaben

Überprüfung der Anlage auf Übereinstimmung mit den behördlichen Vorgaben zur Erlangung einer Benützungsbewilligung

> Mitwirkung bei der Abnahme, Übernahme und Schlussfeststellung

> Überprüfung der vom ausführenden Unternehmen vorgelegten Dokumentation

\subsection{Mängelfeststellung und -bearbeitung}

Die im Zuge der Abnahme und des laufenden Betriebes festgestellten Mängel müssen aufgenommen, überprüft und dem zuständigen Errichter zur Mängelbehebung, mitgeteilt werden. Die Mängelbehebung ist dabei von der ÖBA zu verfolgen und die Mängelfreimeldung des Unternehmens ist zu überprüfen. Die Gewährleistungsfristen sind aufzulisten und mit dem Bauherren abzustimmen. Vor Ablauf der Gewährleistung ist es üblich noch eine Schlussbegehung durchzuführen.

\subsection{Dokumentation}


Von der ÖBA ist der Bauablauf zu dokumentieren, sodass das Baugeschehen nachvollzogen werden kann. Dieser Prozess wird in Form von Bautagesberichten der einzelnen Firmen, von Bautagebüchern und einer ausführlichen Fotodokumentation durchgeführt. Abhängig von den jeweiligen Aufträgen der ÖBA und des Baumanagement werden diese Daten gesammelt und aufbewahrt oder nur gesammelt und dem Bauherren übergeben.

\subsection{Sonstige Teilleistungen}

Unter sonstige Teilleistungen werden sämtliche Leistungen der ÖBA zusammengefasst, die außerhalb der bisher aufgelisteten Leistungen einzuordnen sind. Darunter fallen z.B. Leistungen, bei denen sofort gesetzliche oder sicherheitsrelevante Arbeiten erforderlich sind. In diesem Fall können von der ÖBA Leistungen kurzfristig und direkt beauftragt werden, um den Missstand zu beheben. Der Bauherr muss über die Durchführung spätestens im Nachgang informiert werden.

\subsubsection{Vorraussetzungen in der Ausführung}

Die Beauftragung der ausführenden Firmen, allen voran des Bauunternehmers, kann auf unterschiedliche Arten erfolgen, die unterschiedliche Voraussetzungen und Aufgaben des Auftragnehmers bedeuten. Der Auftragnehmer übernimmt, je nach Ausführungsvariante unterschiedliche Aufgaben aus der Planung, dem Projektmanagement und der Ausführung. Entsprechend der Aufgaben werden auch unterschiedliche Risiken übernommen. Die Standard-Ausführung ist, dass vom Planungsteam ein Projekt von A bis $Z$ geplant wird und die ausführenden Unternehmen das Werk nach dem abgeschlossenen Planungsprozess errichten.

Nachstehend werden verschiedene Alternativen zur „Standardabwicklung“ mit den damit verbundenen unterschiedlichen Aufgaben und Risiken eines Unternehmens dargestellt ${ }^{103}$ :

Planungskonzept: Von der Planungsseite wird nur die Vorplanung durchgeführt. Auf Basis dieser Vorgaben wird die Entwurfsplanung bis zur Ausfüh-

\footnotetext{
${ }^{103}$ Vgl. WKO Bundesinnung Bau: Leitfaden zur Kostenabschätzung: Band 2 Objektplanung, Stand 30.04.2006 S. 6
} 
rungsplanung von den ausführenden Unternehmen unter Berücksichtigung des vertraglich vereinbarten Preises durchgeführt.

Leistungsbeschreibung: Die Definition der Leistungen eines geplanten Projektes kann nicht nur über eine Ausschreibung mit einer detaillierten, positionsweisen Beschreibung und der erforderlichen Stückzahlen erfolgen, sondern es kann auch eine Funktionsbeschreibung die Basis des Werkvertrages sein.

Vergabe: Die Vergabe kann als Einzelvergabe an Fachunternehmen erfolgen, oder es werden sämtliche auszuführenden Leistungen an einen Generalplaner vergeben, der die Teilleistungen wiederum an Sub-Unternehmer vergibt.

Bauvertrag: Die Beauftragung und damit die spätere Abrechnung der erbrachten Leistungen eines Unternehmens können mittels Einheitspreise des Leistungsverzeichnisses erfolgen. Alternativ kann eine Pauschale vereinbart werden, bei der für das gesamte genau definierte Bauvorhaben eine Gesamtsumme unabhängig von einer Detailaufstellung der Einzelleistungen vergütet wird.

\subsubsection{Leistungsträger in der Ausführung}

Das Auftragsverhältnis zwischen dem Bauherren und den ausführenden Firmen kann entweder aus vielen Einzelaufträgen bestehen, die mit jeder Firma separat abgeschlossen werden. Der Auftrag kann aber auch als Gesamtauftrag an ein Unternehmen (Generalunternehmer) vergeben werden, dass die weiteren erforderlichen Leistungsträger an Sub-Auftragnehmer weiter vergibt.

\subsection{Einzelleistungsträger}

Bei der Projektstruktur mit Einzelleistungsträgern muss sich der Bauherr die Frage stellen welche Planer er zu welchem Zeitpunkt und in welchem Umfang benötigt. Der Bauherr muss jede Planungsleistung separat ausschreiben, mit jedem Anbie- 
ter verhandeln, für jedes Gewerk einen eigenen Werkvertrag erstellen und schlussendlich mit jedem Auftragnehmer das Rechnungsprozedere durchführen. ${ }^{104}$

\subsection{Gesamtleistungsträger}

Der Vorteil bei der Beauftragung der gesamten Planungsleistung an einen Generalunternehmer liegt darin, dass die gesamte Ausführungsleistung aus einer Hand kommt und man nur einen Ansprechpartner hat. Sämtliche Koordinierungsaufgaben und Schnittstellenprobleme werden vom Generalunternehmer gelöst. Der Generalunternehmer kann bei der Auswahl seiner Sub-Unternehmen nicht nur den Preis entscheiden lassen sondern auch die Erfahrungen mit dem jeweiligen Unternehmen bei der letzten gemeinsamen Tätigkeit. Für Großbauvorhaben kann der Generalunternehmer damit die qualitativ hochwertigen Unternehmen bevorzugen. Der Generalunternehmer schuldet dem Auftraggeber (Bauherren) die gesamte auszuführende Leistung. Weiters reduziert sich der Aufwand des Bauherren deutlich, da er nur mehr einen Auftrag erteilen und eine Rechnung prüfen muss.

\subsubsection{Vermarktung des Projektes}

Sollte ein Projekt nicht vom späteren Nutzer als Bauherr errichtet worden sein, so sollte das Projekt im Optimalfall nach Baufertigstellung an den Nutzer übergeben werden. Die bevorstehende Fertigstellung eines Objektes bedeutet für die Marketingabteilung nochmals intensiv nach späteren Nutzern zu suchen. Die Suche nach diesen Nutzern hat in der Marketingabteilung bereits in der Projektentwicklungsphase begonnen. Während der gesamten Bauzeit wird versucht einen oder mehrere Mieter oder Käufer für die Räumlichkeiten zu finden. Häufig werden die Aufgaben des Marketings nicht (nur) vom Errichter wahrgenommen, sondern es wird ein externer Makler für die Vermietung oder Veräußerung beauftragt. Die rasche und lukrative Vermietung und Veräußerung ist wesentlicher Bestandteil einer erfolgreichen Immobilie. Nach Baufertigstellung ist jede leer stehende Einheit eine Kostenbelastung für den Errichter. Das primäre Ziel des Projektmarketings besteht darin, dem späteren Nutzer oder Investor einen Nutzenvorteil gegenüber den Konkurrenzobjekten zu ermöglichen. Im Optimalfall ist dies eine Eigenschaft des Objektes. Aufgrund dieses Vorteils kann möglicherweise ein höherer Preis für die

${ }^{104}$ Vgl. Kalusche: Projektmanagement für Bauherren und Planer München/Wien 2005 S. 254 
Immobilie erzielt werden. Die Findung eines angemessenen Mietzinses bzw. Verkaufspreises ist ebenfalls eine entscheidende Einflussgröße im Marketingprozess. $^{105}$

${ }^{105}$ Vgl. W. Schulte: Projektentwicklung Immobilienökonomie Betriebswirtschaftliche Grundlagen, München, 2008 S. 260 


\section{Schluss}

\subsection{Ergebnisse}

Das Diplomarbeitsthema „Projektmanagement im Bauwesen“ ergab sich aus den negativen Erfahrungen in der Praxis. Durch die Aufbereitung dieses Themas wurde versucht die teilweise sehr chaotischen und komplexen Abläufe rund um das Thema Projektmanagement im Bauwesen darzustellen und damit eine Literatur, in der die meisten Grundlagen beschrieben sind, zu erstellen. Dadurch soll ein einfacher verständlicher Überblick über dieses Thema gegeben werden. Einzelne Themen, die nicht den Kernbereich darstellen, wurden dabei nur oberflächlich abgehandelt. Diese Intention schaffte die Grundlage und damit den ersten Teil dieser Diplomarbeit. Nach der Darstellung der Grundlagen des Diplomarbeitsthemas wurde im zweiten Teil das Projektmanagement eines Bauprojektes anhand eines Projektablaufes beschrieben. Wichtige grundsätzliche Themen, die den gesamten Projektverlauf betreffen wurde im ersten Punkt „Projektplanung“ dargestellt. In den Kapitel „Projektentwicklung“, „Projektmanagement in der Planung“ und „Projektmanagement in der Ausführungsphase" wurden die Leistungen der drei großen Überbegriffe und der Vielzahl an handelnden Personen vorgestellt.

\subsection{Konsequenzen}

Die Errichtung eines Bauwerkes kann auf viele verschieden Arten erfolgen. Kleinere Objekte des privaten Bereiches können meist vom Bauherren selbst organisiert und geleitet werden, wobei auch in diesem Fall fachmännische Unterstützung viele Abläufe vereinfacht.

Größere Objekte hingegen bedürfen einer professionellen Abwicklung. Der Bauablauf kann nicht dem Zufall überlassen werden. Damit dieser gesamte Werdegang eines Projektes gezielt gesteuert und gelenkt wird ist der Einsatz eines gezielten Projektmanagements erforderlich. Fehlerhafte Ausführungen aufgrund schlecht geplanter oder koordinierter Abläufe können die gesamte Budgetierung und den gesamten Terminplan und damit den Projektablauf zum Scheitern bringen. 


\section{Literatur}

Bücher:

Aichele, Christian: Intelligentes Projektmanagement. - 1. Aufl. Stuttgart: Kohlhammer, 2006

Arnold, Dieter ; Isermann, Heinz ; Kuhn Axel ; Tempelmeier, Horst ; Furmans Kai: Handbuch Logistik. - 3. Aufl. Berlin/Heidelberg: Springer, 2008

Blecken, Udo ; Bielefeld, Bert: Bauen in Deutschland. - 1. Aufl. Basel: Birkhäuser, 2005

Diederichs, Claus-Jürgen: Grundlagen der Projektentwicklung/Teil1, in Bauwirtschaft. Heft 11, 1994

DIN 69904 Ausgabe 2000-11 Deutsches Institut für Normen

Dziomba, Maike: Städtebauliche Großprojekte der urbanen Renaissance. - 1 Aufl. Berlin LIT, 2009

Ertle-Straub, Susanne: Standortanalyse für Büroimmobilien. - 1. Aufl. Leipzig: Book on Demand, 2002

Führer, Andreas ; Züger Rita-Maria: Projektmanagement Management-Basiskompetenz. 2. Aufl. Zürich: Compendio Bildungsmedien, 2007

Greiner P. ; Mayer P. E. ; Stark K.: Baubetriebslehre- Projektmanagement, Wie Bauprojekte erfolgreich gesteuert werden. - 3. Aufl. Wiesbaden: Vieweg, 2005

Hahn, Rolf: Projektmanagement für Ingenieure. - 1. Aufl. Weinheim : Wiley 2002 
Harlfinger, Thomas: Referenzvorgehensmodell zum Redevelopment von Bürobestandsimmobilien. - 1. Aufl. Norderstedt: Books on Demand 2010

Held, Torsten: Immobilien-Projektentwicklung Wettbewerbsvorteile durch strategisches Projektmanagement. - 1. Aufl. Berlin/Heidelberg : Springer 2010

HOAI, Honorarordnung für Architekten und Ingenieure. Ausgabe 01.1996

Kalusche, Wolfdietrich: Projektmanagement für Bauherren und Planer. - 2. Aufl. München/Wien : R.Oldenbourg 2005

Keßler, Heinrich ; Winkelhofer, Georg A.: Projektmanagement, Leitfaden zur Steuerung und Führung von Projekten. - 1. Aufl. Berlin : Springer, 1997

Kochendörfer, Bernd ; Liebchen, Jens H. ; Viering, Markus G.: Bau-Projekt-Management Grundlagen und Vorgehensweisen. - 4. Aufl. Wiesbaden : Springer Fachmedien, 2010

Litke, Hans-D.: Projektmanagement. - 4. Aufl. München/Wien : Hanser, 2004

Martino, R.L.: Projektmanagement und Control, - 1.Aufl. New York : American Management Association, 1964

Mohrmann, Martin: Bauvorhaben mithilfe von Lean Projektmanagement neu denken, 4.Aufl. Norderstedt : Books on Demand, 2011

Preißner, Andreas: Projekte budgetieren und planen, - 1.Aufl. München/Wien : Hansen, 2003

Preuß, Norbert: Projektmanagement von Immobilienprojekten, Entscheidungsorientierte Methoden, - 1.Aufl. Berlin/Heidelberg: Springer, 2011 
ÖNORM B1801 Teil 1. Ausgabe 2009-06-01 Österreichisches Normungsinstitut

ÖNORM B1801 Teil 3. Ausgabe 1999-07-01 Österreichisches Normungsinstitut

ÖNORM B1801 Teil 5. Ausgabe 2001-06-01 Österreichisches Normungsinstitut

Pfetzing, Karl ; Rohde, Adolf: Ganzheitliches Projektmanagement, - 1.Aufl. Gießen : Dr. Götz Schmidt, 2009

Schröder, Hans ; Kern, Werner: Forschung und Entwicklung in der Unternehmung. - 1. Aufl. Wiesbaden: Rowohlt, 1977

Schulte, Karl-Werner: Immobilien Ökonomie. - 4. Aufl. München: Oldenburg, 2008

Schütz, Ulrich: Projektentwicklung von Verwaltungsgebäuden. - 1. Aufl. RenningenMalmsheim: Expert Verlag, 1994

Sperber, Tim: Aufbau einer Projektmanagementstruktur für Investitinsprojekte. - 1. Aufl. Hamburg: Diplomica, 2008

Ullmann, Stephanie: Projektentwicklung nach dem 4-Phasen-Modell. - 1. Aufl. Hamburg: Diplomica, 2007

Ulrich, P. ; Fluri, E.: Management Eine konzentrierte Einführung. - 7. Aufl. Bern/Stuttgart: Haupt, 1995

Zering, Katharina: Terminplanung im Projektmanagement. - 1. Aufl. Norderstedt: Grin, 2008

Zielasek, Gotthold: Projektmanagement: Erfolgreich durch Aktivierung aller Unterneh- 
mensebenen. - 1. Aufl. Berlin/Heidelberg: Springer, 1995

WKO Bundesinnung Bau: Stempkowski, Rainer ; Mühlabcher, Evelin ; Rosenberger, Robert: Leitfaden zur Kostenabschätzung, Band 1 Grundlagen. Stand 30.04.2006

WKO Bundesinnung Bau: Stempkowski, Rainer ; Mühlabcher, Evelin ; Rosenberger, Robert: Leitfaden zur Kostenabschätzung: Band 2 Objektplanung, Stand 30.04.2006

Internet:

Duden, URL: http://www.duden.de/rechtschreibung/managen\#block_2 17.12.2011

Duden, URL: http://www.duden.de/rechtschreibung/Projektmanagement 17.12.2011

Duden, URL: http://www.duden.de/rechtschreibung/Joint_Venture 14.03.2012

Duden, Feasibility Analysen: „Untersuchung über die Durchführbarkeit eines technischen Projekts“ URL: http://www.duden.de/rechtschreibung/Feasibility_Studie 23.03.2012

K. Bisani, Fachhochschule München, Fachbereich 02 Bauingenieurwesen: Bauproduktionsplanung, $\quad$-steuerung, Terminplanung: http://w3mediapool.hm.edu/mediapool/media/fk02/fk02_lokal/professoren_7/ bisani/downloads_2/terminplanung/fhm_skript_terminplanung_kapitel_3.pdf 01.02.2012

Wikipedia, URL: http://de.wikipedia.org/wiki/\%C3\%96konomisches_Prinzip 26.02.2012

Wirtschaftslexikon, URL: http://www.wirtschaftslexikon24.net/d/controlling/controlling.htm 01.02 .2012 


\section{Selbstständigkeitserklärung}

Hiermit erkläre ich, dass ich die vorliegende Arbeit selbstständig und nur unter Verwendung der angegebenen Literatur und Hilfsmittel angefertigt habe.

Stellen, die wörtlich oder sinngemäß aus Quellen entnommen wurden, sind als solche kenntlich gemacht.

Diese Arbeit wurde in gleicher oder ähnlicher Form noch keiner anderen Prüfungsbehörde vorgelegt.

Seekirchen, den 31.05.2012

Harald Roider 